Explorando dados provindos da internet em dispositivos móveis: uma abordagem baseada em visualização de informação

Felipe Simões Lage Gomes Duarte 



\title{
Explorando dados provindos da internet em dispositivos móveis: uma abordagem baseada em visualização de informação
}

\author{
Felipe Simões Lage Gomes Duarte
}

Orientador: Prof. Dr. Fernando Vieira Paulovich

Dissertação apresentada ao Instituto de Ciências Matemáticas e de Computação - ICMC-USP, como parte dos requisitos para obtenção do título de Mestre em Ciências - Ciências de Computação e Matemática Computacional. VERSÃO REVISADA 
Ficha catalográfica elaborada pela Biblioteca Prof. Achille Bassi e Seção Técnica de Informática, ICMC/USP, com os dados fornecidos pelo(a) autor(a)

\begin{tabular}{|c|c|}
\hline \multirow[t]{3}{*}{ D812e } & $\begin{array}{l}\text { Duarte, Felipe Simões Lage Gomes } \\
\text { Explorando dados provindos da internet em } \\
\text { dispositivos móveis: uma abordagem baseada em } \\
\text { visualização de informação / Felipe Simões Lage Gomes } \\
\text { Duarte; orientador Fernando Simões Lage Gomes } \\
\text { Duarte. -- São Carlos, } 2015 . \\
\quad 92 \text { p. }\end{array}$ \\
\hline & $\begin{array}{l}\text { Dissertação (Mestrado - Programa de Pós-Graduação } \\
\text { em Ciências de Computação e Matemática } \\
\text { Computacional) -- Instituto de Ciências Matemáticas } \\
\text { e de Computação, Universidade de São Paulo, } 2015 .\end{array}$ \\
\hline & $\begin{array}{l}\text { 1. Visualização de dados web. 2. Visualização de } \\
\text { dados em dispositivos móveis. 3. Algoritmo de } \\
\text { preenchimento do espaço visual. I. Simões Lage Gomes } \\
\text { Duarte, Fernando, orient. II. Título. }\end{array}$ \\
\hline
\end{tabular}


À minha esposa Karina e meus pais Rafael e Edna 


\section{Agradecimentos}

À minha esposa Karina, que sempre me apoiou e me deu forças para superar todos os obstáculos desta jornada. Ela esteve ao meu lado nos momentos fáceis e batalhou comigo nos mais difíceis. A ela reconheço grande parte desta conquista. Te amo!

Aos meus pais, Rafael Clever e Edna Lage, que em nenhum momento mediram esforços para realização dos meus sonhos. Me guiaram competentemente pelos caminhos corretos da vida, ensinando a fazer as melhores escolhas e mostrando-me que a honestidade e o respeito são virtudes essenciais à vida. A eles devo a pessoa que me tornei, sou extremamente feliz e tenho muito orgulho por chamá-los de pai e mãe. Amo vocês!

Ao meu irmão Bernardo Duarte que sempre me ajudou e esteve ao meu lado no que foi preciso. "Valew vei", não poderia ter irmão melhor!

Ao meu tio Elmo e família, tio Geraldo e família, tia Fernanda, tia Valéria e meus avós Pedro e Terezinha que pertinhos ou distantes nunca pouparam orações e pensamentos positivos para que este meu sonho virasse realidade. Estes fazem parte da minha base e minha família.

Ao meu sogro Edson, minha sogra Elisabete e meu cunhado Edson Jr. por todo carinho e atenção dedicados a mim e acolhendo-me como integrante de sua família.

Ao meu orientador Prof. Dr. Fernando Vieira Paulovich pela paciência, orientação e risadas nas reuniões. Ele que fez o possível (e as vezes o impossível) para tornar o sonho da pós graduação realidade para mim e é um exemplo a ser seguido. Obrigado!

Aos funcionários e professores da USP-São Carlos, em especial aos professores Dra. Maria Cristina Ferreira de Oliveira, Dra. Rosane Minghim e o Dr. João do Espirito Santo Batista Neto, Dr. Moacir Pereira Ponti Junior e Dr. Rodrigo Fernandes de Mello, que nunca se abstiveram em me ajudar sempre que precisei.

Aos amigos e parceiros Carol Ramos, Danilo Coimbra, Edvaldo José, Fábio Sikansi, Fábio (Texugo), Fernando (Fêu), Francisco (Chicão), Guilherme (Baiano), Jorge, Samuel (Fadel), Luciana Longo (Tieta) e Tácito (Párea) (em ordem alfabética pra ninguém se sentir menos ou mais amigo) que seja nas discussões teóricas, nas noites culinárias ou na bagunça do dia-a-dia fizeram com que tudo ficasse mais fácil e mais divertido. "Valew galera"!

Aos professores Dra. Maria Cristina Ferreira de Oliveira, Dr. Paulo Aristarco Pagliosa e Dr. Afonso Paiva Neto que gentilmente aceitaram compor a banca de defesa ou qualificação e fizeram comentários e observações pertinentes a conclusão deste trabalho.

À FAPESP (Processo 2012/21022-0) e Capes pelo aporte financeiro durante todo o período de mestrado. 
Com o progresso da computação e popularização da Internet, a sociedade entrou na era da informação. Esta nova fase é marcada pela forma como produzimos e lidamos com a informação. Diariamente, são produzidos e armazenados milhares de Gigabytes de dados cujo valor é reduzido se a informação ali contida não puder ser transformada em conhecimento. Concomitante a este fato, o padrão da computação está caminhando para a miniaturização e acessibilidade com os dispositivos móveis. Estes novos equipamentos estão mudando o padrão de comportamento dos usuários que passam de leitores passivos a geradores de conteúdo. Neste contexto, este projeto de mestrado propõe a técnica de visualização de dados NMap e a ferramenta de visualização de dados web aplicável a dispositivo móvel SPCloud. A técnica NMap utiliza todo o espaço visual disponível para transmitir informações de grupos preservando a metáfora distância-similaridade. Teste comparativos com as principais técnicas do estado da arte mostraram que a técnica NMap tem melhores resultados em preservação de vizinhança com um tempo de processamento significativamente melhor. Este fato coloca a NMap como uma das principais técnicas de ocupação do espaço visual. A ferramenta SPCloud utiliza a NMap para visualizar notícias disponíveis na web. A ferramenta foi desenvolvida levando em consideração as características inerentes aos dispositivos móveis o que possibilita utilizá-la nestes equipamentos. Teste informais com usuários demonstraram que a ferramenta tem um bom desempenho para sumarizar grandes quantidades de notícias em um pequeno espaço visual.

Palavras chave: Visualização de dados Web; Visualização de dados em dispositivos móveis; Algoritmo de preenchimento do espaço visual. 
With the development of computers and the increasing popularity of the Internet, our society has entered the information age. This era is marked by the way we produce and deal with information. Everyday, thousand of Gigabytes are stored, but their value is reduced if the data cannot be transformed into knowledge. Concomitantly, computing is moving towards miniaturization and affordability of mobile devices, which are changing users behavior who move from passive readers to content generators. In this context, in this master thesis we propose and develop a data visualization technique, called NMap, and a web data visualization tool for mobile devices, called SPCloud. NMap uses all available visual space to transmit information preserving the metaphor of distance-similarity between elements. Comparative evaluations were performed with the state of the art techniques and the result has shown that NMap produces better results of neighborhood preservation with a significant improvement in processing time. Our results place NMap as a major space-filling technique establishing a new state of the art. SPCloud, a tool which uses NMap to present news available on the web, was developed taking into account the inherent characteristics of mobile devices. Informal user tests revealed that SPCloud performs well to summarize large amounts of news in a small visual space.

Keywords: Web data visualization; Data visualization on mobile devices; Space-filling algorithm. 
1 Introdução 1

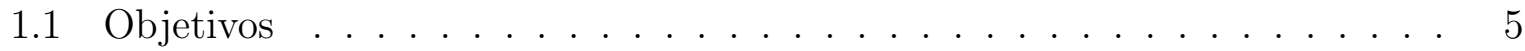

1.2 Resultados . . . . . . . . . . . . . . . . . . 6

1.3 Organização . . . . . . . . . . . . . . . . . . . 7

2 Visualização de dados textuais $\quad 9$

2.1 Semântica da palavra e suas relações . . . . . . . . . . . . . . . . . . . . 10

2.2 Paradigma de nuvens de palavras . . . . . . . . . . . . . . . . . . . 14

2.3 Técnicas baseadas em plotagem . . . . . . . . . . . . . . . . . . . 19

2.4 Considerações Finais . . . . . . . . . . . . . . . . . . . 20

3 Visualização de dados provindos da Internet $\quad 23$

3.1 Paradigma unidimensional . . . . . . . . . . . . . . . . . . 24

3.2 Paradigmas Multidimensionais . . . . . . . . . . . . . . . . . . . . 29

3.3 Considerações Finais . . . . . . . . . . . . . . . . . . . 34

4 Técnicas de preenchimento do espaço visual e dispositivos móveis $\quad 37$

4.1 Técnicas de preenchimento do espaço visual . . . . . . . . . . . . 38

4.2 Visualização de Dados em dispositivos móveis . . . . . . . . . . . . . . . . 42

4.3 Considerações Finais . . . . . . . . . . . . . . . . . . . . . . . . 44

5 Neighborhood map (NMap) $\quad 47$

5.1 Algoritmo de Recorte e Escala . . . . . . . . . . . . . . . . . . . . . . 48

5.2 Definição do Recorte . . . . . . . . . . . . . . . . . . . . . 51

5.3 Posicionamento Inicial . . . . . . . . . . . . . . . . . . . 53

5.4 Complexidade Computacional . . . . . . . . . . . . . . . 54

5.5 Considerações Finais . . . . . . . . . . . . . . . . . . . 55

6 Resultados e avaliações $\quad 57$

6.1 Métricas de Avaliação . . . . . . . . . . . . . . . . . . . . . . . 57

6.1.1 Razão de Aspecto . . . . . . . . . . . . . . . . . . . . . . . . . . . . . . . . . 58

6.1 .2 Deslocamento . . . . . . . . . . . . . . . . 58 
6.1.3 Preservação de Vizinhança . . . . . . . . . . . . . . . . . . . . . . . 59

6.1.4 Tempo de processamento . . . . . . . . . . . . . . . 59

6.2 Base de Dados . . . . . . . . . . . . . . . . . . . . . . . . . . . . . 60

6.3 Avaliação Visual . . . . . . . . . . . . . . . . . . . . . . . . 61

6.4 Avaliação Quantitativa . . . . . . . . . . . . . . . . . . . . 64

6.5 Considerações Finais . . . . . . . . . . . . . . . . . . . . . 66

$\begin{array}{lll}7 & \text { Squarified ProjCloud (SPCloud) } & 67\end{array}$

7.1 Squarified ProjCloud . . . . . . . . . . . . . . . . 68

7.2 Matrizes de Frequência dos Termos . . . . . . . . . . . . . . . . . 70

7.3 Confiabilidade . . . . . . . . . . . . . . . . . . 72

7.3 .1 Matriz Binária dos Termos . . . . . . . . . . . . . . . . . 72

7.3.2 Termos mais importantes . . . . . . . . . . . . . . . . . 73

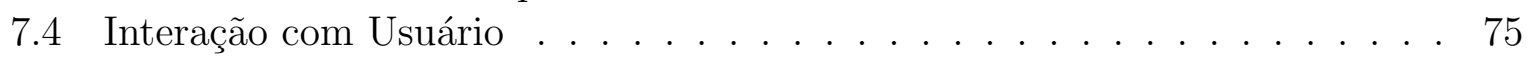

7.5 Estudo de Caso . . . . . . . . . . . . . . . . . . . . . . . . . . 77

7.6 Considerações Finais . . . . . . . . . . . . . . . . . . . . 79

8 Conclusões $\quad 81$

8.1 Limitações . . . . . . . . . . . . . . . . . . . . . . . . . . . . . . 83

8.2 Trabalhos Futuros . . . . . . . . . . . . . . . . . . . . 83 


\section{Lista de Figuras}

2.1 Ferramenta Concordance . . . . . . . . . . . . . . . . . 11

2.2 Técnica WordTree . . . . . . . . . . . . . . . . . . . . . 12

2.3 Técnica Phrase Nets . . . . . . . . . . . . . . . . . . . . . . . . . 13

2.4 Ferramenta TextArc . . . . . . . . . . . . . . . . . . . 14

2.5 Ferramentas TagCrowd . . . . . . . . . . . . . . 15

2.6 Técnica Wordle . . . . . . . . . . . . . . . . . . . 16

2.7 Técnica ManiWordle . . . . . . . . . . . . . . . . . . . . . . 17

2.8 Técnica ProjCloud . . . . . . . . . . . . . . . . . . . . . . 18

3.1 Técnica TileBars e Técnica Insyder . . . . . . . . . . . . . . . . . . 24

3.2 Ferramenta Hotmap . . . . . . . . . . . . . . . . . . . . 25

3.3 Ferramenta Concept Highlighter . . . . . . . . . . . . . . . . . . . . . 26

3.4 Ferramenta Google . . . . . . . . . . . . . . . . . . 27

3.5 Ferramenta Google Reader e Feedly . . . . . . . . . . . . . . . . . . 28

3.6 Ferramenta $\mathrm{Pex}-\mathrm{Web} \ldots \ldots \ldots$. . . . . . . . . . . . . 30

3.7 Técnica ProjSnippet . . . . . . . . . . . . . . . . . . . . 31

3.8 Ferramenta NewsMap . . . . . . . . . . . . . . . . . . . . . . . 32

3.9 Ferramenta VisGets . . . . . . . . . . . . . . . . . . 33

4.1 Algoritmos Cushion Treemap e Squarified Treemap . . . . . . . . . . . . 39

4.2 Técnica Ordered Treemap . . . . . . . . . . . . . . . . . . . . . 40

4.3 Técnica Ordered Squarified Treeemap . . . . . . . . . . . . . . . . . 41

4.4 Técnica Spatially Ordered Treeemap . . . . . . . . . . . . . . . . . . 41

4.5 Técnica Radial Edgless Tree . . . . . . . . . . . . . . . . . . . . . . . 42

4.6 Ferramenta para visualização, em dispositivos móveis, de diversos tópicos discutidos em fóruns utilizando a técnica Squarified Treemap . . . . . . . . 43

5.1 Processo de Recorte e Escala do algoritmo NMap . . . . . . . . . . . 50

5.2 Diferença entre NMap-AC e NMap-EW . . . . . . . . . . . . . . . . . 52

6.1 Configuração inicial das bases dados utilizadas para testes comparativos. . 60

6.2 Resultado ao aplicar as técnicas NMap-AC, NMap-EW, OOT e SOT com as 9 diferentes configurações iniciais . . . . . . . . . . . . . . . 62

6.3 Comparação visual entre as técnicas NMap-AC, NMap-EW, SOT e OOT. . 63 
6.4 Boxplots das medidas razão de aspecto, preservação de vizinhança e deslo-

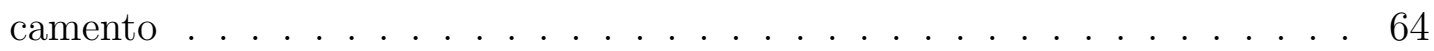

6.5 Gráfico tamanho da base de dados versus tempo de processamento . . . . 65

7.1 Ferramenta Squarified ProjCloud . . . . . . . . . . . . . . . 68

7.2 Fluxograma do processo de criação da visualização da ferramenta SPCloud. 69

7.3 Gráfico de termos por importância calculado pelo Fiedler Vector . . . . . . 74

7.4 Gráfico de termos pela derivada da função $f$. . . . . . . . . . . . . . . . 74

7.5 Subdivisão do grupo inferior esquerdo da Figura 7.1 em 5 subgrupos. . . . 76

7.6 Interação com o usuário garante o zoom no grupo de interesse. . . . . . . . 76

7.7 Interação com o usuário garante o zoom no grupo de interesse. . . . . . . . 77

7.8 Visualização da base de dados de notícias com a ferramenta SPCloud. . . . 78

7.9 Interação com o usuário na ferramenta SPCloud analiasando a base de dados de notícias. . . . . . . . . . . . . . . . . . . . . 79 


\section{Lista de Siglas}

$\begin{array}{ll}\text { APP } & \text { Associated Press } \\ \text { BBC } & \text { British Broadcasting Corporation } \\ \text { CNN } & \text { Cable News Network } \\ \text { FDP } & \text { Force-directed placement } \\ \text { ICMC } & \text { Instituto de Ciências Matemátias e de Computação } \\ \text { HiPP } & \text { Hierarchical Point Placement } \\ \text { KWIC } & \text { Keyword in context } \\ \text { LSP } & \text { Least Square Projection } \\ \text { NMap } & \text { Neighborhood Map } \\ \text { NMap-AC } & \text { Neighborhood Map Alternate Cut } \\ \text { NMap-EW } & \text { Neighborhood Map Equal Weight } \\ \text { OOT } & \text { One-dimension Ordered Treemap } \\ \text { RSS } & \text { Rich Site Summary } \\ \text { SOT } & \text { Spatially-Ordered Treemap } \\ \text { SPCloud } & \text { Squarified ProjCloud } \\ \text { TF } & \text { Term Frequency } \\ \text { TFIDF } & \text { Term Frequency Inverse Document Frequency } \\ \text { URL } & \text { Uniform Resource Locator } \\ \text { USP } & \text { Universidade de São Paulo } \\ \text { XML } & \text { eXtensible Markup Language }\end{array}$




\section{Lista de Publicações}

1. Samuel G. Fadel, Francisco M. Fatore, Felipe S. L. G. Duarte, FerNANDO V. PAULOVICH, LoCH: A neighborhood-based multidimensional projection technique for high-dimensional sparse spaces, Neurocomputing, Available online 27 Oct. 2014, ISSN 0925-2312, doi: 10.1016/j.neucom.2014.07.071. (Qualis A1)

2. Duarte, F. S. L. G.; Sikansi, F.; Fatore, F.M.; Fadel, S.G.; Paulovich, F.V., Nmap: A Novel Neighborhood Preservation Space-filling Algorithm, Visualization and Computer Graphics, IEEE Transactions on, vol.20, no.12, pp.2063,2071, Dec. 31 2014. doi: 10.1109/TVCG.2014.2346276. (Qualis A1) 


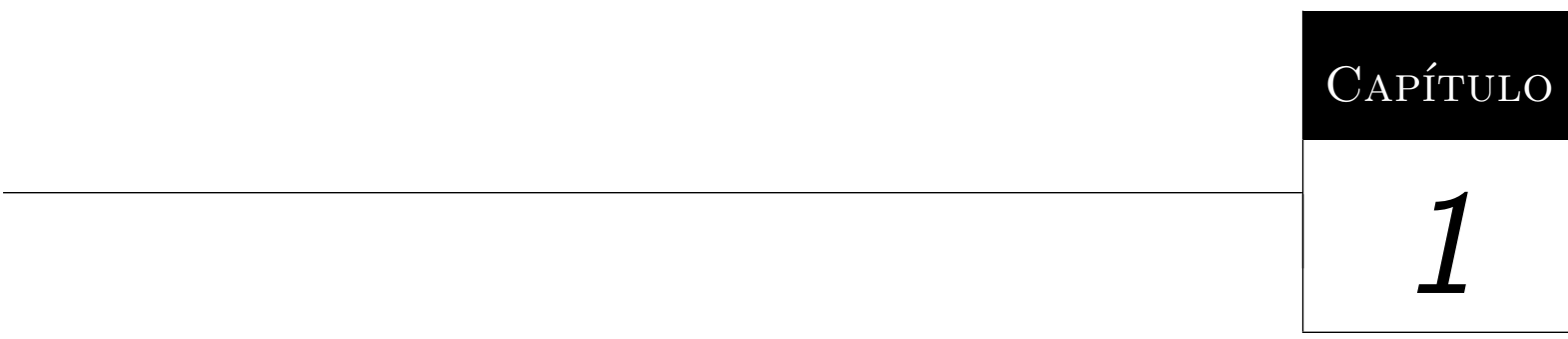

\section{Introdução}

om o progresso da computação e popularização da Internet, a sociedade entrou
na era da informação (Drucker, 1996). A nova fase em que vivemos é marcada
pela forma como produzimos e lidamos com a informação. Diariamente, são produzidos e armazenados milhares de Gigabytes de dados cujo valor é reduzido se a informação ali contida não puder ser transformada em conhecimento. Além disto, o poder dos computadores e algoritmos disponíveis para exploração e interpretação dos dados não está aumentando na mesma velocidade que o armazenamento, tornando a diferença entre o que é produzido e o que é interpretado cada vez maior. O resultado disso é a dificuldade, ou impossibilidade, em explorar toda a informação disponível (Berners-Lee e Fischetti, 2000).

A capacidade visual humana vem sendo explorada na análise de dados por meio da criação de representações visuais interativas. Diversas técnicas e ferramentas foram assim desenvolvidas com o objetivo de acelerar o poder analítico humano possibilitando a interpretação de uma maior quantidade de dados em um menor período de tempo. As técnicas TileBars (Hearst, 1995), Hotmap (Hoeber e Yang, 2006b) e Concept Highlighter (Hoeber e Yang, 2006c) fornecem visualizações e funcionalidades extras que auxiliam os usuários a explorar uma lista de resultados de busca. De maneira similar, as Ferramentas Google 
Reader (Google, 2012) e Feedly (Feedly, 2012), por meio de RSS Feeds ${ }^{1}$, organizam as informações em seções e permitem a filtragem e seleção de notícias.

O paradigma de lista tem um bom desempenho quando os dados visualizados possuem uma relação de ordem ou cassificação entre eles. Porém este não é capaz de exibir possíveis relações ou padrões entre os elementos dos dados. Ademais, em alguns casos, os dados dispostos na web trazem consigo diversas informações que, devido ao paradigma unidimensional, não são exibidas ao usuário. Em uma loja virtual, por exemplo, não é possível visualizar a relação do custo de um produto com o seu índice de satisfação. Para contornar este problema, é comum encontrar a possibilidade de reordenar a lista de acordo com um dos vários atributos dos dados cabendo ao usuário fazer o cruzamento de informações para determinar a melhor relação, por exemplo, custo e índice de satisfação.

Assim, para visualizar e relacionar os diversos atributods dos dados, a ferramenta Pex-Web (Paulovich et al., 2008b) usa o paradigma de plotagem de pontos e, agrupando os documentos relacionados, exibe uma maior quantidade de informação, o que facilita a localização e acesso aos documentos. Para isto, a técnica processa os dados e projeta-os no plano obedecendo a metáfora distância-similaridade, i.e., pontos similares são posicionados próximos e dissimilares distantes. Como em qualquer técnica baseada em plotagem de pontos, os dados são representados por um único ponto que por sua vez não traz informação nenhuma que identifique o documento ou conteúdo ali representado.

A técnica NewsMap (Weskamp, 2004) utiliza a bidimensionalidade dos displays para exibir os diferentes grupos e categorias de notícias. Utilizando o canal de notícias do Google, a ferramenta separa o layout de visualização em diferentes áreas, em que cada uma representa uma categoria de notícia. No entanto, a característica temporal é perdida neste tipo de visualização. Ao contrário, a técnica VisGets (Dork et al., 2008) utiliza visões coordenadas para exibir as diferentes características associadas a uma notícia, como tempo e espaço. No entanto, suas visões podem atrapalhar o usuário, que ao manipular uma visão tem todas as outras alteradas, ocasionando assim a perda de contexto.

Apesar de todos os esforços para sumarizar e processar as informações, um possível obstáculo está relacionado ao baixo poder de processamento textual do ser humano. O tempo necessário para que uma pessoa leia um texto, interprete, abstraia aquela informação e a transforme em conhecimento é alto. Tomemos como exemplo um jornal como o "The New York Times". Por hora, ele é capaz de gerar centenas de notícias de diversas categorias. Um usuário que deseja se manter atualizado com as notícias mais

\footnotetext{
${ }^{1}$ RSS Feeds: (Rich Site Summary) é um conjunto de padrões web usado para publicar atualizações, muito utilizado em blogs, canais de notícias, rede sociais, etc. Um documento RSS (muitas vezes chamado de "feed da web" ou simplesmente "feed") inclui um texto resumido sobre a atualização e metadados como data e autor
} 
importantes, precisaria ler e explorar maior parte delas para se inteirar dos assuntos do dia. Considerando que o mesmo demore aproximadamente dois minutos para ler e interpretar uma única notícia, ele demoraria mais de 3 horas para processar e abstrair toda a informação gerada em apenas uma hora.

Diversas técnicas foram desenvolvidas com o objetivo de sumarizar o conteúdo de um documento ou de uma coleção. As técnicas Concordance (Watt, 2012), Word Tree (Wattenberg e Viegas, 2008), Phrase Nets (Ham et al., 2009) e TextArc (Paley, 2002), exibem a estrutura interna de documentos e como suas palavras se relacionam. Esta abordagem é particularmente interessante quando se deseja efetuar um estudo das semânticas das palavras e como elas estão inseridas no contexto dos documentos. No entanto, estas técnicas não fornecem uma maneira de visualizar a relação estabelecida entre os documentos ou a sumarização do conteúdo deles.

Uma maneira de sintetizar o conteúdo de um documento ou de uma coleção é exibir para o usuário somente as palavras mais importantes. Esta abordagem busca garantir que o usuário consiga saber o tema abordado sem ter a necessidade de ler os documentos por completo. Diversas técnicas foram desenvolvidas com este fim, dentre elas estão a TagCrowd (Steinbock, 2006), Wordle (Viegas et al., 2009) e ManiWordle (Koh et al., 2010). Estas utilizam o paradigma de nuvens de palavras, que exibe os termos mais relevantes variando o tamanho da fonte de acordo com a frequência dos mesmos, i.e., quanto maior o termo desenhado, mais frequente ele é dentro do texto ou do conjunto. Este paradigma permite sumarizar todo o conteúdo de um grupo de documentos porém não permite visualizar a relação entre eles.

As técnicas Hipp (Paulovich e Minghim, 2008) e InfoSky (Andrews et al., 2002) são capazes de processar grandes coleções de documentos agrupando-os de acordo com a similaridade. Estas utilizam uma metáfora visual baseado em pontos plotados no espaço, taque documentos similares são 1 posicionados próximos e dissimilares distantes. No entanto, estas técnicas representam cada documento como apenas um ponto no espaço, não exibindo para o usuário os principais assuntos abordados ou qualquer outra informação que identifique os documentos ali presentes.

A técnica ProjCloud (Paulovich et al., 2012) tenta unir o agrupamento proposto pelas técnicas de plotagem de pontos e o poder de síntese das técnicas baseadas em nuvens de palavras. Esta desenha uma nuvem de palavras dentro do fecho convexo que contém os pontos plotados de cada grupo. Deste modo, ela consegue garantir uma comparação entre grupos bem como manter o poder de síntese oferecido pelas técnicas de nuvens de palavras. No entanto, o uso do fecho convexo pode induzir o usuário a acreditar que as palavras de grupos esparsos apareceram mais vezes que as palavras de grupos mais densos. 
Uma possível solução para este problema, ainda em aberto no estado da arte, seria levar em consideração a quantidade de elementos em um grupo para determinar o tamanho da área que será desenhado a nuvem de palavras.

Concomitante a todo este processo, nos últimos anos, houve uma mudança comportamental dos usuários que passaram de leitores passivos a geradores de dados. Com a disseminação das redes sociais e a popularização dos dispositivos móveis, muitos usuários passaram a compartilhar cada momento de suas vidas através de fotos, vídeos e textos. Empresas que têm em sua carta de produtos Tablets e Smartphones estão batendo recordes de vendas a cada ano, o que visivelmente demonstra que a computação está trilhando um caminho em direção à utilização de dispositivos móveis. Esta nova tecnologia traz consigo uma mudança no padrão de interação do homem com a máquina em que a presença de telas sensíveis ao toque, em detrimento do mouse e teclado, é uma das principais características desta nova arquitetura. Além disto, características como o tamanho dos displays, razões de aspectos da tela e hardwares menos poderosos impossibilitam a simples migração, para dispositivos móveis, das técnicas de visualização de dados já consolidadas (Chittaro, 2006).

O baixo poder de processamento e resolução das telas estão sendo resolvidos com a evolução tecnológica dos dispositivos móveis. No entanto, o tamanho limitado das telas ainda continua sendo um problema e que dificilmente se resolverá, uma vez que, para manter a mobilidade, espera-se um dispositivo menor. Assim, levando em consideração esta limitação, é imprescindível que as técnicas de visualização aplicadas a dispositivos móveis utilizem todo o espaço visual para transmitir informação. A categoria de algoritmos que atendem esta exigência denomina-se "técnicas de preenchimento do espaço visual" (do inglês Space-filling).

Uma das primeiras técnicas desta categoria é a Treemap (Johnson e Shneiderman, 1991). Devido a sua simplicidade, baixa complexidade e alta taxa de ocupação do espaço visual, a Treemap se tornou um dos algoritmos mais conhecidos. Esta divide todo o espaço visual disponível em retângulos com áreas proporcionais a algum atributo dos dados. No entanto, esta técnica produz regiões alongadas e estreitas, o que dificulta a comparação de sua área com as demais regiões da mesma visualização. Como o objetivo de melhorar a razão de aspecto ${ }^{2}$ das regiões formadas, Bruls et al. (1999) desenvolveram a técnica Squarified Treemap. Diferente da Treemap, esta produz retângulos cuja razão de aspecto se aproxima de 1, i.e., produz regiões mais próximas de um quadrado. Porém, ela

\footnotetext{
${ }^{2}$ Razão de aspecto: medida que indica a proporção dos lados de um retângulo dado pela formula: $\max ($ altura/largura, largura/alura). Deste modo, o menor valor possível para razão de aspecto é 1 , obtido quando o retângulo é um quadrado.
} 
necessita de uma ordenação prévia dos dados, o que pode ser problema se estes possuírem uma ordenação intrínseca.

Utilizando o paradigma "dividir para conquistar", a técnica Ordered Treemaps (Bederson et al., 2002) tem o intuito de preservar esta ordenação e posicionar próximo os elementos que estão adjacentes na lista. Ainda que, ao contrário da Squarified Treemap, esta técnica obtenha melhores resultados em preservar a ordenação original dos dados, ela ainda apresenta regiões com altas razões de aspecto, apesar de não serem tão frequentes quanto na técnica original Treemap.

De acordo com um dos princípios da Gestalt (Todorovic, 2008), pontos similares devem estar posicionados próximos e dissimilares distantes. Com o objetivo de preservar esta característica, conhecida como metáfora distância-similaridade, as técnicas Ordered Squarified Treeemaps e Spatially Ordered Treeemaps (Wood e Dykes, 2008) tentam repartir o espaço visual disponível em regiões que obedeçam uma ordem bidimensional estabelecida nos dados. Além disto, elas procuram produzir regiões com razões de aspecto próximos de 1, tal como na técnica Squarified Treemap.

Assim, devido a utilização de todo o espaço visual para sumarizar informação (o que é importante em dispositivos móveis devido ao tamanho reduzido das telas) e a razão de aspecto próximo de 1 (o que produz regiões quadradas e mais fáceis de selecionar com telas sensíveis ao toque) estas técnicas vêm sendo amplamente utilizadas em dispositivos móveis. Engdahl et al. (2005) utilizou a técnica de Squarified Treemap para visualizar grupos de discussões em fóruns. De modo similar, a ferramenta PRISMA Mobile (da Silva Junior et al., 2012) utiliza a técnicas Treemap para visualizar dados de turismo em dispositivos móveis.

\subsection{Objetivos}

Neste contexto, o objetivo deste projeto foi desenvolver uma nova visualização que possa ser usada em dispositivos móveis e leve em consideração suas características. Esta deve auxiliar a execução de tarefas exploratórias sobre dados provindos da Internet, potencialmente diminuindo o tempo e a perda de informação nesse processo. O seguinte parágrafo define de modo geral este objetivo.

"Este projeto de mestrado tem por objetivo desenvolver e/ou aplicar técnicas de visualização de informação, em dispositivos móveis, com o intuito de aumentar o poder analítico e exploratório das ferramentas disponíveis para a interpretação de dados provindos da Internet. O propósito é permitir ao 
usuário não somente processar mais informações empregando o mesmo espaço visual que as ferramentas vigentes, fator especialmente importante quando se está utilizando dispositivos móveis, mas também fornecer diferentes tipos de análises que não estão atualmente disponíveis."

Especificamente, objetivou-se construir uma visualização capaz de sumarizar centenas ou até milhares de notícias provenientes da Internet. Esta nova visualização foi elaborada com um arquitetura cliente-servidor e levou em consideração as especificidades dos dispositivos móveis bem como os padrões de interação do usuário com estes equipamentos. Assim, com o intuito de se atingir estes objetivos, diversos estudos foram elaborados na tentativa de identificar no estado da arte as principais dificuldades e a melhor forma para tratar os problemas.

\subsection{Resultados}

Com o intuito de implementar os objetivos elencados, foram desenvolvidas a técnica Neighborhood Map (NMap) (Duarte et al., 2014) e a ferramenta Squarified ProjCloud (SPCloud). A NMap (Capítulo 5) é uma técnica de preenchimento do esáço visual que aborda o problema da preservação da metáfora de distância-similaridade enquanto constrói a visualização. Para isso ela se baseia na estratégia de corte e escala em que o espaço visual é sucessivamente seccionado em cortes horizontais e verticais e as novas regiões são redimensionadas de acordo com um peso atrelado a cada nova região. Todo este processo é repetido até que cada retângulo represente apenas uma unidade dos dados analisados.

Duas abordagens foram desenvolvidas, NMap-AC e NMap-EW. A primeira, NMap-AC, alterna entre cortes verticais e horizontais para formar a visualização final. Esta técnica produz bons resultados porém forma algumas regiões com razões de aspecto ruim. Ao contrário, a NMap-EW secciona o espaço visual tentando manter o mesmo peso para as duas novas regiões criadas. Esta característica faz com que as regiões formadas possuam razões de aspecto mais próximas de 1 . Teste comparativos entre as abordagens da NMap e as duas principais técnicas do estado da arte comprovaram o resultado superior da NMap com relação a preservação de vizinhança, deslocamento e tempo de processamento (Capítulo 6).

Para validar e verificar todo o potencial da técnica NMap, foi desenvolvida a ferramenta SPCloud. Esta ferramenta é capaz de sumarizar grandes coleções de documentos texto e 
exibí-los em uma visualização que se adapta as necessidades e características dos dispositivos móveis. Funcionando com uma arquitetura cliente-servidor, todo o processamento dos dados, agrupamento e calculo dos termos mais importantes é feito no lado servidor, cabendo ao dispositivo móvel somente a visualização final e interação com usuário.

O usuário, por sua vez, consegue escolher o assunto de interesse filtrando os documentos e os lendo quando necessário. Através da seleção de cada grupo, ele consegue dividir cada região em outros grupos refinando ainda mais a visualização. Devido ao pequeno tamanho das telas, é possível que algum grupo fique ilegível. Para contornar este problema, é possível fazer um zoom na região de interesse, ampliando-a, facilitando assim a visualização do assunto ali abordado. Teste informais no laboratório evidenciaram a eficiência da ferramenta em visualizar notícias provindas da Internet.

\subsection{Organização}

Por se tratar de um trabalho que abrange diferentes áreas, estudos sobre técnicas de visualização textuais, visualização de dados web e técnicas de visualização aplicadas a dispositivos móveis foram desenvolvidos e a revisão foi dividida em três capítulos distintos. É apresentada também à técnica de visualização NMap bem como avaliações comparativas feitas com o estado da arte. Ao fim, é apresentada a ferramenta SPCloud, que utiliza a técnica NMap, e uma conclusão geral do trabalho desenvolvido. Esta dissertação está estruturada da seguinte maneira:

- No Capítulo 2 estão descritos os trabalhos com enfoque em visualização de dados textuais. O destaque é dado aos aspectos positivos e negativos de cada técnica e a relação delas com o trabalho aqui proposto.

- No Capítulo 3 o enfoque é dado aos trabalhos relacionados à visualização de dados web, em particular dados textuais, por estarem mais relacionados com o trabalho aqui proposto.

- No Capítulo 4 são apresentadas técnicas que tem por objetivo ocupar todo o espaço visual disponível e sua aplicação em dispositivos móveis.

- No Capítulo 5 está descrito as características e o funcionamento da técnica NMap.

- No Capítulo 6 é apresentado uma avaliação completa da técnica NMap e uma comparação dela contra as técnicas atuais do estado da arte. 
- No Capítulo 7 é apresentado todo o processo necessário para sair de uma coleção de documentos até a visualização final da ferramenta SPCloud. Por fim, um estudo de caso é feito mostrando as vantagens da ferramenta.

- Por fim, no Capítulo 8, são apresentadas as principais conclusões do trabalho aqui desenvolvido bem como limitações e possíveis trabalhos futuros. 


플

\section{Visualização de dados textuais}

escrita consiste na utilização de símbolos ou sinais gráficos para registrar com alta
precisão a linguagem falada e as ideias humanas. Com importância indiscutível,
permite o armazenamento e a propagação de informações, em forma de textos, não só entre indivíduos, mas também por gerações. Com o passar dos anos, e com o avanço da computação e dos meios de telecomunicação, a sociedade moderna está produzindo e armazenando cada vez mais informações, de forma textual, que precisam ser interpretadas e processadas de alguma forma.

Apesar dos textos conseguirem sintetizar e descrever com perfeição as informações que se pretende armazenar e transmitir, um leitor comum necessita de um maior tempo para interpretar as informações que ali estão escritas do que se elas estivessem sintetizadas em uma única imagem. Ou seja, o tempo necessário para um usuário ler a descrição de uma cena e abstraí-la é maior que o tempo necessário para obter a mesma informação através de uma imagem desta mesma cena (Wong, 1999).

Baseado nesse fato, as técnicas de visualização textuais são comumente utilizadas com o intuito de acelerar a interpretação dos dados e facilitar a abstração de informações de um texto ou um conjunto deles. De modo geral, elas são capazes de sintetizar o conteúdo textual, utilizando representações visuais, exibindo para os usuários os tópicos mais relevantes baseado em alguma métrica ou qualquer outra informação que o desenvolvedor da técnica julgue importante. 
Com o intuito de criar um embasamento teórico para este projeto de pesquisa, este capítulo irá apresentar técnicas de visualização de dados textuais. Elas estão organizadas em visualização da semântica da palavra e suas relações, visualização de documentos utilizando o paradigma de TagCloud e visualização de coleção de documentos utilizando técnicas baseadas em plotagem. Por fim, é apresentado na seção de considerações finais um apanhado das técnicas e uma breve discussão de como elas se relacionam com o trabalho aqui descrito.

\subsection{Semântica da palavra e suas relações}

Diversas palavras podem apresentar significados distintos dependendo do contexto que está inserido. Por exemplo a palavra "manga" pode referir-se a uma fruta bem como a região dos braços de uma camisa. A essa possível variação de significado damos o nome de semântica, i.e., o significado que uma dada palavra tem dentro de um contexto. Para determinar a semântica de uma palavra, é necessário analisar todo o contexto que normalmente é formado pelas palavras e sentenças que precedem e sucedem o termo em estudo. Este paradigma é denominado "Keyword in context" (KWIC).

Utilizando o KWIC, a ferramenta Concordance (Watt, 2012) (Figura 2.1) possibilita visualizar o contexto das diversas palavras presentes em um documento ou em uma coleção deles. Para isso, a ferramenta exibe uma lista com todos os termos encontrados nos documentos para que o usuário selecione aquele de seu interesse. Todas as orações que contém o termo selecionado são então exibidas em uma lista centralizando-as pela palavra em estudo (Figura 2.1). Essa visualização permite analisar e determinar a semântica que a palavra está inserida.

Apesar disso, a ferramenta fornece apenas uma visualização superficial das palavras dentro de um texto, não possibilitando uma visão global do documento e tampouco mostra a relação das palavras uma com as outras. Assim, com o intuito de visualizar não só a semântica, mas também a relação das palavras dentro de um documento, a técnica WordTree (Wattenberg e Viegas, 2008) (Figura 2.2) constrói uma árvore de relacionamento de um termo dentro de um documento.

Uma característica particular da WordTree está na fase de processamento do documento que, ao contrário da maioria, não remove pontuação, artigos e preposições. A razão para isso consiste no fato que, em geral, artigos, preposições e pontuações dão sentido a oração e são cruciais para o correto entendimento do texto e da construção semântica e por esse motivo não devem ser retirados da análise textual. 


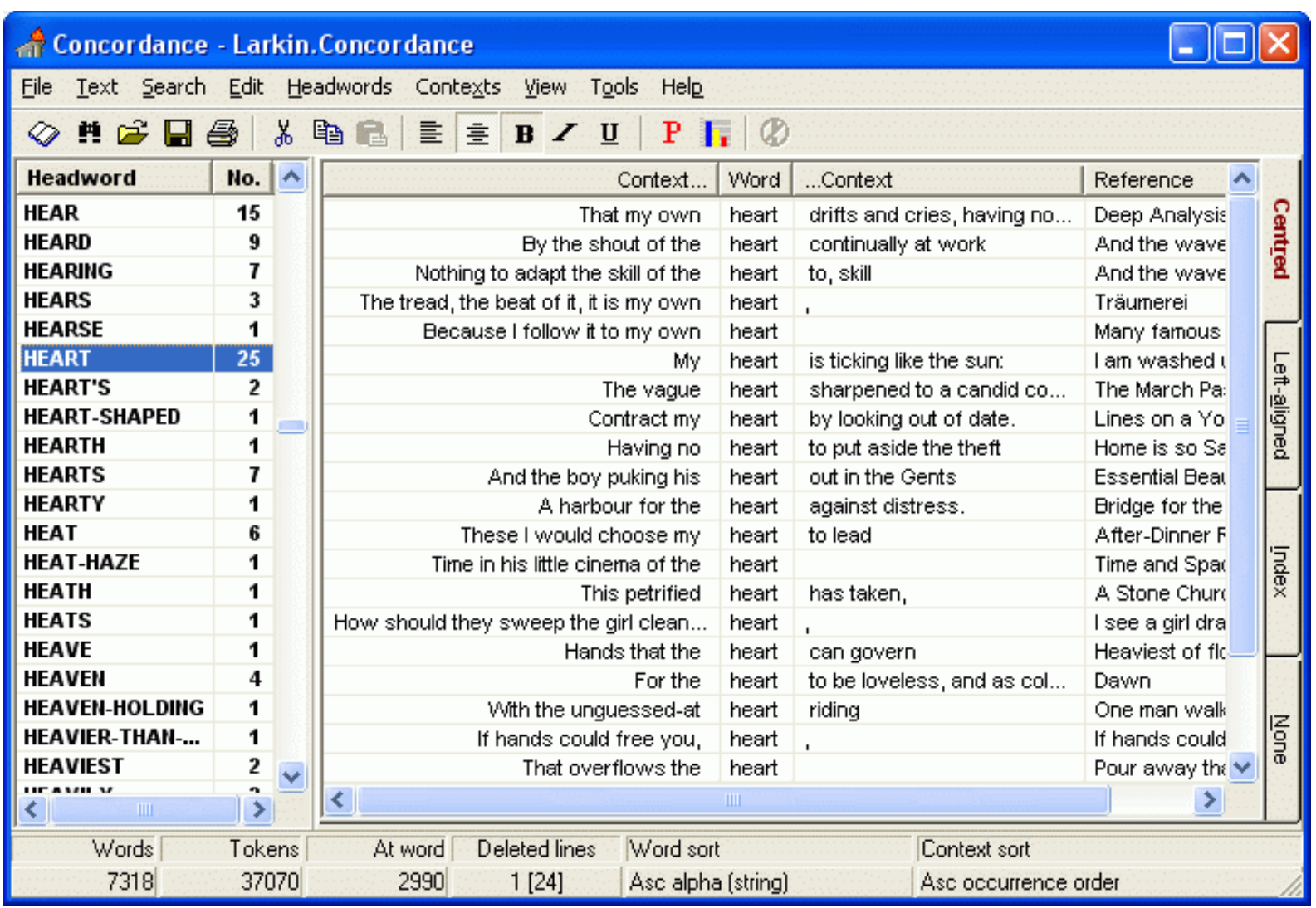

Figura 2.1: Ferramenta Concordance: análise de uma coleção de poemas de Philip Larkin. À esquerda, a lista de todos os termos encontrados nos poemas e, à direita, a visualização do contexto em que a palavra selecionada na coluna esquerda está inserida.

$\mathrm{Na}$ visualização final, a ferramenta produz uma árvore tomando como raiz o termo que o usuário deseja estudar. Esta é então ligada às outras palavras que a sucedem nas orações, formando assim uma árvore de relacionamento. O tamanho que as palavras são exibidas está relacionada com a frequência ${ }^{1}$ que elas aparecem no texto, i.e., quanto maior a palavra mais vezes ela aparece no documento em estudo.

A interação com a ferramenta é feita de dois modos. Em um primeiro cenário, o usuário pode selecionar um termo qualquer na árvore, gerando uma nova árvore tendo como raiz uma sequência de palavras partindo do termo de pesquisa até o termo clicado (vide cenário B na Figura 2.2). Uma segunda possível interação, consiste em selecionar um termo gerando assim uma nova árvore em que a raiz é a palavra selecionada pelo usuário (vide cenário C na Figura 2.2).

Com abordagem similar a WordTree, a ferramenta Phrase Nets (Ham et al., 2009)(Figura 2.3), exibe a relação das palavras ligando-as na visualização final com arestas.

\footnotetext{
${ }^{1}$ Neste contexto, entende-se por frequência como o número de vezes que uma determinada palavra aparece no documento em estudo.
} 


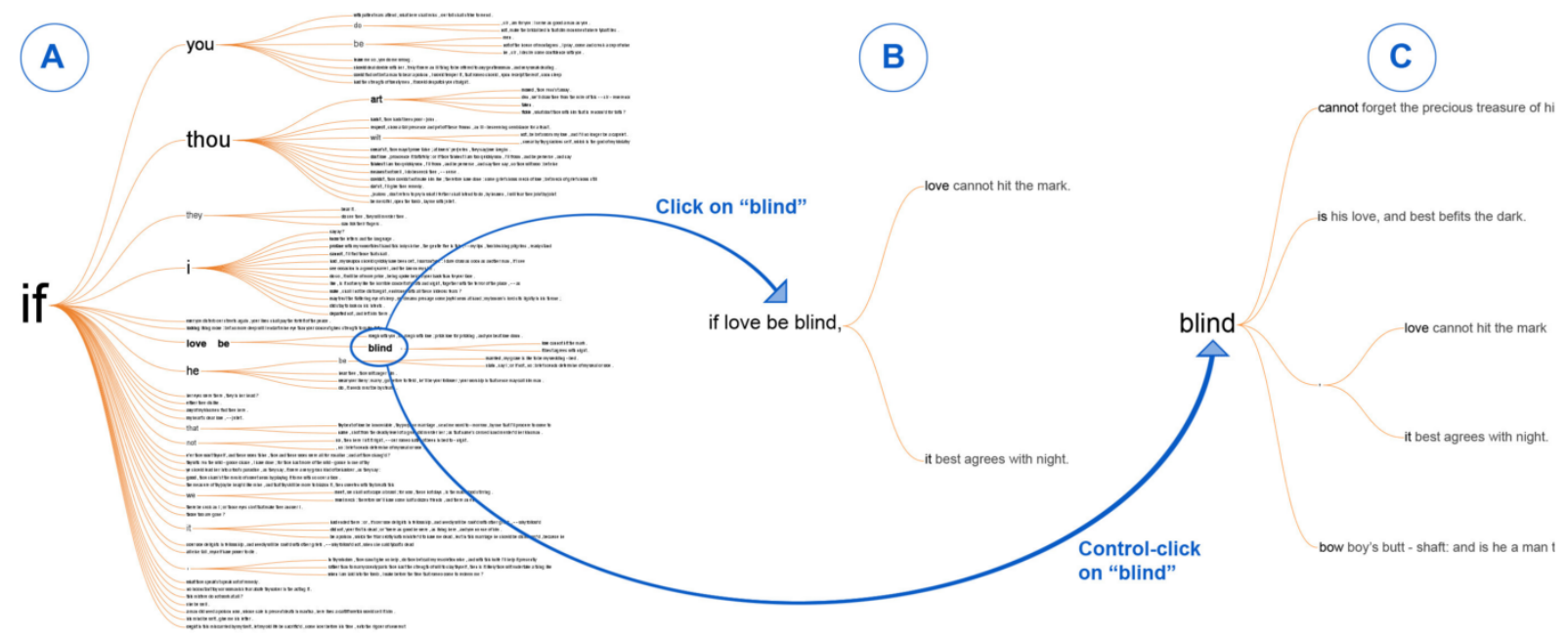

Figura 2.2: Técnica WordTree: a região "A" mostra a árvore formada pelo termo "if" no livro "Romeo and Juliet". Em "B", um exemplo de interação em que o usuário clicou sobre o termo "blind" forçando a visualização a remontar a árvore tomando como base o termo de busca até o termo clicado. Por fim, em "C", uma interação final em que a árvore é remontada tomando como base para a busca a nova palavra clicada.

No entanto, esta ferramenta possibilita que o usuário informe uma relação de interesse, criando assim um grafo em que os nós são as palavras do texto e as arestas que as ligam representam a relação informada pelo usuário. Cada palavra tem o seu tamanho ligado à sua frequência no texto, porém as larguras das arestas são variadas de acordo com a quantidade de vezes que aquela associação ocorreu.

De acordo com Ham et al. (2009), há duas vantagens em possibilitar que o usuário escolha uma relação de interesse em detrimento de utilizar a relação de adjacência. A primeira vantagem está na possibilidade do usuário refinar e controlar mais a criação da rede de palavras, o que possibilita dar destaque maior a algum tipo de relação particular dentro da rede. Outra vantagem está na solução de um problema inerente à ordem das palavras; Na sentença "a chave foi encontrada", por exemplo, um tipo de dependência "typed-dependency" traria como resultado que os termos "chave" e "encontrada" estão ligados mesmo que um não suceda o outro diretamente.

Um fator que desfavorece a ampla utilização da técnica Phrase Nets é o alto tempo de processamento. Para processar $1 \mathrm{Mb}$ de texto é necessário mais de $24 \mathrm{~h}$, inviabilizando assim qualquer tipo de interação mais rebuscada com o usuário. Além disso, as técnicas Phrase Nets e WordTree maximizam a utilização do espaço visual inviabilizando a sua utilização em telas pequenas. Ademais, todas as técnicas até agora mencionadas não são capazes de exibir uma visão global do documento. 


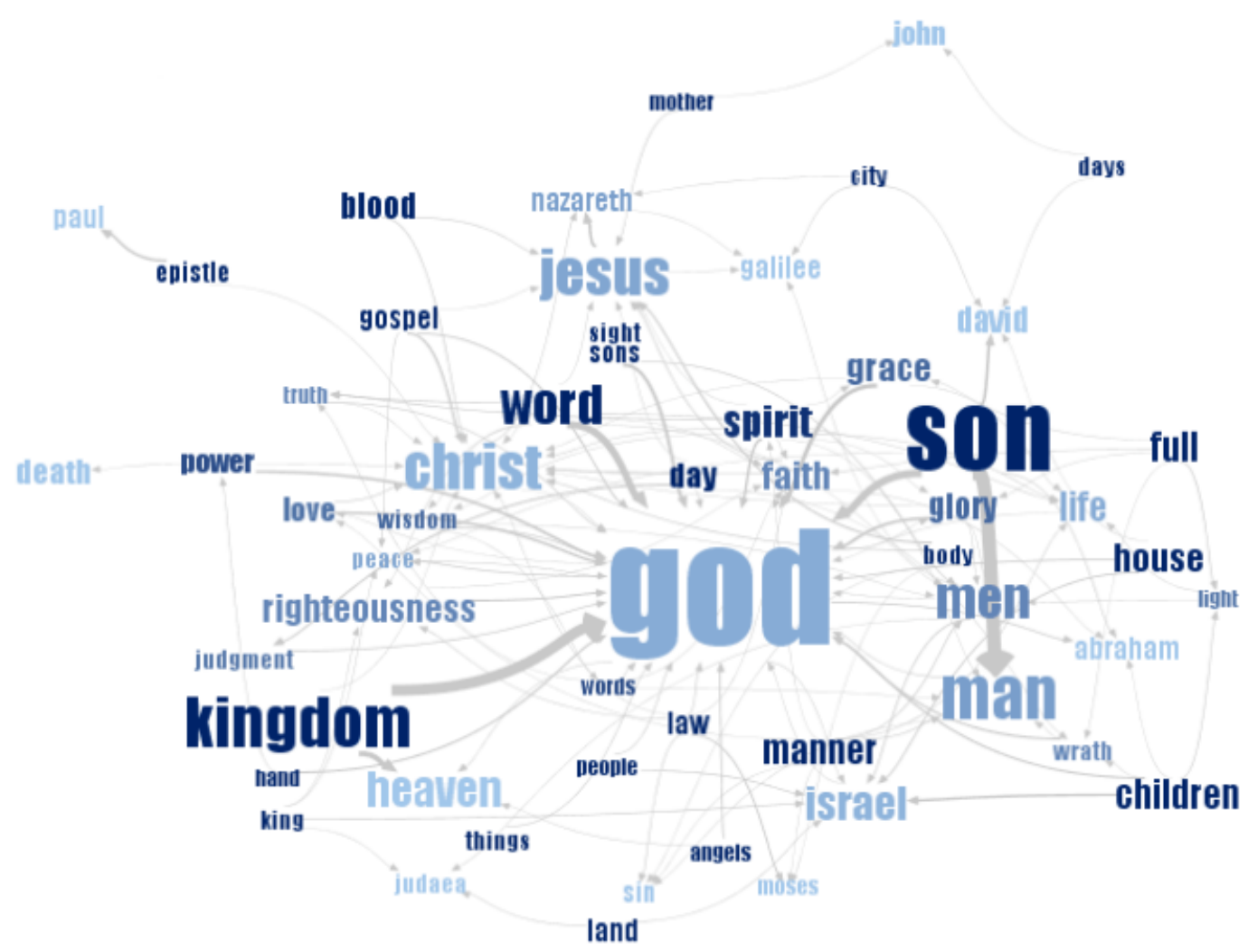

Figura 2.3: Técnica Phrase Nets: visualização do novo testamento da bíblia. O tamanho das palavras está relacionado com a frequência com que elas aparecem no texto e a espessura da seta com o número de vezes que um termo está ligado ao outro sem que haja uma pontuação no meio deles.

Ao contrário, a técnica TextArc (Paley, 2002) (Figura 2.4) fornece uma visão de todo o texto preservando a estrutura tipográfica bem como a ordem das palavras. Em uma escala de cinza, a importância de uma palavra é mapeada em branco permitindo assim que o usuário identifique rapidamente os termos mais frequentes e o assunto abordado. $\mathrm{O}$ formato elíptico é utilizado para maximizar o uso do espaço visual em telas retangulares, minimizar o número de sobreposições de palavras e garantir uma consistência na posição das palavras repetidas internamente à elipse.

Cada oração do documento é reproduzida na elipse externa da visualização, em ordem, para que se mantenha a estrutura tipográfica. Na elipse interna as palavras presentes no texto são posicionadas em sequência sem que haja repetição. Caso a palavra apareça mais de uma vez no documento, ela será desenhada apenas uma vez no centroide de todos os pontos que a palavra deveria aparecer na elipse interna, garantindo o preenchimento do centro da elipse.

Para melhorar a legibilidade do texto, ao se sobrepor o ponteiro a uma palavra, exibe-se uma aresta para todos os pontos em que ela deveria aparecer além de dar um destaque a 


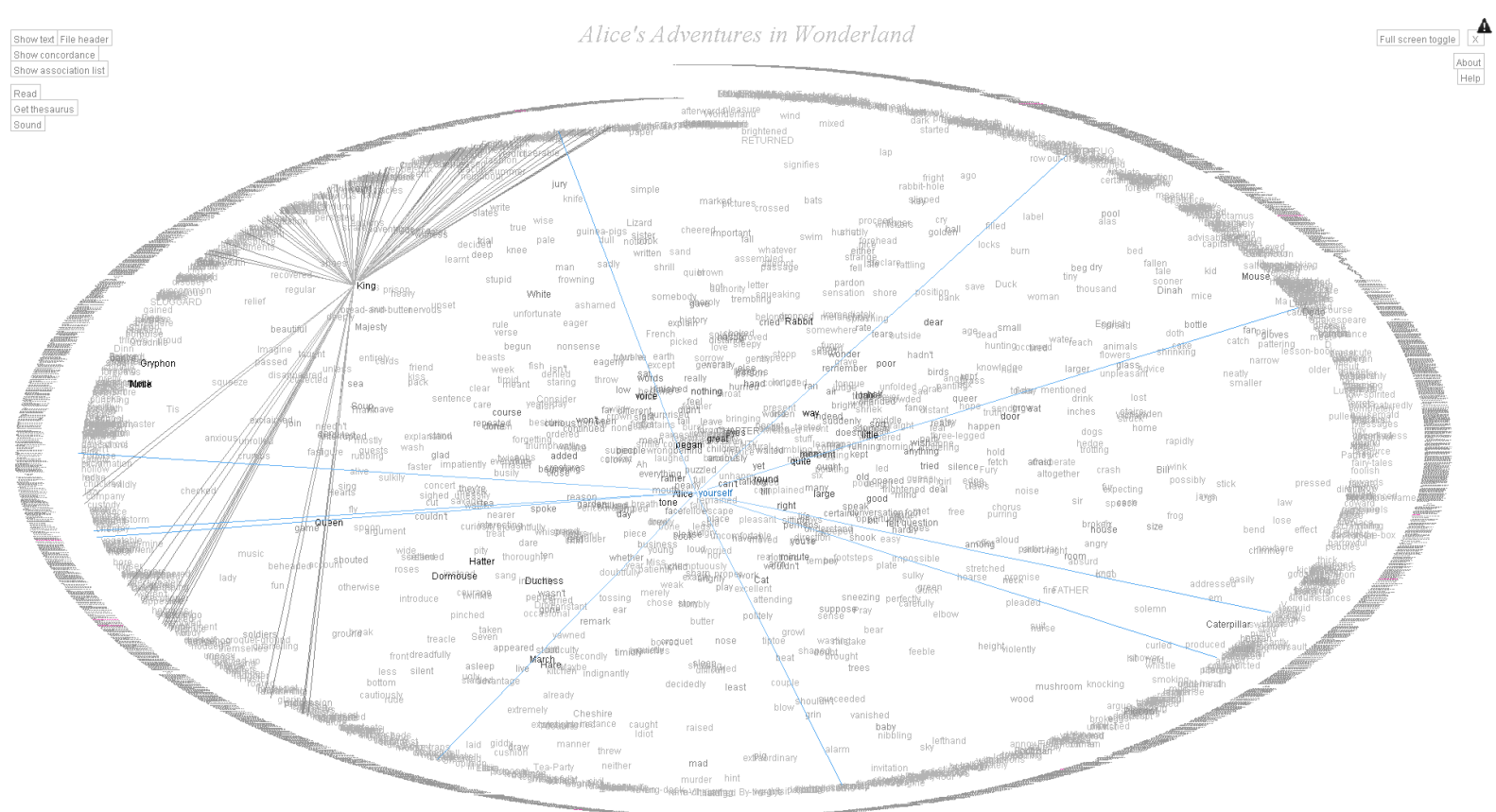

Figura 2.4: Ferramenta TextArc: análise do livro Alice's Adventures in Wonderland (Alice no país das maravilhas). Na elipse externa estão todas as sentenças do texto e na elipse interna todas as palavras. Palavras que aparecem mais de uma vez no texto estão posicionadas no centroide dos pontos que deveriam estar na elipse interna.

ela. Outra possibilidade é colocar o ponteiro sobre as orações contidas na elipse exterior, aumentando-a, e possibilitando a leitura do usuário.

Todavia, apesar das interações garantirem uma melhor legibilidade do documento, a técnica TextArc demonstrou ser impraticável para visualizar grandes documentos. Devido ao tamanho reduzido, não é possível identificar as orações e palavras; Sendo assim, quando se deseja encontrar uma palavra específica ou uma determinada oração, a tarefa se torna exploratória e difícil.

Verificar como as palavras estão interligadas e como estão relacionadas entre si é importante principalmente quando é necessário saber a semântica da palavra. No entanto, apesar de todos os esforços, as técnicas de visualização baseadas em relação de palavras ainda encontram grandes problemas para visualizar grandes coleções de documentos ou um único documento grande.

\subsection{Paradigma de nuvens de palavras}

Notoriamente, visualizar todas as palavras e suas relações de um documento grande ou de uma coleção pode não ser tão eficiente. Propõe-se então visualizar as palavras mais relevantes, aquelas que aparecem mais vezes em um dado documento e que, na teoria, 
descrevem o conteúdo ali contido. Assim, uma possível solução para apresentar os termos mais frequentes com maior clareza seria mapear a frequência das palavras com o seu tamanho na visualização final, ou seja, quanto mais frequente a palavra no texto maior o tamanho da sua fonte. Este é o conceito por trás das técnicas baseadas em nuvens de palavras (do inglês "TagClouds").

A técnica TagCrowd (Steinbock, 2006) (Figura 2.5) seleciona as $n$ palavras mais frequentes, em que $n$ é determinado pelo usuário. Estas são então dispostas em ordem alfabética e com o tamanho da fonte relacionada à frequência com que elas aparecem no documento processado.

No entanto, o espaço visual é pouco aproveitado, deixando bastante regiões em branco e que não transmite qualquer informação ao usuário. Este cenário pode ser observado na Figura 2.5 com a palavra "microsoft" e suas palavras vizinhas. Quando existe duas palavras vizinhas onde uma é muito frequente e outra não, a visualização final gera uma região em branco entre a palavra menor e a linha acima.

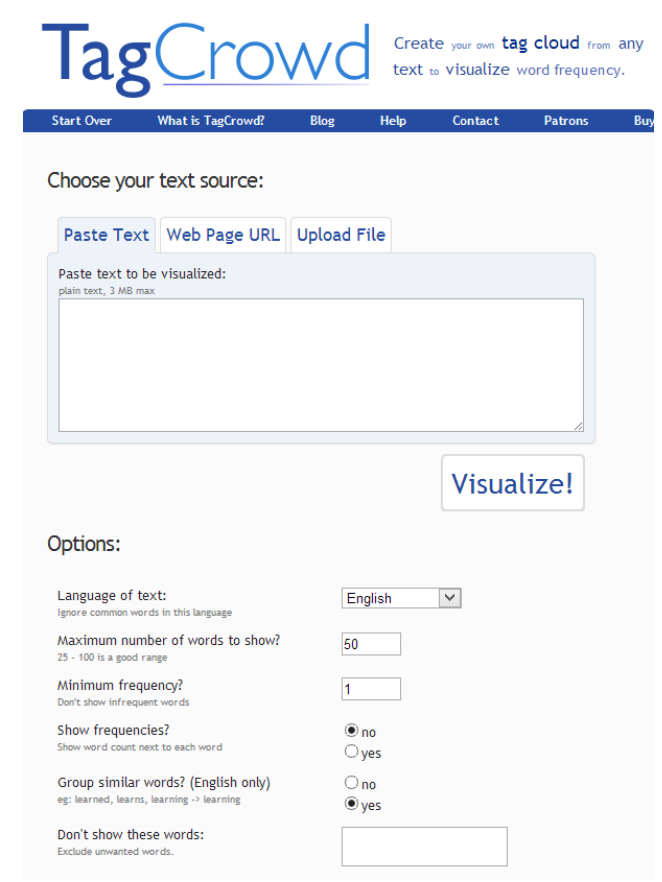

(a) Página inicial da ferramenta TagCrowd.

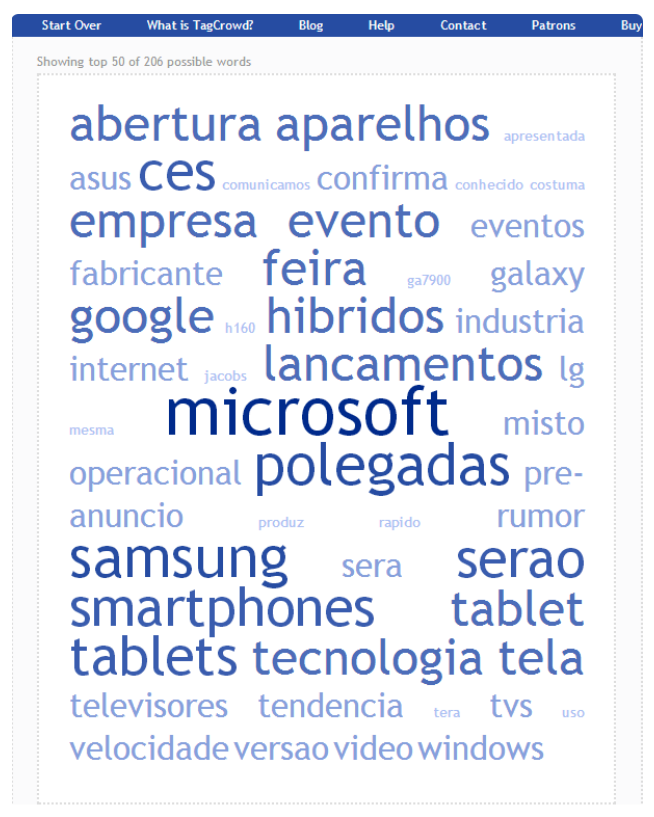

(b) Nuvem gerada pela técnica utilizando como texto uma notícia sobre tecnologia.

Figura 2.5: Ferramentas TagCrowd: utiliza o paradigma de nuvens de palavra. Em (a) temos a tela inicial da ferramenta e em (b) uma nuvem gerada a partir de uma notícia de tecnologia.

Os espaços em branco poderiam ser utilizados para o posicionamento de novas palavras, transmitindo mais informação com um mesmo espaço visual. Com este objetivo, 
a técnica Wordle (Viegas et al., 2009; Feinberg, 2013) (Figura 2.6) utiliza técnicas de mineração de texto para selecionar os termos mais importantes e os posicionam maximizando o uso do espaço visual disponível. Por utilizar o paradigma de nuvem de palavras, o tamanho das palavras desenhadas na visualização é diretamente proporcional à frequência que elas aparecem no texto.

Calculando a ocupação de cada letra no layout de visualização, a técnica Wordle consegue aproveitar ao máximo os espaços disponíveis, possibilitando que palavras menos frequentes, e por conseguinte menores, fiquem dentro de espaços não ocupados pelas palavras mais frequentes e maiores. Esta característica pode ser vista na Figura 2.6 que apresenta algumas palavras menores posicionadas dentro do espaço disponível entre a letra "W" e no centro das letras "o" e "d" da palavra "Wordle".

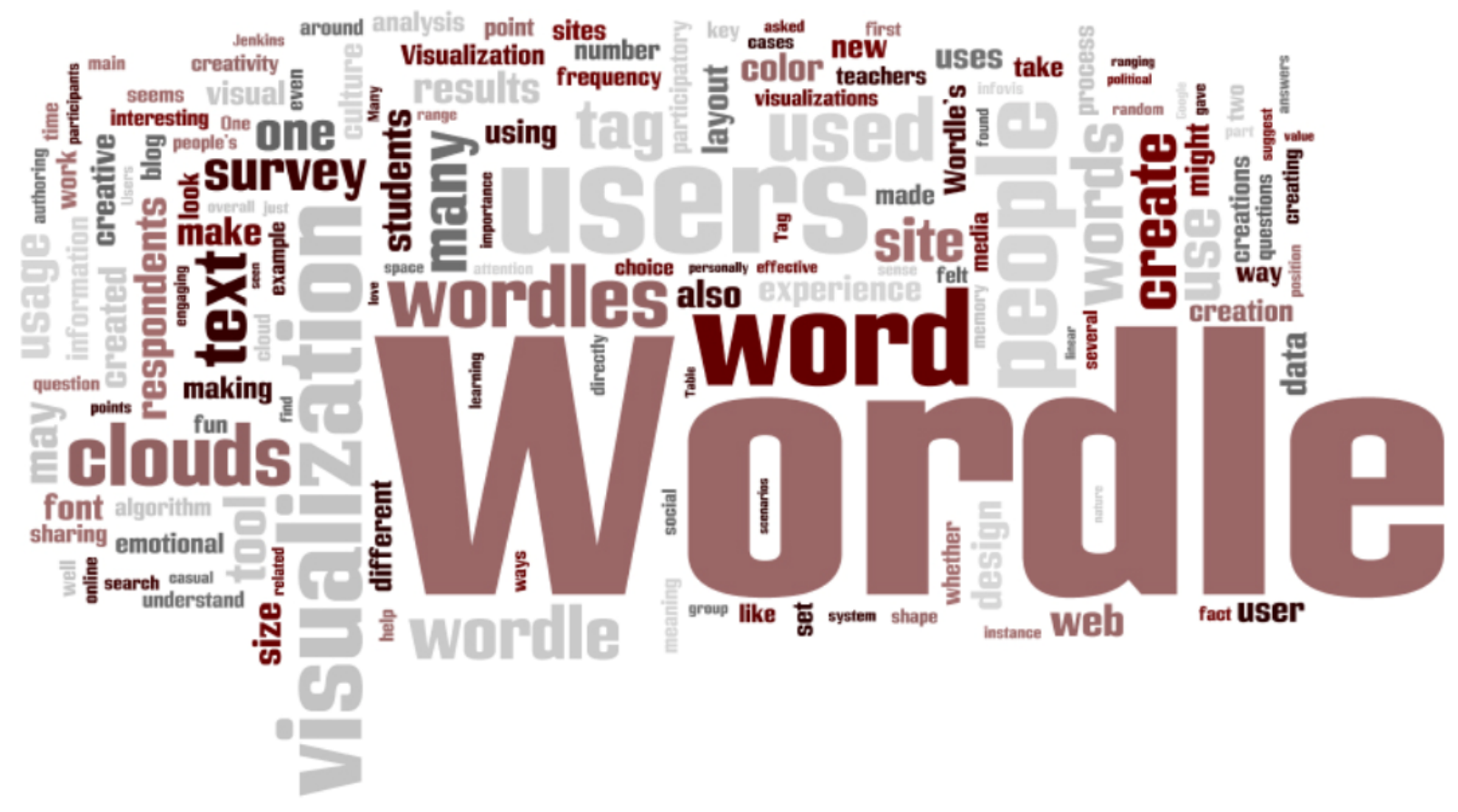

Figura 2.6: Técnica Wordle: nuvem de palavras formada pela técnica Wordle utilizando como base o artigo "Participatory Visualization with Wordle" (Viegas et al., 2009)

Outra modificação perceptível, e importante para maximizar o uso do espaço visual, é a possibilidade de posicionar palavras na vertical. Isto garante que regiões estreitas e altas sejam preenchidas. Por fim, possibilita que o usuário mude cor, fonte, e outros parâmetros que influenciam também no layout final.

Devido à alta complexidade computacional para posicionamento das palavras, a técnica Wordle não permite uma interação com a nuvem de palavras criada, i.e., todas as alterações possíveis são feita antes do processamento do texto e criação da visualização. Visando aumentar a interação do usuário com a visualização final, a técnica de ManiWor- 
dle (Koh et al., 2010) (Figura 2.7) possibilita que o usuário interaja com a visualização pós-processamento mudando a cor das palavras ou o layout final movendo e/ou rotacionando as palavras já posicionadas.

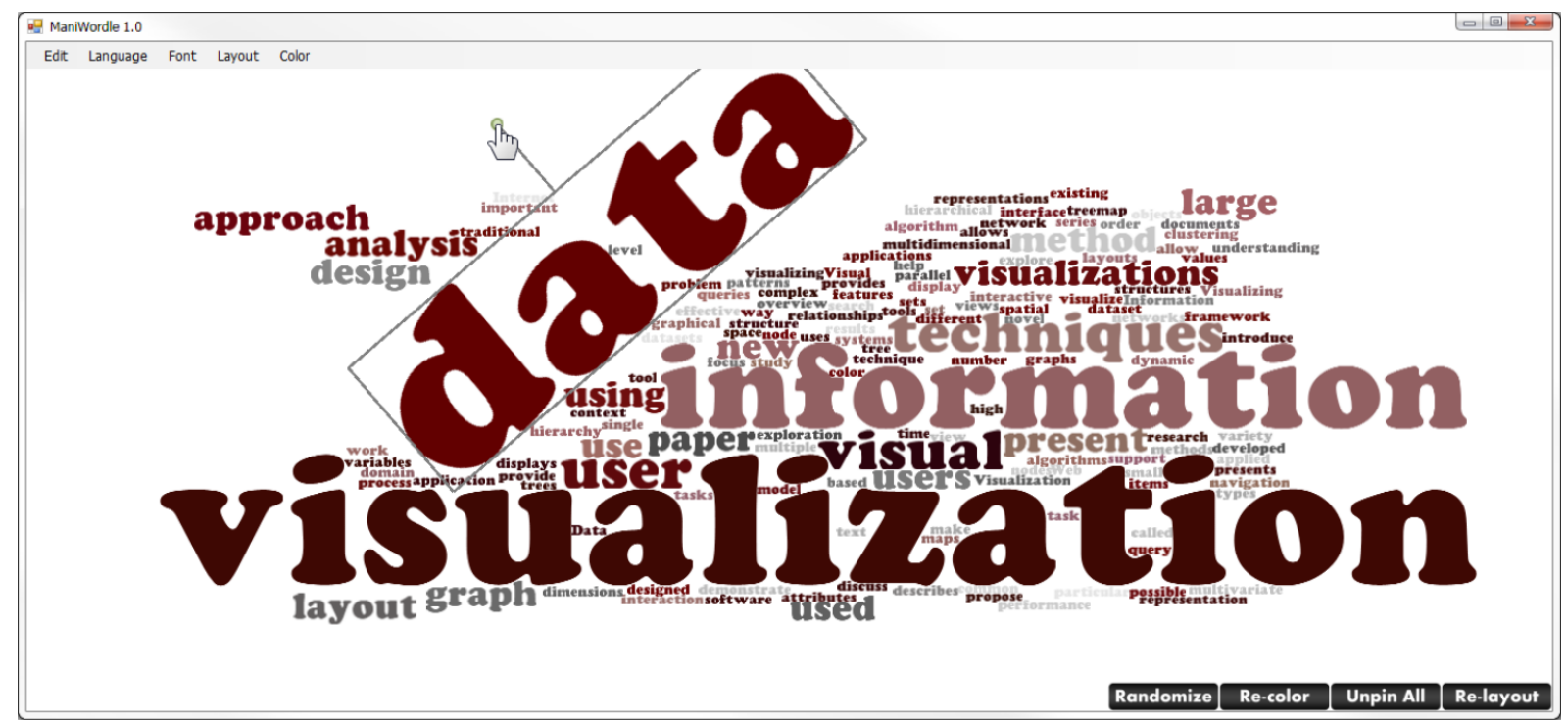

Figura 2.7: Técnica ManiWordle: nuvem de palavras formada pela técnica ManiWordle utilizando como base o título e o resumo dos artigos publicados no InfoVis de 1995. A palavra "data" está sendo rotacionada(Koh et al., 2010).

Estudo comparativo mostrou que a técnica de ManiWordle é simples, intuitiva e não introduz grandes desafios para o usuário que deseja usá-la para manipular a nuvem de palavras formada. Ao fim, os usuários disseram preferir a técnica ManiWordle à técnica Wordle pura.

Em suma, as técnicas baseadas no paradigma de nuvens de palavras têm demonstrado excelentes resultados quando se pretende sumarizar um documento ou uma coleção deles. No entanto, estas ainda não são capazes de visualizar como os documentos da coleção em estudo se relacionam, quais os grupos ali presentes ou o principal assunto de cada grupo. Além disso, as técnicas até então abordadas produzem nuvens de palavras amorfas, i.e., sem nenhum formato preestabelecido, o que dificulta o posicionamento em um polígono que define o espaço a ser preenchido.

Uma possível solução para a análise de coleções de documentos é oferecida pela técnica ProjCloud (Paulovich et al., 2012) (Figura 2.8). Esta utiliza projeção multidimensional para posicionar os documentos no espaço visual respeitando a relação de vizinhança e similaridade entre eles. A combinação da projeção com a nuvem de palavras fornece aos usuários uma análise tanto global quanto local dos documentos, facilitando assim a exploração desta coleção. 


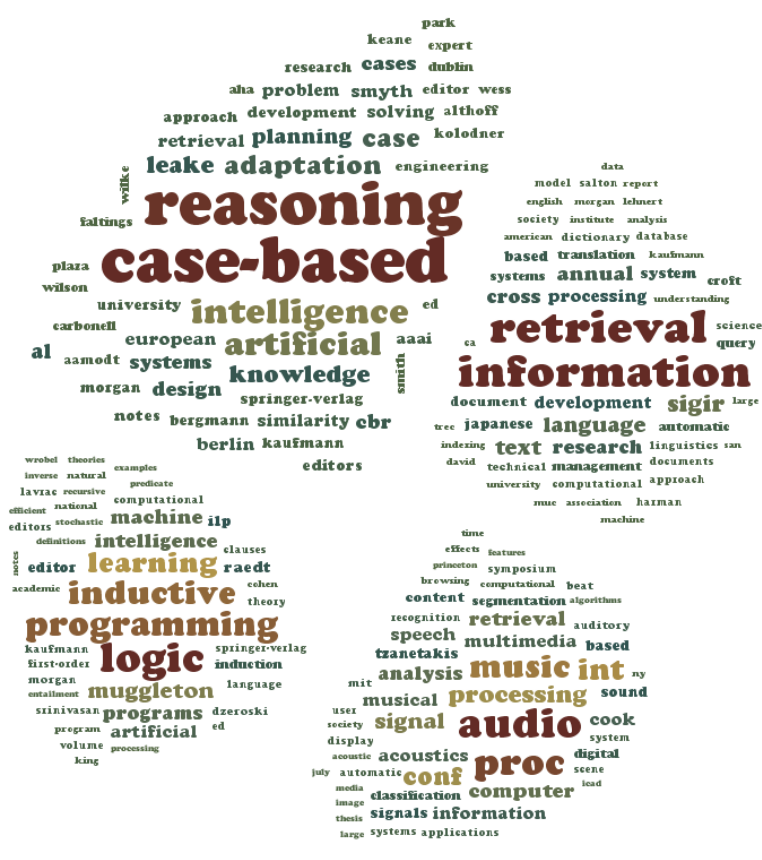

(a) 4 grupos.

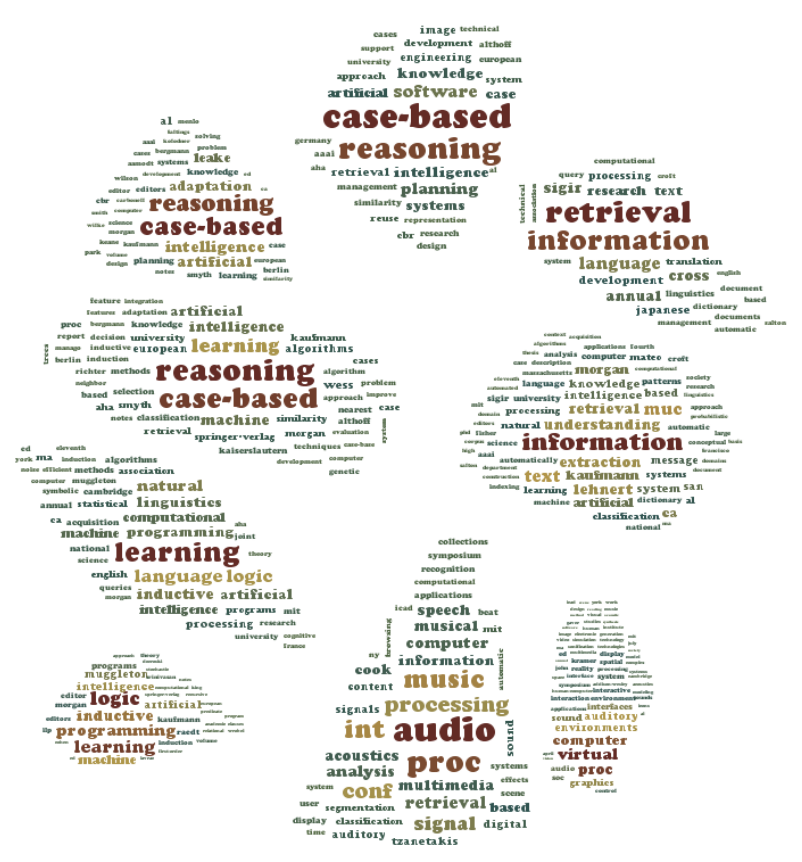

(b) 9 grupos.

Figura 2.8: Técnica ProjCloud: visualização de artigos científicos de 4 áreas de conhecimentos distintas. Na figura (a) temos os dados agrupados em 4 clusters diferentes e em (b) 9 clusters(Paulovich et al., 2012).

Para isso, a coleção de documentos é processada e mapeada no espaço visual utilizando alguma técnica de projeção multidimensional (em particular foi utilizado a Least Square Projection (LSP) (Paulovich et al., 2008a)). Em sequência, com os documentos já mapeados em um espaço bidimensional, aplica-se o algoritmo de agrupamento de dados bisecting k-means para encontrar os grupos presentes no conjunto de textos. Estas duas etapas garantem que os documentos similares estarão mais próximos no espaço visual e presentes no mesmo grupo.

Por fim, as palavras mais relevantes de cada grupo de documentos são encontradas para formar a nuvem de palavras bem como o fecho convexo de cada grupo é calculado para delimitar o polígono no qual a nuvem deve ser desenhada. O resultado pode ser visto na Figura 2.8 em que a técnica foi calculada utilizando um conjunto de artigos científicos de 4 diferentes áreas do conhecimento.

É notório que a técnica ProjCloud deixa muito espaço em branco entre seus grupos. Isso é particularmente um problema quando o espaço disponível para a visualização é limitado, como é o caso dos dispositivos móveis. Outro problema está associado à forma como os polígonos são encontrados e as palavras são desenhadas. Em um cenário hipotético, composto por dois grupos distintos, um extremamente denso e compacto e 
outro esparso e rarefeito, o primeiro grupo seria representado por uma nuvem de palavra pequena e o outro, ao contrário, uma grande nuvem. Esta característica pode levar o usuário à incorreta conclusão de que a maior nuvem de palavra representa o grupo com mais documentos e com palavras que apareceram mais vezes.

\subsection{Técnicas baseadas em plotagem}

Outra abordagem adotada para visualizar grandes coleções de documentos utiliza plotagem de pontos em um espaço bidimensional para visualizar similaridade, grupos e hierarquias, a exemplo da técnica HiPP (Paulovich e Minghim, 2008). Esta processa os documentos, projeta-os em um espaço bidimensional com a técnica LSP (Paulovich et al., 2008a) e, por fim, agrupa os dados com o algoritmo Bisecting K-means.

Importante ressaltar que cada grupo é representado no plano de visualização por um círculo com o tamanho relacionado à quantidade de documentos ali presentes, evitando assim armadilhas visuais (como no caso da técnica ProjCloud).

O usuário consegue interagir com a visualização dividindo cada grupo em $\sqrt{n}$ subgrupos (em que $n$ é o número de elementos no agrupamento total). Assim, uma hierarquia é estabelecida sobre os dados possibilitando que o usuário consiga explorar o grupo de interesse, refinando o seu espaço de busca, até chegar no documento final. De acordo com Paulovich e Minghim (2008), testes mostraram que o usuário consegue navegar até o documento final em não mais que 5 cliques.

De maneira similar, a técnica InfoSky (Andrews et al., 2002) (Figura 2.9(b)) produz uma visualização sobre grandes coleções hierárquicas de documentos. Utilizando uma metáfora visual que lembra as imagens de telescópio, os documentos são visualizados como "estrelas" e são posicionados no espaço visual utilizando um algoritmo de Force-directed placement (FDP). A utilização deste garante que documentos similares, baseado em uma distância de cosseno, são colocados próximos e, consequentemente, documentos distintos são posicionados distantes.

Os diversos grupos do mesmo nível de hierarquia são representados por áreas que dividem o espaço visual utilizando uma versão modificada do diagrama de Voronoi. O tamanho de cada área é dado pelo peso dos pontos que aquela região representa ou a quantidade de documentos contidos naquela área. 


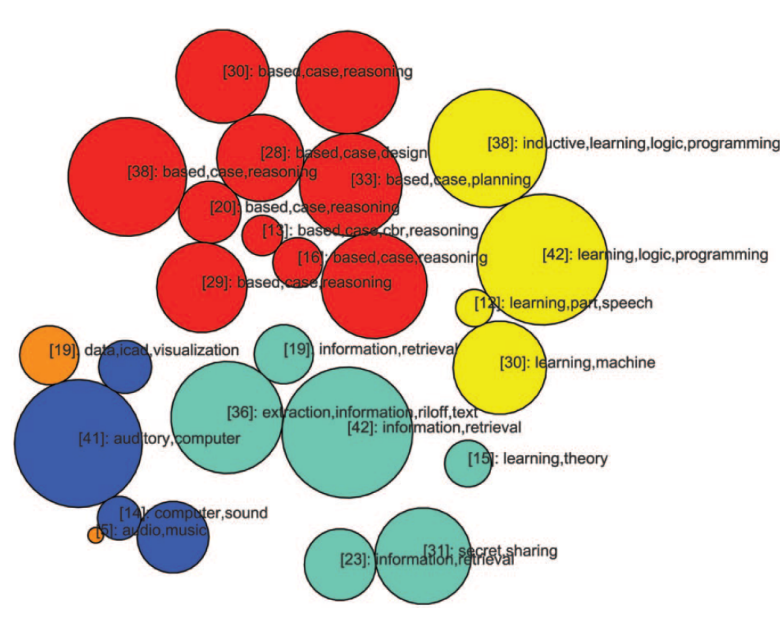

(a) HiPP

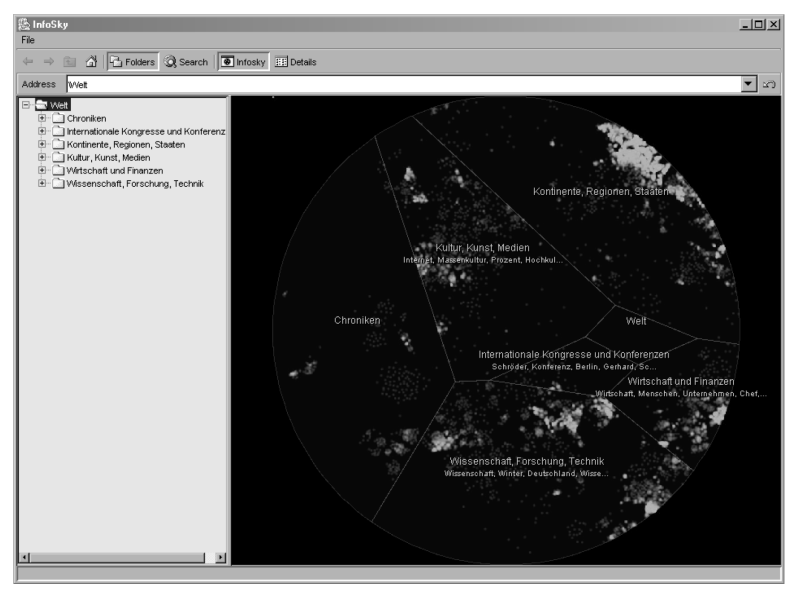

(b) Infosky.

Figura 2.9: Exemplos de técnicas baseadas em plotagem. Em (a) tem visualização gerada pela técnica HiPP para uma coleção de documentos científicos de 4 áreas distintas. Em (b) tem a visualização da ferramenta InfoSky com uma base de dados de 109 mil notícias em alemão do Jornal "German daily", divididas em 6900 coleções e 15 níveis hierárquicos.

\subsection{Considerações Finais}

Técnicas para visualização da relação das palavras são necessárias quando se pretende visualizar a semântica de uma palavra, ou como elas se relacionam entre si. No entanto, a visualização do texto como um todo se torna uma tarefa exploratória em que o usuário deve sempre buscar pelas palavras e navegar em suas relações, não conseguindo assim ter uma visão global do texto.

Uma possível solução é visualizar as palavras mais importantes do documento. Essas palavras, de modo geral, são as mais frequentes e revelam para o usuário qual o assunto e o domínio que o documento aborda. Além disso, é possível aplicar tais técnicas para visualização de grandes coleções de documentos, em que as palavras mais importantes seriam aquelas com maior frequência em todos os textos daquela coleção. Esta abordagem no entanto não trata da semântica dos termos, pois é possível que tenhamos um texto sobre "Jaguar" animal e outro sobre o carro sendo representados igualmente na visualização final.

Uma forma de abrandar tal problema, é a utilização de técnicas de visualização que deem suporte para coleção de documentos. Elas são capazes de exibir para o usuário os diferentes grupos existentes dentro de uma coleção de documentos. Desta forma, o usuário pode observar quanto um documento é diferente ou similar a outro, e se os mesmos pertencem ao mesmo grupo ou grupos distintos. Esta abordagem poderia assim tratar 
a visualização semântica da palavra. Por exemplo, novamente o termo "Jaguar", textos tratando sobre o animal poderiam estar em um grupo diferente daquele que aborda o assunto automóveis.

Como forma de exibir as palavras mais frequentes e importantes, um dos paradigmas mais utilizados é a de nuvens de palavras. Em particular, a técnica de Wordle tem se destacado pela grande quantidade de usuários que a utiliza. Desde textos particulares, poesias, declarações de amor, estampas de camisetas até visualizações sobre a eleição nos Estados Unidos, com aproximadamente 14 mil visitas diárias, a técnica de Wordle mostrou que o paradigma de nuvens de palavra é uma boa forma para sumarizar conteúdos textuais.

Neste mestrado, foi desenvolvido uma técnica capaz de visualizar uma coleção de documentos e sua estrutura de grupos hierárquicos sem apresentar armadilhas visuais, tal como proposto na técnica HiPP. O conteúdo de cada grupo foi sumarizado utilizando nuvens de palavras por já ter sua eficácia comprovada pela técnica Wordle. Por fim, uma nuvem foi gerada para cada grupo, tal como a técnica ProjCloud, possibilitando que o usuário visualize a diferença semântica entre os grupos de documentos da coleção. 


\section{Visualização de dados provindos da Internet}

Internet tornou-se a principal forma de comunicação e busca de conhecimento
da sociedade moderna. De acordo com a Internet World Stats (Group, 2012),
aproximadamente 2,405 bilhões de pessoas (34\% da população mundial), tinham acesso à rede em junho de 2012. Estes dados representam um crescimento de 566,4\% de 2000 até 2012. A magnitude destes números nos fazem ter ideia da velocidade de crescimento da web e de sua irrefutável grandiosidade.

Com o surgimento de redes sociais bem como a evolução da infraestrutura de telecomunicações e dos dispositivos móveis, os usuários da Internet passaram do modo passivo para geradores de conteúdo. Esta mudança comportamental fez com que $90 \%$ de todos os dados disponíveis atualmente na web fossem produzidos somente nos últimos dois anos (Bae, 2013). Toda essa quantidade de dados precisa ser processada e interpretada para que a informação ali contida seja transformada em conhecimento, o que demanda o desenvolvimento de técnicas e abordagens para este fim, como, por exemplo, técnicas de visualização.

Este capítulo apresenta as principais técnicas de visualização de dados provindos da Internet. Estas estão divididas em técnicas que utilizam predominantemente o paradigma unidimensional de lista e técnicas que tentam explorar as diversas características e dimensões inerentes dos dados. Ao fim, na seção de considerações finais, é feito um apanhado das técnicas e uma breve discussão de como elas se relacionam com o trabalho aqui descrito. 


\subsection{Paradigma unidimensional}

O paradigma de lista é exaustivamente aplicado por páginas web como forma de apresentar para os usuários notícias, imagens, vídeos, produtos em uma loja virtual ou resultados de busca. Este paradigma pressupõe uma classificação nem sempre presente no conjunto de dados. Estudo realizado em 2006 mostrou que 88\% dos usuários efetuam uma nova busca caso não encontrem o que procuram nas três primeiras páginas (iProspect, 2006). Este comportamento sugere a necessidade de ferramentas que apõem o usuário na manipulação e interpretação dos resultados.

Com este intuito, a técnica TileBars (Hearst, 1995) (Figura 3.1(a)) exibe os resultados de busca em coleções de documentos evidenciando a forma encontrada para impor a ordenação sobre os dados. Para isto, ela processa todos os documentos extraindo a estrutura básica de cada um e os principais tópicos de acordo com o algoritmo TextTiling (Hearst, 1994).

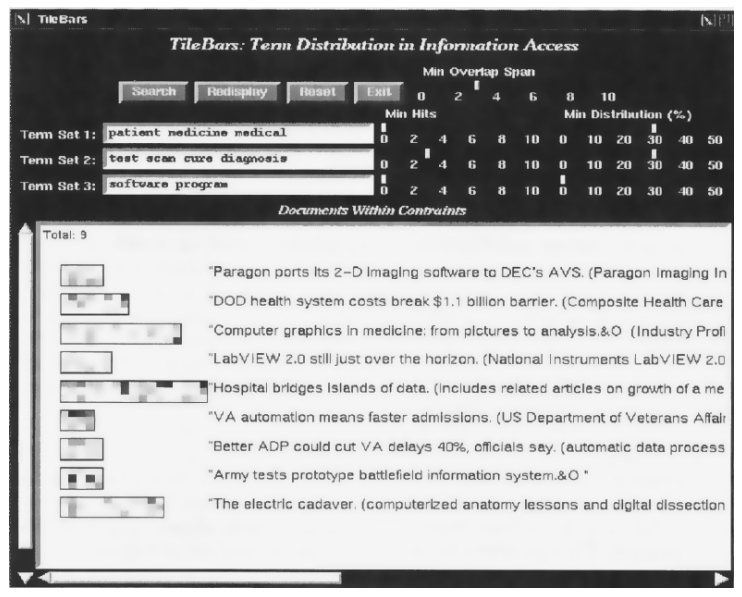

(a) Técnica TileBars.

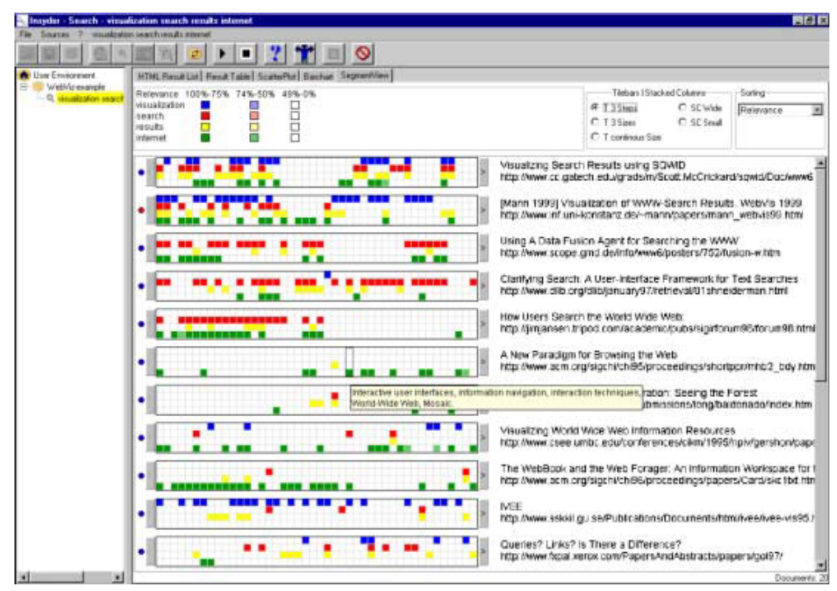

(b) Ferramenta Insyder.

Figura 3.1: Em (a) temos a técnica TileBarsdesenvolvida para visualizar resultados de busca em coleção de documentos. Em (b), a ferramenta Insyder que adaptou a técnica de TileBars como forma de visualizar os resultados de busca web.

Como a discrepância do tamanho dos documentos pode afetar no resultado do algoritmo, TileBars exibe ao lado de cada item da lista um retângulo com o comprimento associado ao tamanho do documento. Cada retângulo, por sua vez, é dividido em diversos quadrados que representam os tópicos encontrados na etapa de processamento dos dados. Estes são pintados de acordo com uma escala de cinza para indicar a frequência das palavras de busca dentro de cada documento do resultado. 
Reiterer et al. (2005) adaptou a técnica original TileBars, dentro da ferramenta Insyder (Figura 3.1(b)), para visualizar resultados de busca web. Para cada snippet ${ }^{1}$ retornado $^{2}$ no processo de busca, processa-se o resumo ali presente mensurando a similaridade deste com os termos de busca. Como os resumos possuem praticamente o mesmo tamanho, ao contrário de TileBars, os comprimentos dos retângulos são sempre iguais. Apesar de todos os esforços para informar ao usuário a metodologia utilizada para impor a ordenação sobre os dados, não existe a possibilidade de interação com a visualização final.

Ao contrário, a ferramenta Hotmap (Hoeber e Yang, 2006b) (Figura 3.2) possibilita a reordenação e a filtragem do resultado de busca. O usuário pode selecionar uma das palavras utilizadas na busca e, ao fazer tal ação, a ferramenta reordena todos os resultados tomando como base a frequência da palavra selecionada dentro dos itens. Esta opção possibilita que se dê maior importância para uma palavra específica da busca.

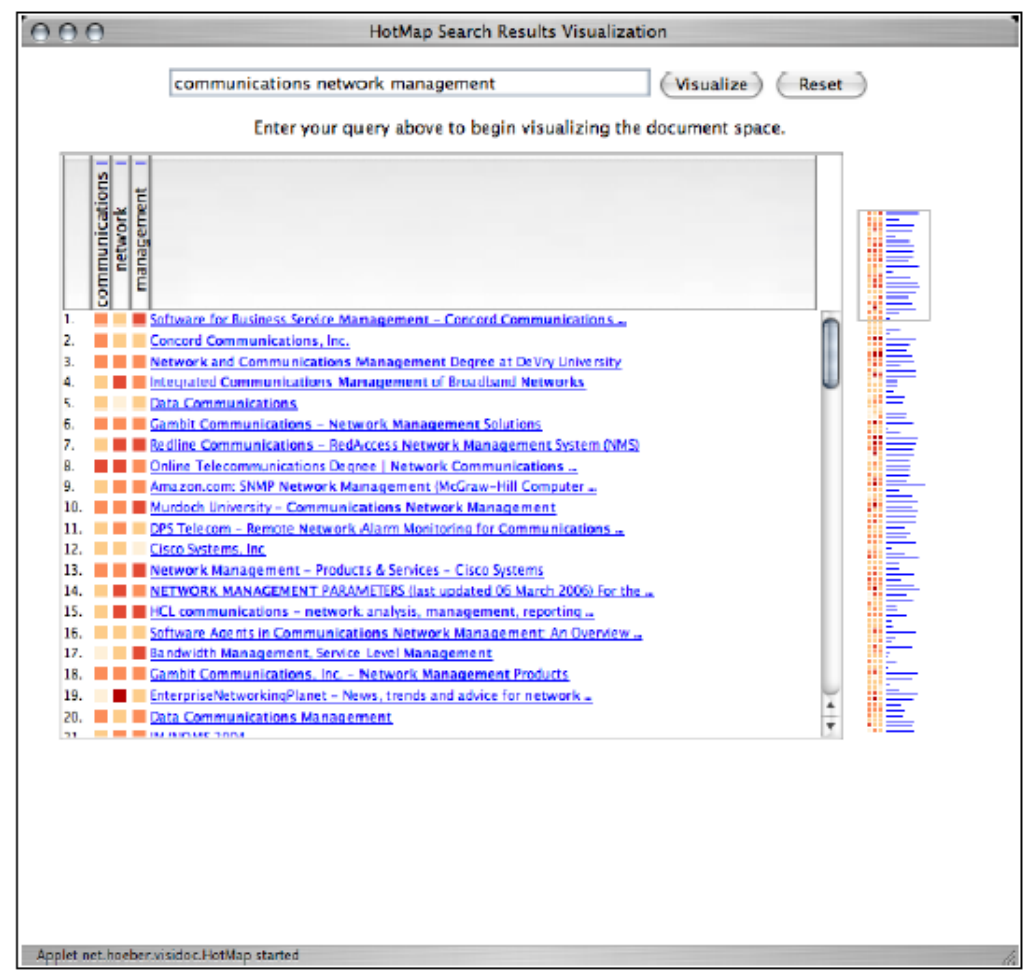

Figura 3.2: Ferramenta Hotmap: utilizada para visualizar resultados de busca web com apoio a visualização da frequência dos termos de busca.

Com o título e resumo de cada item do resultado, calcula-se a frequência das palavras utilizadas para busca e mapeia o resultado em uma sequência de quadrados, um para cada palavra, por meio de uma escala de cor, do amarelo para o vermelho, em que vermelho significa alta frequência e amarelo baixa frequência. Assim, com estas interações

\footnotetext{
${ }^{1}$ Snippet: Conjunto de informações sobre um determinado site. São formados pela tríade título do site, endereço (URL) e um pequeno texto descrevendo o conteúdo da página em questão.
} 
oferecidas, o usuário é capaz de julgar a qualidade da ordenação imposta sobre os dados e alterá-la caso julgue necessário.

Além disto, esta ferramenta fornece duas visualizações coordenadas. No lado direito exibe uma lista diminuída do resultado da busca, oferecendo assim uma visão global dos resultados, e no lado esquerdo a visão da lista em detalhe, possibilitando visualizar aproximadamente 20 resultados por vez e oferecendo assim uma visão local da busca. Como as visões são sincronizadas, o usuário pode interagir com a ferramenta e percorrer toda a lista de resultados de maneira rápida e prática por meio da visão global vendo o efeito de sua interação na visão detalhada.

Outra ferramenta que também utiliza o paradigma de lista como visualização final do seu resultado de busca é a ferramenta Concept Highlighter (Hoeber e Yang, 2006c) (Figura 3.3). Esta ferramenta, assim como Hotmap, apresenta uma visualização separada em duas regiões onde é possível ter uma visão global dos resultados de busca (à direita) e ao mesmo tempo uma visão mais detalhada de uma porção deste resultado (à esquerda).

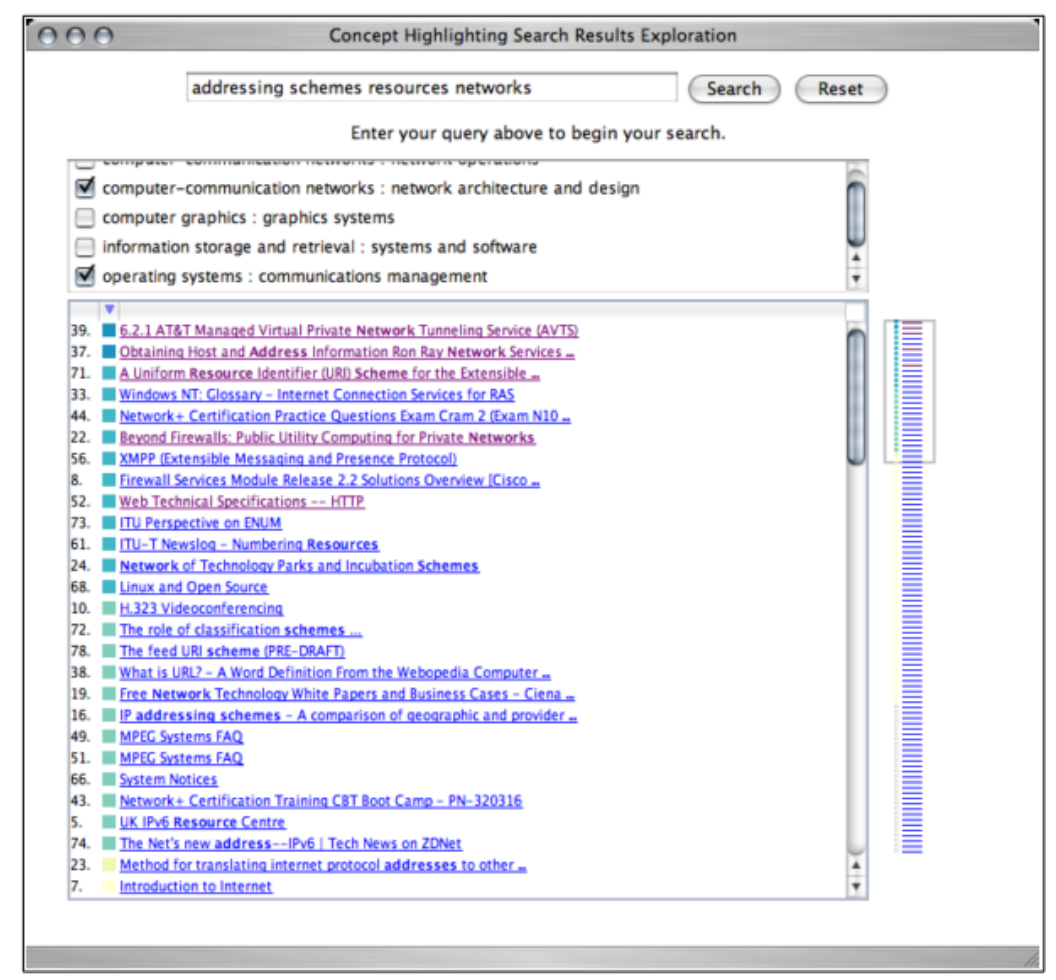

Figura 3.3: Ferramenta Concept Highlighter: efetua várias buscas relacionadas as palavras informadas pelo usuário e exibe o resultado em uma única lista.

Quando o usuário informa os termos de busca, a ferramenta pré-processa esta informação buscando, em uma base de dados de conhecimento previamente montada, os conceitos que estão relacionados àquela pesquisa de interesse do usuário. Para cada busca 
será retornado, após este processamento, os próprios termos da busca, mais alguns termos que estão conceitualmente próximos de acordo com a base de conhecimento.

São efetuadas buscas utilizando os termos fornecidos pelo usuário e os termos inferidos pelo sistema. Os resultados são agrupados de acordo com o algoritmo Concept-based Fuzzy (Hoeber e Yang, 2006d) gerando no fim uma única lista. Cada pesquisa feita pelo algoritmo é listada no topo, onde o usuário pode selecionar um ou mais termos buscados para visualização. Assim, utilizando o paradigma de lista, é apresentado uma intersecção dos resultados pertencentes aos grupos selecionados. À esquerda de cada resultado tem-se um número que representa a classificação daquele item de acordo com a pesquisa feita utilizando as palavras informadas pelo usuário. Desta forma, o usuário é capaz de saber a relação de cada resultado com a sua pesquisa original.

Com o intuito de validar os resultados obtidos, Hoeber e Yang (2006a) submeteram as ferramentas Google (Figura 3.4), Hotmap (Figura 3.2) e Concept Highlighter (Figura 3.3) a uma bateria de testes com usuários a fim de verificar se houve realmente um ganho de desempenho no processo de busca pela informação com as novas ferramentas. Dados os resultados de uma mesma busca nas três ferramentas, foram avaliadas diversas questões como tempo total para encontrar uma informação, precisão das informações, facilidade em usar a interface, dentre outras.

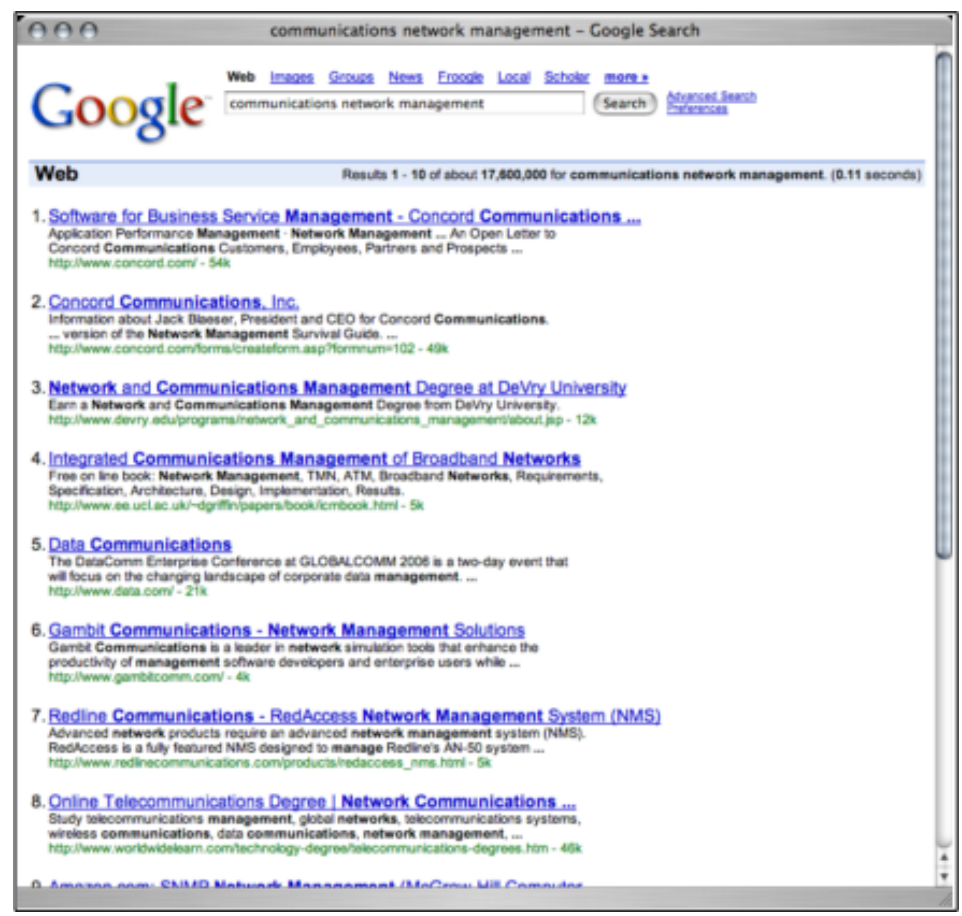

Figura 3.4: Ferramenta Google: paradigma unidimensional empregado pela ferramenta para visualizar resultados de busca na web. 
Os resultados mostraram que a técnica de Hotmap obteve o melhor desempenho em todos os quesitos, ficando em segundo lugar apenas em precisão dos resultados. A técnica Concept Highlighter ficou em segundo lugar na maioria dos testes, porém teve o melhor desempenho em precisão de resultados por apresentar uma resposta mais rápida ao interesse do usuário. Como resultado final dos testes, comprovou-se a eficácia de visualizações e ferramentas que auxiliem o usuário na tarefa de busca e recuperação da informação, deixando claro a necessidade de aperfeiçoar o atual paradigma de lista.

Além da atividade de busca pela informação, usuários constantemente utilizam da Internet para se manterem informados das notícias do país e do mundo. Tradicionais jornais impressos como "The New York Times", "The Guardian" e "O Globo" já possuem sua versão online para se adaptar às mudanças comportamentais dos novos usuários que preferem versões online às impressas. As vantagens das versões online são inúmeras pois conseguem transmitir novas notícias em uma velocidade superior e em um dinamismo muito maior. Soma-se ainda o fato que os usuários podem ter notícias novas a todo momento e não precisam esperar por uma única e nova versão todas as manhãs como é feito nos jornais impressos.

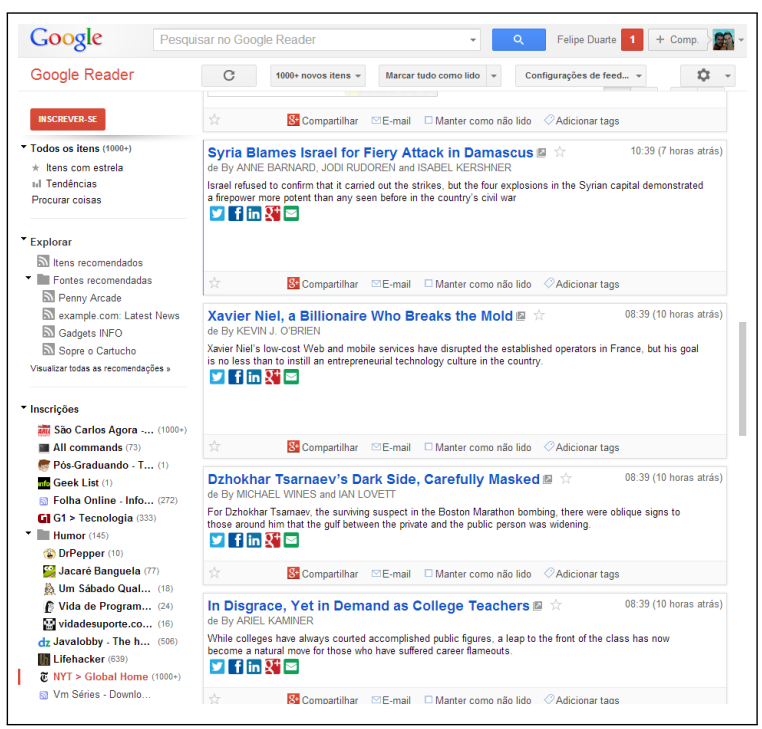

(a) Google Reader: www.google.com/reader.

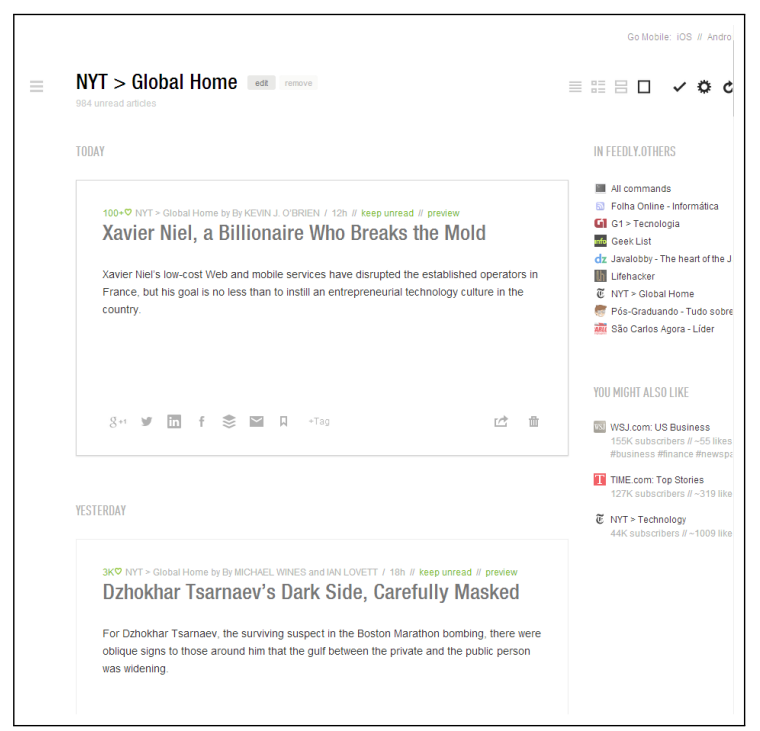

(b) Feedly: www.feedly.com.

Figura 3.5: Ferramentas de visualização de notícias baseadas no paradigma de lista unidimensional. Em (a) temos a ferramenta Google Reader e em (b) a ferramenta Feedly, em ambos os casos está sendo exibido as notícias do jornal "The New York Times".

Diversas ferramentas foram desenvolvidas para concentrar as notícias de múltiplos jornais em um só lugar, como por exemplo o Google Reader (Figura 3.5(a)) e o Feedly (Figura 3.5(b)). Os usuários podem se cadastrar nestas ferramentas e indicar quais os jornais que desejam ter como fontes de notícias. Estas ferramentas monitoram estes 
jornais e apresentam as notícias mais recentes utilizando o paradigma de lista. A ordem da lista é cronológica, posicionando as notícias mais recentes no topo e as mais antigas em sequência na lista.

\subsection{Paradigmas Multidimensionais}

Apesar de demonstrar bom desempenho quando existe uma relação de ordem ou classificação entre os itens apresentados, o paradigma de lista unidimensional não é capaz de exibir possíveis relações ou padrões entre estes itens. Além disso, em alguns casos, os dados dispostos na web trazem consigo diversas informações que, devido ao paradigma unidimensional, não são exibidas ao usuário. Por exemplo, em uma loja virtual não é possível visualizar a relação do custo de um tipo de produto com o índice de satisfação dos mesmos. É comum encontrar a possibilidade de reordenar a lista de acordo com um dos vários atributos dos dados como forma de contornar esta deficiência da lista, no entanto cabe ao usuário fazer o cruzamento de informações para determinar a melhor relação, por exemplo, custo e índice de satisfação.

Uma possível alternativa para auxiliar o usuário e facilitar este cruzamento de informação é utilizar técnicas baseadas em posicionamento de pontos no espaço visual. Este novo paradigma é capaz de utilizar a bidimensionalidade, característica intrínseca dos dispositivos de exibição como os monitores e projetores, para exibir os resultados de busca. A ferramenta Pex-Web (Paulovich et al., 2008b) (Figura 3.6) utiliza técnicas de projeção multidimensional para visualizar dados provindos da internet como resultado de busca, notícias ou patentes. Em sua representação visual, cada item é exibido como um ponto no plano em que a relação de similaridade é preservada, i.e., os itens mais similares são posicionados mais próximos no espaço visual.

Para isto, a ferramenta discretiza cada item em um vetor multidimensional capturando deste modo os principais atributos inerentes aos dados em estudo. Devido à característica multidimensional esparsa destes vetores, não é possível criar um mapeamento direto para o espaço visual. Deste modo, utiliza-se uma técnica de projeção multidimensional capaz de encontrar o melhor mapeamento bidimensional preservando a similaridade entre os elementos.

O usuário pode interagir com a visualização de maneira exploratória para descobrir o significado de cada ponto no plano. Uma seleção do ponto de interesse revela quais eram os vizinhos mais próximos no espaço multidimensional e, consequentemente, com conteúdo mais similar. É possível também selecionar uma região e ter acesso a toda informação ali contida. 


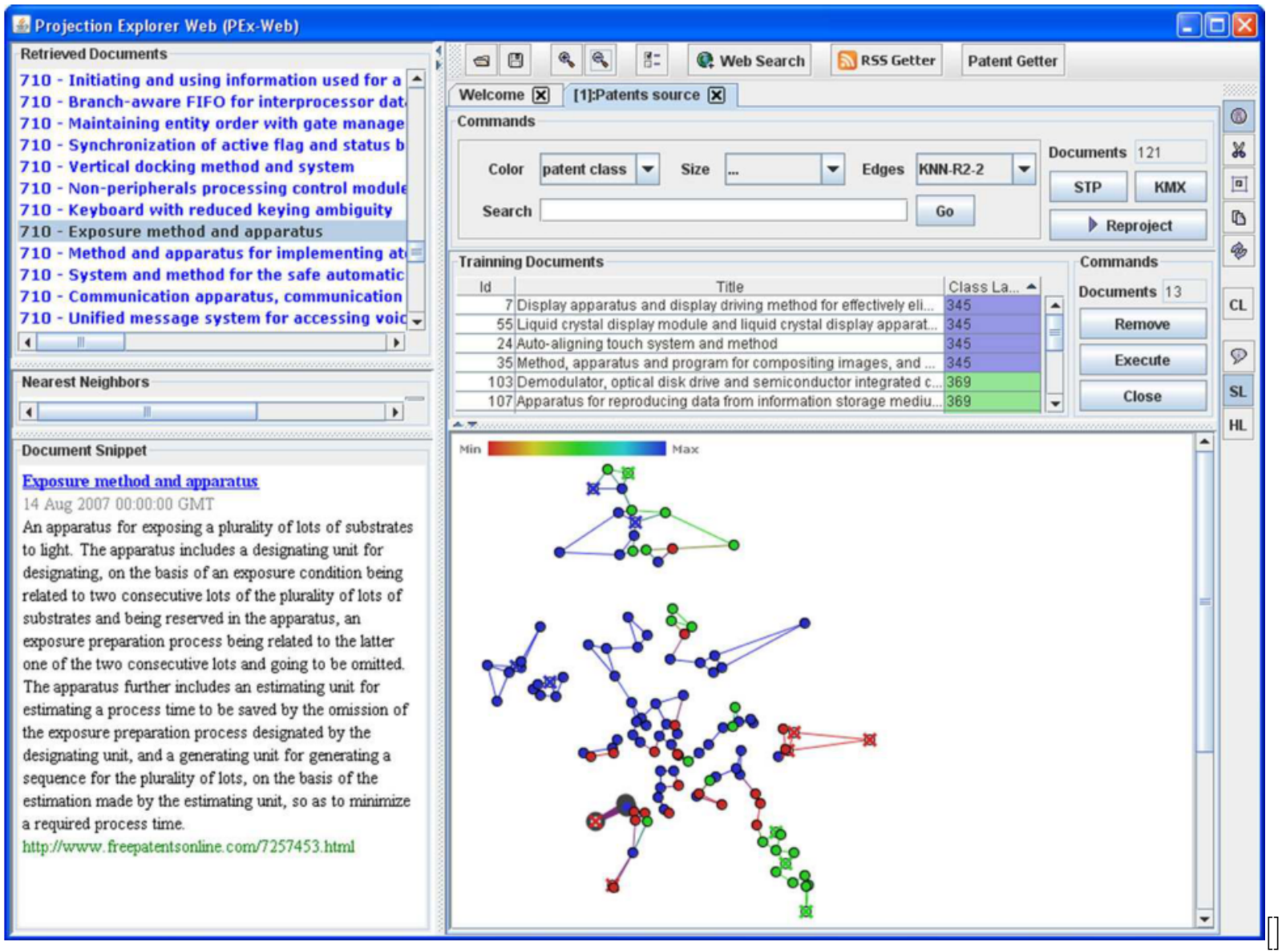

Figura 3.6: Ferramenta $P e x-W e b$ : visualização de um resultado de busca por patentes no site http://www.freepatentsonline.com/

Além disso, é possível fazer diferentes buscas e utilizar, sobre as projeções, operadores lógicos 'e' e 'ou'. Estes irão indicar quais elementos estão presentes na intersecção ou união das diversas projeções. Esta interação possibilita uma exploração mais precisa e clara. Por fim, informações adicionais podem ser mapeadas na cor e no tamanho dos pontos no plano, como por exemplo o tamanho do documento mapeado ao tamanho do ponto e a cor com a classificação retornada na busca.

Uma avaliação com diversos usuários mostrou que, em todos os cenários pesquisados, a abordagem proposta pela ferramenta aumentou a eficiência em buscar e encontrar informações, diminuindo o tempo de análise de cada resultado. Apesar dos excelentes resultados reportados, pontos em um plano é pouco ilustrativo para um conjunto de dados pois não transmite a informação sobre o que cada ponto significa. Além disso, caso o usuário, por exemplo, deseje visualizar uma notícia sobre um tópico específico ou qual o assunto mais importante do dia, a tarefa se torna totalmente exploratória em um cenário que pode facilmente passar dos milhares de itens por dia. 
De maneira análoga a Pex-Web, a técnica ProjSnippet (Gomez-Nieto et al., 2014) (Figura 3.7) utiliza projeção multidimensional para visualizar resultados de busca web. Diferente da metodologia tradicional empregada por buscadores, esta técnica exibe os resultados tentando tirar proveito da bidimensionalidade intrínseca do espaço visual.

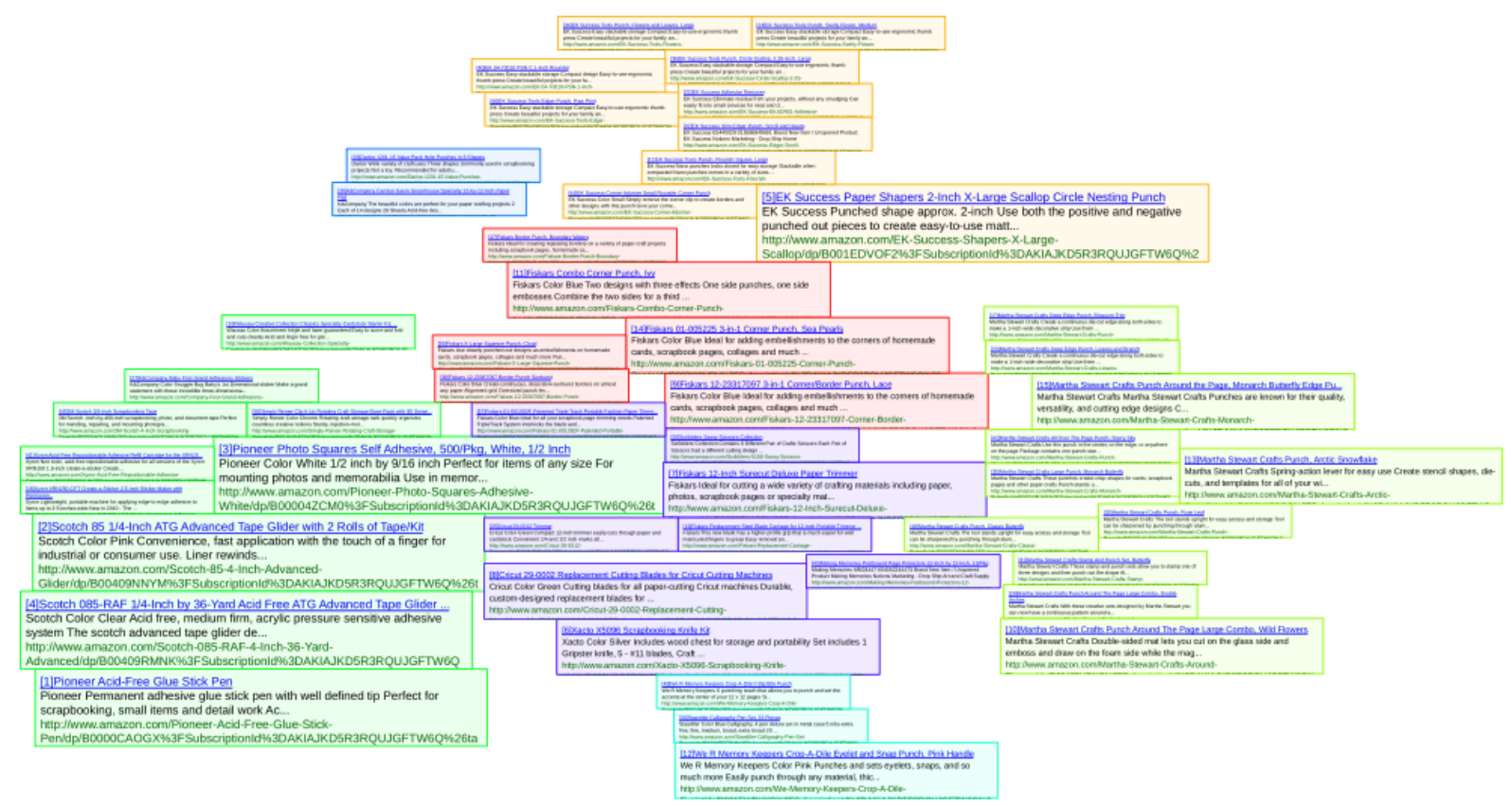

Figura 3.7: Técnica ProjSnippet: visualização de 50 resultados de busca.

Todo o processo se inicia com uma busca que fornece como resultando uma coleção de snippets. Esses são processados e discretizados utilizando técnicas de processamentos de texto que posiciona cada item do resultado no espaço multidimensional. Para posicioná-los no espaço visual, utiliza-se técnicas de projeções multidimensionais para garantir que as relações de similaridade entre os elementos sejam preservadas no posicionamento.

Com o posicionamento inferido pela projeção, é posicionado um retângulo contendo as informações do snippet ali representado. O tamanho do retângulo está relacionado com a ordem que os elementos são retornados na busca, possibilitando assim que o usuário consiga visualmente perceber a sequência com que os elementos foram apresentados na busca. Devido a esta característica, os últimos elementos são representados por um elemento gráfico muito pequenos e ilegíveis, transmitindo assim pouca ou quase nenhuma informação.

Além disso, é irrefutável o fato que esta técnica necessita de grande espaço visual para exibir os resultados, além de apresentar um baixo aproveitamento do espaço visual por deixar bastante regiões em branco entre os elementos. Para tentar amenizar este problema, a técnica ProjSnippet aplica um processamento de imagem, sobre a visualização final, 
aproximando ao máximo os elementos gráficos e minimizando o espaço desperdiçado. No entanto, ao efetuar esta operação, a relação de distância e similaridade calculada pela técnica de projeção é afetada pois reposicionamento pode aproximar elementos dissimilares.

Utilizando todo o espaço visual, o portal de notícias interativo NewsMap (Weskamp, 2004) (Figura 3.8), emprega a técnica Squarified Treemap (Bruls et al., 1999) para organizar as diferentes notícias provenientes do Google News². Desenvolvida por Marcos Weskamp em 2004, está em sua versão Beta com mais de 6 mil visitas diárias em 2009. É um sucesso na Internet quando o assunto é visualização de notícias. Desde o seu surgimento, nunca foi publicado nenhum artigo científico sobre o assunto e a única documentação disponível sobre a ferramenta é um blog ${ }^{3}$ mantido pelo autor. Neste blog não existe qualquer tipo de informação sobre a forma como os cálculos são efetuados ou a maneira como o peso de cada notícia é determinado.

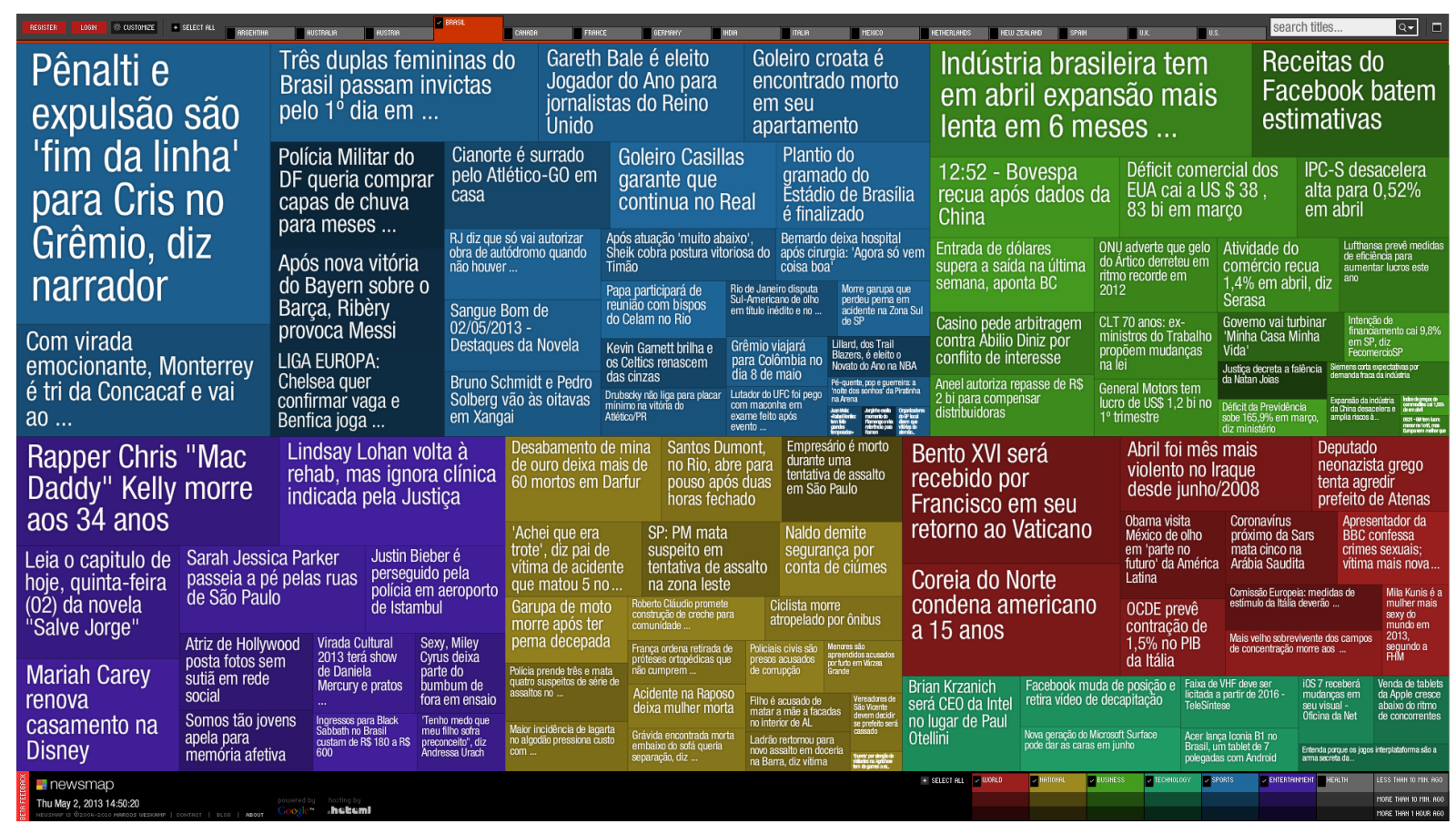

Figura 3.8: Ferramenta NewsMap: na imagem, visualização de notícias indexadas no Google News para o Brasil, cada cor representa um tema entre mundo, tecnologia, nacional, negócios, esporte e entretenimento.

De modo geral, é possível inferir que a visualização implementada em NewsMap separa por cor as diferentes categorias de notícias e o usuário, interativamente, pode filtrá-las fazendo com que a ferramenta exiba somente as categorias de seu interesse. Há indícios de

\footnotetext{
${ }^{2}$ https://news.google.com/

${ }^{3}$ http://newsmap.blogspot.com.br/
} 
que o tamanho de cada categoria na Squarified Treemap é dado pela soma da quantidade de artigos ali presentes. Do mesmo modo, cada notícia tem o seu tamanho relacionado a quantidade de artigos relacionados a ela. Assim, as principais notícias do dia têm o seu tamanho maior. No entanto, quando uma notícia tem poucos artigos relacionados a ela o elemento gráfico no espaço visual é muito pequeno, o que impossibilita a leitura do título. Uma tentativa de minimizar tal problema é feita por meio da interação do usuário com a visualização. Ao posicionar o ponteiro do mouse sobre qualquer notícia é exibido uma caixa com o título, um resumo da notícia, a data de publicação e onde ela foi veiculada.

Utilizando outra abordagem, a ferramenta VisGets ${ }^{4}$ (Dork et al., 2008) (Figura 3.9) é capaz de analisar e visualizar coordenadamente uma coleção de notícias e seus diversos atributos. Deste modo, uma ação praticada pelo usuário em uma das visões refletirá instantaneamente nas outras. A ferramenta começa por considerar três dimensões comuns: temporal, geográfica e por tópicos. Isto permite a interpretação de aspectos que não são facilmente explorados usando representações unidimensionais.
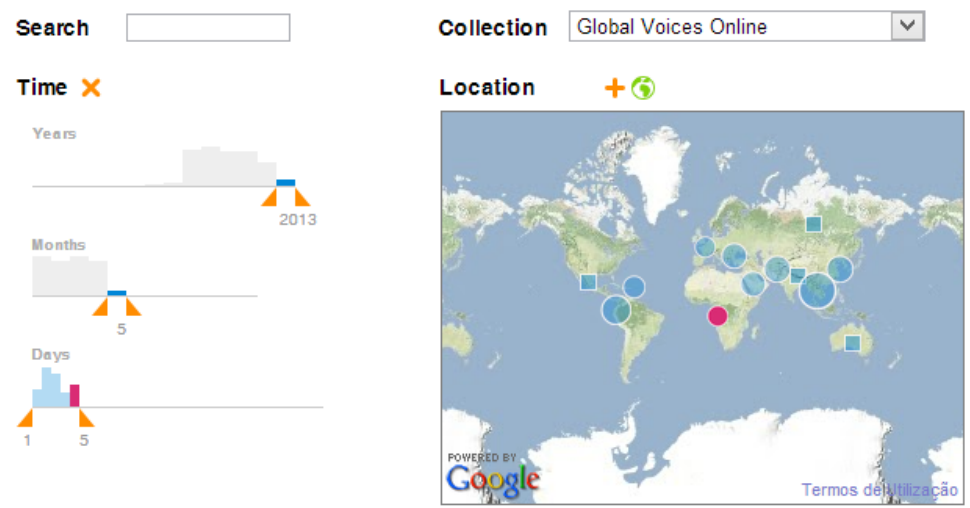

About Help

Tags

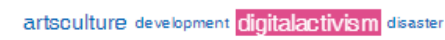

economicsbusiness elections environment ethnicityrace

fim freedomofspeech governance health history

humanitarianresponse humanrights humor hungarian

ideas internationalrelations labor languages law

literature mediajournalism migrationmmigration music

photography photos politics protest

quickreads religion romeninan runetecho

science sport technology video warconflict womengender world youth

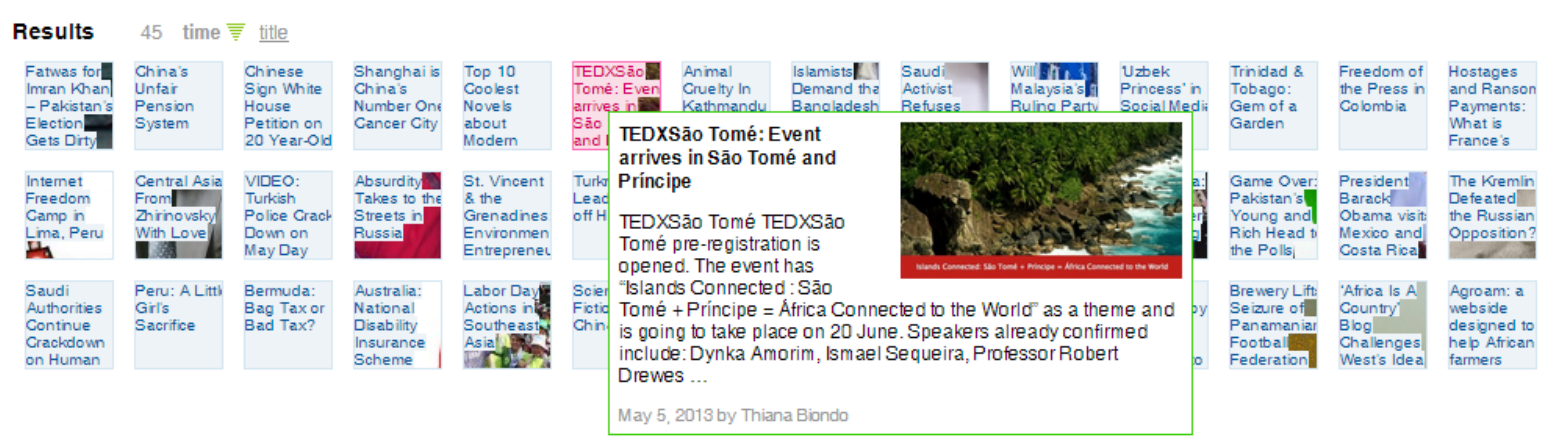

Figura 3.9: Ferramenta VisGets: coordenadamente combina diferente técnicas de visualização para auxiliar o usuário na leitura de notícias.

A ferramenta VisGets apresenta quatro tipos de visões distintas. A primeira delas possibilita o usuário escolher um intervalo de tempo, filtrando deste modo as notícias e

\footnotetext{
${ }^{4}$ Disponível em http://mariandoerk.de/visgets/demo/
} 
exibindo, por exemplo, somente as notícias mais recentes ou dentro de um intervalo de tempo. Uma segunda visão permite explorar a dimensão geográfica. Sobre o mapa mundo são posicionadas circunferências na região que as notícias se referem. Estas circunferências têm o seu tamanho diretamente relacionado à quantidade de notícias que ela representa. Ao selecionar o círculo, as notícias, ali representadas, ganham destaque nas outras visões.

A terceira visão, à direita da ferramenta, explora os tópicos mais importantes dentro do grupo de notícias. Estes tópicos são exibidos para o usuário utilizando o paradigma TagCloud em que os maiores termos são os mais frequentes dentro do grupo visualizado. Por fim, uma visão na parte inferior lista todas as principais notícias que estão sendo visualizadas. Interativamente é possível visualiza o título, resumo e uma imagem ilustrativa das reportagens ali listadas.

Apesar de conseguir sumarizar e exibir os diversos atributos presentes nos dados, a visualizações coordenadas pode causar uma perda de contexto do usuário em que, ao interagir com umas das visualizações, há uma mudança em todas as outras. Esta mudança em cascata dificulta para o usuário acompanhar todas as alterações causadas pela sua ação. Ainda, nenhuma das visões empregadas permite a representação das relações entre os diferentes documentos, um dos objetivos presentes neste projeto.

\subsection{Considerações Finais}

A Internet está cada vez mais presente na sociedade moderna. A evolução da infraestrutura de telecomunicação concomitantemente com o processo de popularização dos dispositivos móveis, fizeram com que os usuários passassem a ser geradores de conteúdos. A consequência disto é que cerca de $90 \%$ de todos os dados disponíveis na web foram produzidos somente nos últimos dois anos (Bae, 2013).

Neste contexto, as técnicas TileBars, Hotmap e Concept Highlighter propõem a utilização de informações adicionais para acelerar o processo exploratório do usuário sobre dados. Em comum, estas técnicas utilizam o paradigma unidimensional em que o usuário, interagindo com os dados, consegue filtrar e refinar a busca, facilitando encontrar o documento desejado. Este processo é importante principalmente quando se tem pouco espaço para visualização dos dados, como no caso dos dispositivos móveis.

No entanto, ao utilizar uma lista unidimensional, o usuário não consegue relacionar as diversas características intrínsecas dos dados. Assim, utilizando a bidimensionalidade do espaço visual, a ferramenta $P E x-W e b$ e a técnica ProjSnippet posicionam os dados no plano seguindo a metáfora distância-similaridade. Este posicionamento é fornecido através de técnicas que conseguem posicionar dados, que estão inicialmente em um espaço 
multidimensional e com todas as características lá mapeadas, no espaço bidimensional mantendo a relação de vizinhança estabelecida no espaço original. Entretanto, estas técnicas desperdiçam bastante espaço o que não é interessante para situações em que o espaço é restrito.

Ao contrário, as ferramentas VisGets e NewsMap tentam utilizar todo o espaço visual disponível para transmitir informação. Assim, com o objetivo de visualizar as diversas características inerentes a uma notícia, a ferramenta VisGets utiliza uma visualização coordenada que possibilita o usuário selecione notícias somente de uma determinada região do mundo ou um período do tempo. Apesar disso, ela permite a visualização de poucas notícias de apenas um canal. Diferente, a ferramenta NewsMap sumariza e exibi algumas dezenas de notícias das mais diversas categorias e fontes da imprensa. Para isto, ela utiliza uma técnica de preenchimento do espaço visual que divide o layout em regiões que representa cada uma das reportagens. Estas regiões têm suas áreas relacionadas a quantidade de visualizações que a respectiva reportagem tem. Ao contrário da ferramenta SPCloud (Capítulo 7), a NewsMap não consegue criar uma hierarquia sobre a coleção de notícias, o que restringe a visualização a apenas algumas dezenas de notícias. Além disso, as notícias são posicionadas no plano sem que exista uma cuidado com a similaridade distância, violando assim um dos princípios da Gestalt (Todorovic, 2008). 


\section{Técnicas de preenchimento do espaço visual e dispositivos móveis}

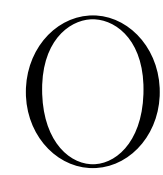
contínuo avanço da computação proporcionou a criação de aparelhos cada vez menores e mais potentes. Hoje, já é possível ter nas mãos mais poder computacional que a NASA em 1969, quando ela enviou dois astronautas para a Lua (Kaku, 2012). Os atuais equipamentos móveis, como tablets e smartphones, estão em constante evolução e cada vez mais incorporados à sociedade atual.

Na conferência em dispositivos móveis "Dive Into Mobile", que ocorreu em Nova York em abril de 2013, o então presidente da Google afirmou que até o fim daquele ano seriam 1 bilhão de usuários cadastrados como donos de dispositivos Android. Ainda, de acordo com Levkowitz e Kelleher (2012), em um curto período de tempo a maioria dos jornais impressos atuais serão substituídos pelas suas versões eletrônicas. Estes números e previsões demonstram como a computação está caminhando para a miniaturização e acessibilidade de seus dispositivos.

No entanto, problemas como tamanho dos displays, razões de aspectos da tela, hardwares menos poderosos e padrões de interação com usuário impossibilitam a simples migração, para dispositivos móveis, das técnicas de visualização de dados já consolidadas (Chittaro, 2006).

Devido a constante mudança na arquitmetura e no poder computacional dos dispositivos móveis, poucos trabalhos foram publicados utilizando unicamente tablets ou 
smartphones como plataforma de visualização. Estes trabalhos apresentam ferramentas que tentam adaptar técnicas já estabelecidas para atender o propósito do trabalho ali apresentado.

Como forma de contextualizar o trabalho no cenário do estado-da-arte, este capítulo apresenta técnicas de preenchimento do espaço visual e trabalhos que utilizam exclusivamente dispositivos móveis para visualização de dados. Ao fim, na seção de considerações finais, é apresentado uma breve discussão sobre o assunto abordado neste capítulo e como ele se relaciona com o trabalho aqui proposto.

\subsection{Técnicas de preenchimento do espaço visual}

Problemas como o baixo poder de processamento e conexões lentas estão sendo resolvidos com a evolução dos dispositivos móveis. No entanto, o tamanho limitado das telas ainda continua sendo um problema e que dificilmente se resolverá uma vez que, para manter a mobilidade, espera-se um dispositivo menor. Assim, levando em consideração esta limitação bem como a razão de aspecto da tela e o método de interação com usuário, é imprescindível que as técnicas de visualização que sejam aplicadas a dispositivos móveis utilizem todo o espaço visual para transmitir informação. A categoria de algoritmos que atendem esta exigência denomina-se "técnicas de preenchimento do espaço visual".

Um dos primeiros algoritmos desta categoria, o Slice-and-dice Treemap (Johnson e Shneiderman, 1991), ou simplesmente Treemap, utiliza todo o espaço visual disponível para exibir dados hierárquicos. Cada item é representado por uma região que é dividida, utilizando linhas paralelas, em retângulos menores que representam os seus filhos na hierarquia.

Devido a sua simplicidade, baixa complexidade e alta taxa de ocupação do espaço visual, a técnica Treemap se tornou um dos algoritmos mais conhecidos. No entanto, este produz retângulos com razão de aspecto muito alta. Além disso, a falta de percepção da hierarquia dos dados e relação de similaridade entre os elementos fizeram surgir diversos trabalhos com o propósito de aperfeiçoá-lo.

A técnica Cushion Treemap (van Wijk e van de Wetering, 1999) propõe utilizar efeito de iluminação sobre cada retângulo para facilitar a visualização da relação de hierarquia produzida. No entanto, por utilizar como base o algoritmo Treemap, esta técnica ainda possui problemas com regiões com alta razão de aspecto, como pode ser visto na Figura 4.1(a).

A técnica Squarified Treemap (Bruls et al., 1999) (Figura 4.1(b)) propõe uma abordagem que tenta produzir regiões cuja razão de aspecto se aproxima de 1. Para isso, cada 
elemento é posicionado na mesma coluna (ou linha) do elemento anterior e a razão de aspecto dos elementos já posicionados é calculada. Caso esta razão piore com relação ao valor encontrado antes do ultimo posicionamento, o novo elemento é inserido em uma nova coluna (ou linha). Este fato garante que nenhum posicionamento irá afetar negativamente o layout até então construído. Todo este processo é repetido até que todos os elementos sejam posicionados no plano.

Como os elementos são inseridos em sequência, a ordem com que eles são processados interfere no resultado final do algoritmo. Deste modo, para obter melhores resultados, eles são inseridos de maneira decrescente, necessitando assim de uma ordenação antes da construção da visualização. Esta necessidade pode representar uma limitação para visualizar dados que possuam uma ordenação intrínseca.

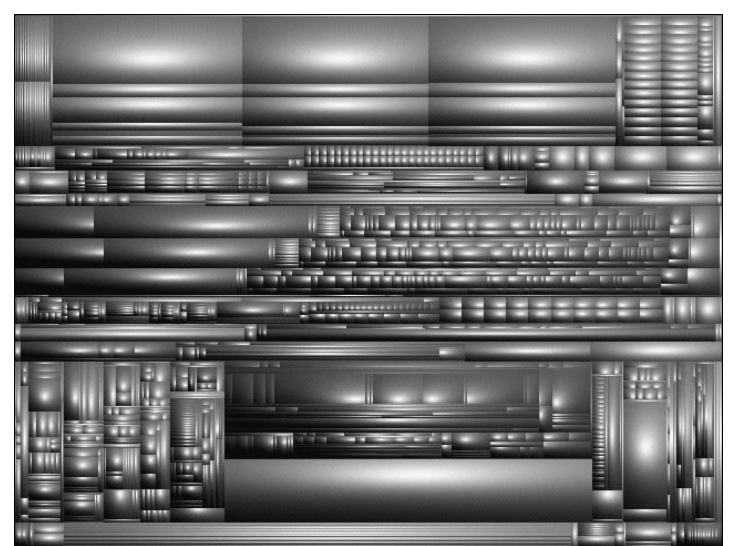

(a) Cushion Treemap

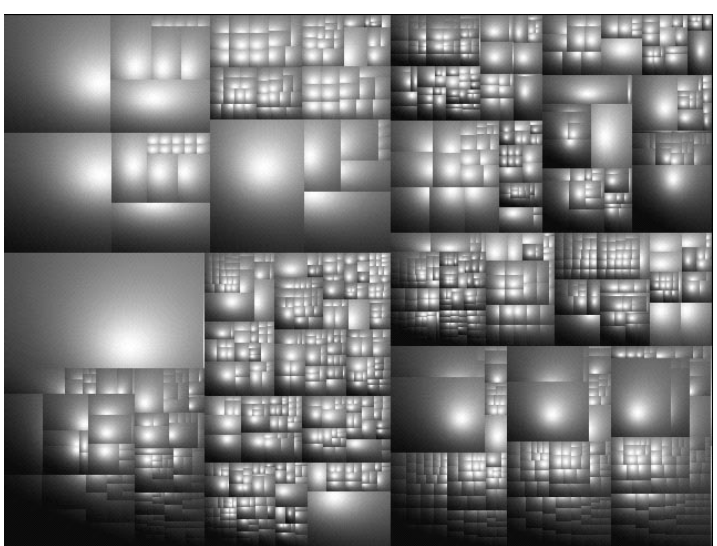

(b) Squarified Treemap

Figura 4.1: Algoritmos derivados da técnica original Treemap. Em (a) o algoritmo Cushion Treemap que propõe a utilização de iluminação para facilitar a visualização da estrutura hierárquica dos dados. Em (b) a técnica Squarified Treemap tenta produzir regiões com razão de aspecto mais próximas de um possível.

Com o intuito de preservar esta ordenação e posicionar próximos os elementos adjacentes na lista, Bederson et al. (2002) desenvolveram a técnica Ordered Treemap (Figura 4.2). Este algoritmo utiliza o paradigma "dividir para conquistar" e escolhe um pivô que é posicionado no plano de visão. A lista de dados é então dividida em três outras que serão posicionadas a esquerda, exatamente abaixo e a direita do pivô. O tamanho com que cada elemento será desenhado é fornecido por uma função peso que descreve alguma característica do dado.

Três estratégias foram propostas para escolha do elemento que será o pivô. A primeira, pivot-by-size, seleciona o maior elemento que, devido o seu tamanho, é teoricamente o mais difícil de se posicionar. Uma segunda abordagem, pivot-by-middle, propõe utilizar 


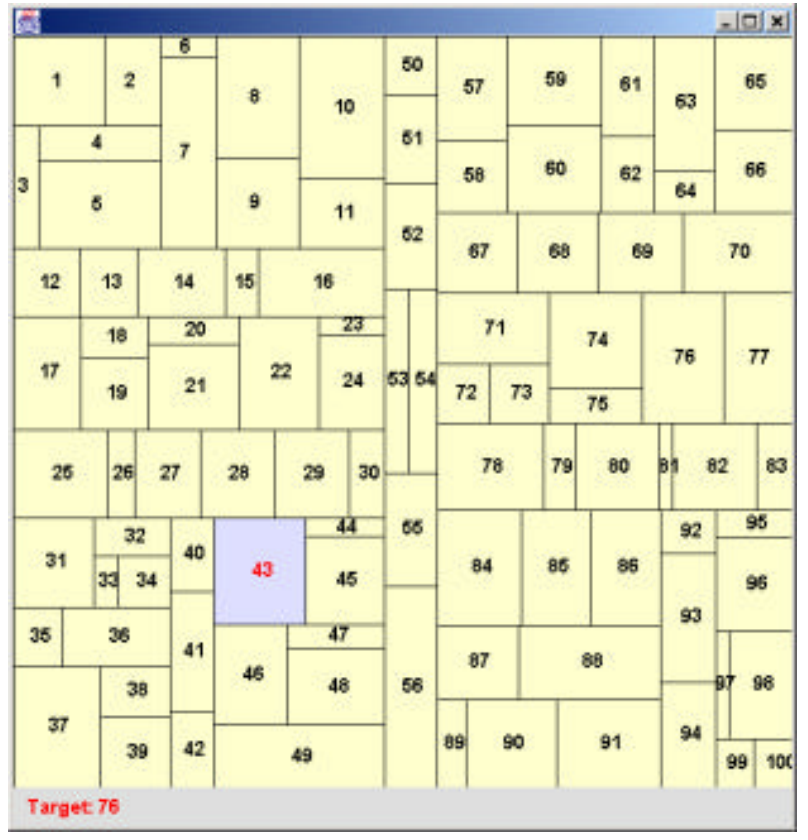

Figura 4.2: Técnica Ordered Treemap: com a posição de um elemento conhecida, encontrar os elementos adjacentes a ele é fácil devido a preservação da ordenação dos elementos.

o elemento do meio da lista para gerar um layout mais balanceado sem depender dos pesos dos elementos da lista. Por fim, a terceira abordagem, pivot-by-split-size, escolhe o elemento que divide a lista em duas regiões com pesos próximos, gerando assim layouts balanceados.

Ainda que, ao contrário da Squarified Treemap, a técnica Ordered Treemap obtenha melhores resultados em preservar a ordenação original dos dados, ela apresenta regiões com razões de aspecto ruins, apesar de não serem tão frequentes quanto na técnica original Treemap. Com o objetivo de produzir uma visualização que preserve a metáfora similaridade-distância e ainda produza retângulos com baixa razão de aspecto, Wood e Dykes (2008) desenvolveram a técnica Ordered Squarified Treeemap (Figura 4.3).

Esta técnica adapta a Squarified Treemap impondo aos dados uma ordenação inicial para que, após a construção da visualização, os elementos fiquem posicionados de forma a preservar a metáfora distância-similaridade. Para isso, assume-se que o canto superior esquerdo é a origem. Todos as regiões são então ordenadas, de modo crescente, de acordo com a distância euclidiana do seu centro geométrico até a origem. Deste modo, eles conseguiram determinar uma ordenação unidimensional do layout mapeando diretamente os dados para a visualização gerada.

Esta abordagem é uma tentativa de proporcionar um mapeamento mais consistente de uma ordenação unidimensional para um espaço bidimensional. No entanto, esta não é 

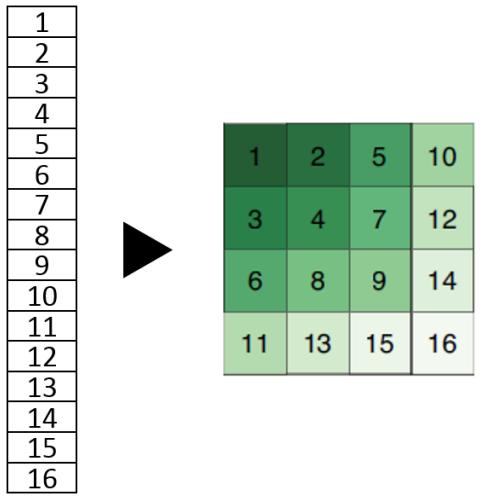

Figura 4.3: Técnica Ordered Squarified Treemaps: utiliza a técnica Squarified Treemaps impondo a ela uma ordenação dos elementos que favorece a preservação da metáfora similaridade-distância. Nesta figura, visualização de 16 elementos ordenados linearmente.

capaz de mapear eficientemente dados já dispostos em um espaço bidimensional Assim, Wood e Dykes (2008) propuseram a técnica Spatially Ordered Treeemap (Figura 4.4) capaz de posicionar cada elemento o mais próximo possível de sua localização inicial ao mesmo tempo que forma regiões com razão de aspecto boa.
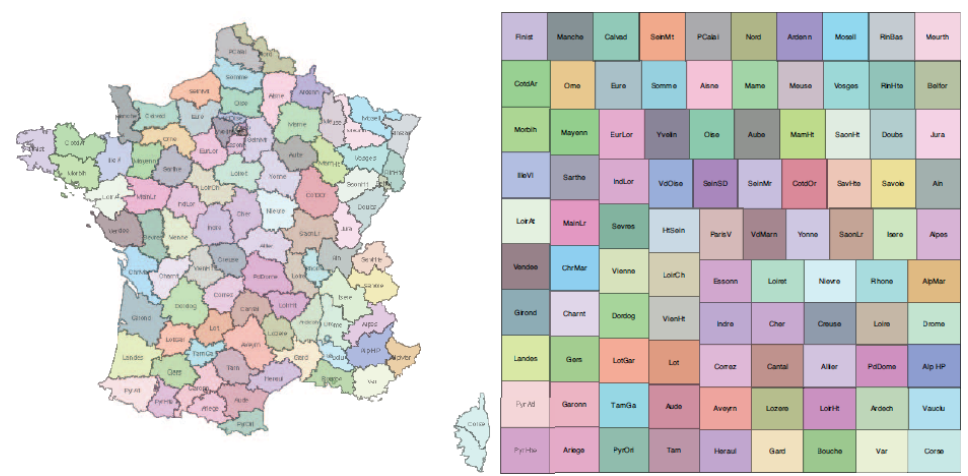

Figura 4.4: Técnica Spatially Ordered Treeemap: a esquerda, mapa dos 95 departamentos franceses e a direita a visualização correspondente utilizando a técnica.

Para isto, ela utiliza uma modificação da técnica Ordered Squarified Treeemap procurando alocar uma região de acordo com o posicionamento geográfico do elemento. Ao fim, de acordo com o retângulo delimitador da visualização, encontra uma transformação afim que escala o layout gerado para o espaço visual disponível.

Diversas outras técnicas foram desenvolvidas com o objetivo de gerar visualizações que ocupem todo o espaço visual como as técnicas Sunburst (Stasko e Zhang, 2000), Quantum Treemap (Bederson et al., 2002), Voronoi Treemap (Balzer et al., 2005; Nocaj e Brandes, 2012), Cluster Treemap (Wattenberg, 1999), Spiral Treemap (Tu e Shen, 2007) e Hilbert-Moore Treemap (Tak e Cockburn, 2013). No entanto, nenhuma delas possue relação direta com os objetivos deste trabalho. 


\subsection{Visualização de Dados em dispositivos móveis}

Devido ao tamanho limitado do espaço visual, as técnicas de visualização usadas em dispositivos móveis precisam utilizar ao máximo o espaço disponível para transmitir informação. Por este motivo, as técnicas de preenchimento do espaço visual (Seção 4.1) são empregadas por ferramentas na tentativa de amenizar o problema como na Radial Edgless Tree (RELT) (Hao et al., 2010)(Figura 4.5).

Esta técnica utilizada todo o espaço visual disponível para exibir o menu de ações do dispositivo. A hierarquia é exibida ao usuário com a raiz no canto superior esquerdo e os próximos dois níveis ao longo de um círculo centrado na raiz. Ao selecionar um subitem deste menu, este passa ser a nova raiz exibindo-se então os próximos dois níveis abaixo do item selecionado.

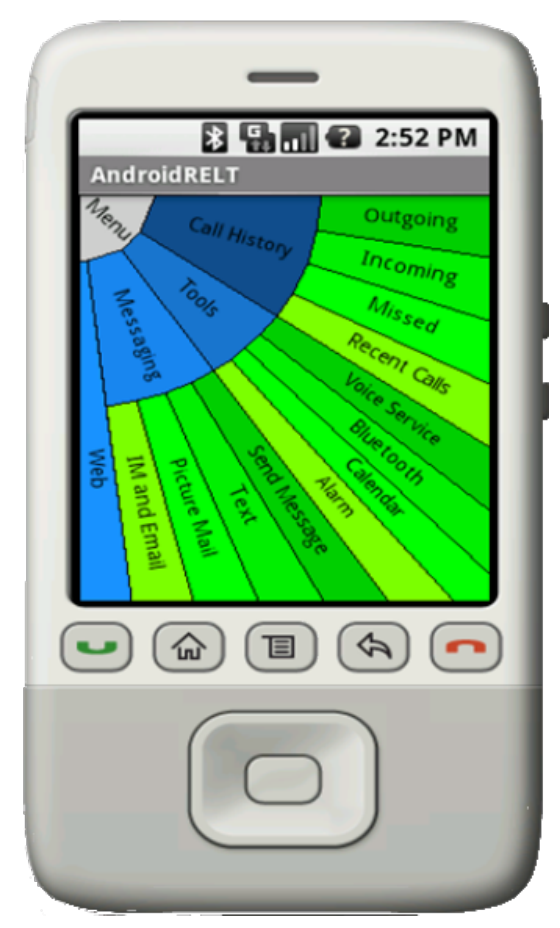

Figura 4.5: Visualização do Menu de Opções do aparelho utilizando a técnica de Radial Edgless Tree implementada sobre o sistema operacional Android (Hao et al., 2010).

Com a profundidade máxima igual a cinco, a técnica RELT garante que o usuário consiga acessar todos os itens em menos de três cliques. Teste com usuários foram realizados e mostraram que em cenários que o usuário precisa acessar uma opção que não esteja nos dois primeiros níveis da hierarquia, e consequentemente visíveis no layout inicial, o tempo foi maior com a técnica RELT que com a modelo tradicional de menus. Além disso, dependendo do número de filhos e do nível da árvore que está sendo desenhado, 
os elementos podem ficar finos e pequenos, dificultando ou até impossibilitando a seleção por parte dos usuários.

Levando em consideração estas limitação, Engdahl et al. (2005) utilizou a técnica Squarified Treemap para visualizar grupos de discussões em fóruns (Figura 4.6). Além de utilizar toda a tela do dispositivo para transmitir informação, a técnica garante a exibição de centenas de itens em um layout compacto sem que o usuário perca a visão global dos dados e suas relações.

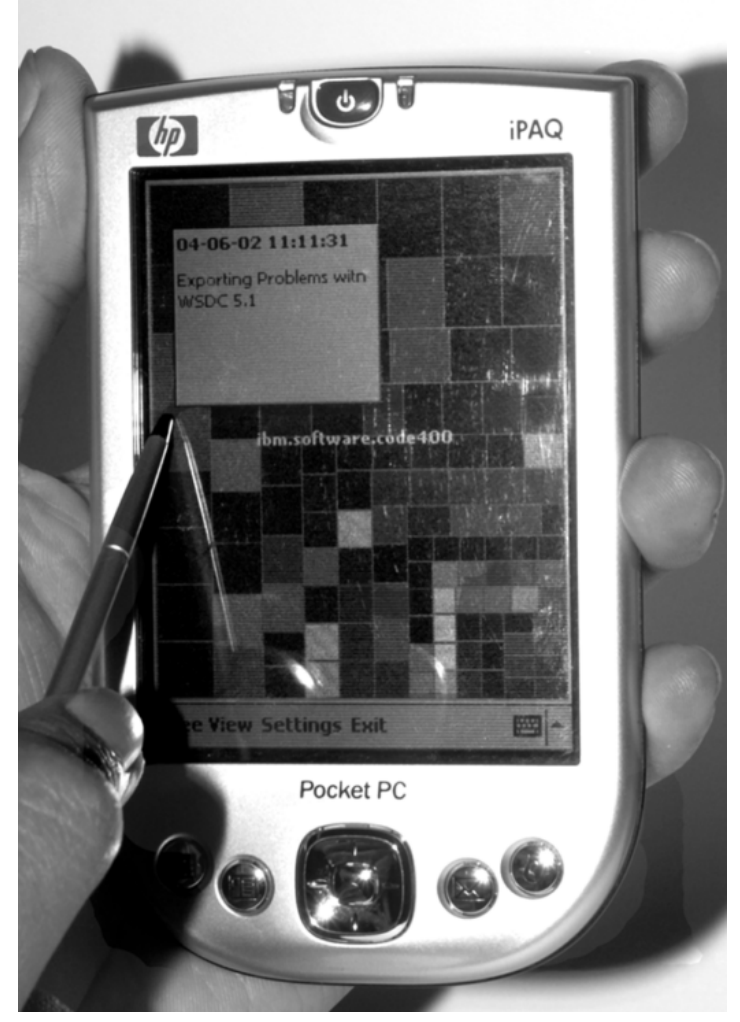

(a) Foto da interação do usuário com a técnica implementada (Aparelho Pocket PC HP iPAQ 4150).

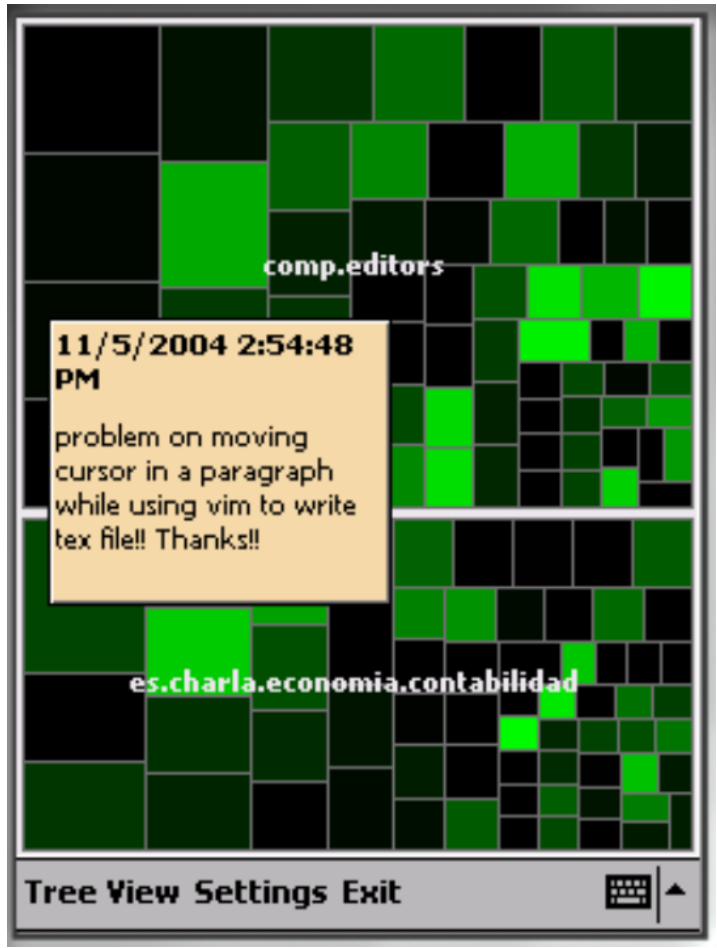

(b) Técnica Squarified Treemaps aplicada para visualização de dados em dispositivos móveis .

Figura 4.6: Ferramenta proposta por (Engdahl et al., 2005) para visualização, em dispositivos móveis, de diversos tópicos discutidos em fóruns utilizando a técnica Squarified Treemap.

Cada retângulo da visualização representa um assunto distinto dentro do fórum e o seu tamanho o número de artigos ali presente. A cor, por sua vez, pode ser mapeada de acordo com a atividade de cada assunto no fórum ou informar a relevância dos termos de uma busca dentro de cada fórum. Devido a utilização da técnica Squarified Treemap, os cortes para montagem do layout são feitos levando em consideração a razão de aspecto que deve ser o mais próximo possível de um. Esta característica é particularmente interessante 
para telas pequenas pois ajuda na interação com o usuário facilitando a seleção daquele quadrante e a comparação entre as áreas.

De modo similar, a ferramenta PRISMA Mobile (da Silva Junior et al., 2012) também implementa a técnicas Squarified Treemap bem como scatterplot (Becker e Cleveland, 1987) e coordenadas paralelas (Inselberg, 1985) para visualizar dados turísticos em dispositivos móveis. Utilizando uma arquitetura cliente-servidor, esta ferramenta é capaz de exibir para o usuário os restaurantes mais próximos e, em outra aba, uma Treemap contendo algumas características e avaliações destes restaurantes. No entanto, a ferramenta Prisma Mobile bem como a proposta por Engdahl et al. (2005), para visualização de tópicos de fórum, adotam a técnica Squarified Treemap sem utilizar qualquer outro tipo de artificio visual para transmitir informações sobre o que cada região representa. Essa característica faz com que encontrar e relacionar os dados seja uma tarefa difícil e lenta.

Algumas outras técnicas foram desenvolvidas para visualização de dados em dispositivos móveis mas tem pouco em comum com o trabalho aqui descrito. A ferramenta desenvolvida por Mosmondor et al. (2006) propõe uma visualização tridimensional em que os dados são processados e armazenados fora do dispositivo e a renderização é feita eficientemente no dispositivo móvel. A técnica Minimap (Roto et al., 2006) foi desenvolvida com o intuito de visualizar sites da internet em dispositivos com telas pequenas. Para isso, ela busca na página uma imagem que melhor representa o conteúdo e, juntamente com um pequeno texto, exibe um resumo. Com o objetivo de visualizar mapas, a técnica ZoneZoom (Robbins et al., 2004) possibilita que o usuário interaja não só em dispositivos de interação através de toques mas os que utilizam teclados. A técnica de Tablorer (Shin et al., 2011) propõe uma visualização da árvore de pastas e arquivos em dispositivos móveis com tamanho médio.

\subsection{Considerações Finais}

Os dispositivos móveis estão tomando lugares que antes eram dos notebooks e computadores de mesas. Estes novos equipamentos não só aumentam o acesso à informação por parte dos usuários mas também mudam o paradigma de interação e a forma como as técnicas de visualização da informação devem ser desenvolvidas. Estas novas características dificultam a simples migração, para os dispositivos móveis, das técnicas de visualização já desenvolvidas e consolidadas.

O tamanho reduzido dos visores faz com que as técnicas de preenchimento do espaço visual ganhem uma ampla utilização nesta nova arquitetura. Para sua utilização em 
dispositivos móveis é necessário que estas não formem regiões estreitas e alongadas pois isto dificulta a seleção utilizando as telas sensíveis ao toque. Desta forma, as técnicas Treemap (Johnson e Shneiderman, 1991), Cushion Treemap (van Wijk e van de Wetering, 1999) e Ordered Treemap (Bederson et al., 2002) se tornam ineficientes para visualizar dados em dispositivos móveis.

Assim, algumas ferramentas utilizaram a técnica Squarified Treemap (Bruls et al., 1999) para visualizar os dados nos dispositivos móveis. No entanto, esta técnica não obedece à metáfora de similaridade-distância por necessitar de uma ordenação prévia nos dados de entrada. Ao contrário, a técnica desenvolvida neste trabalho produz uma visualização que assemelha a Spatially Ordered Treeemap mantendo a relação de similaridade e produzindo elementos com razão de aspecto boa. 


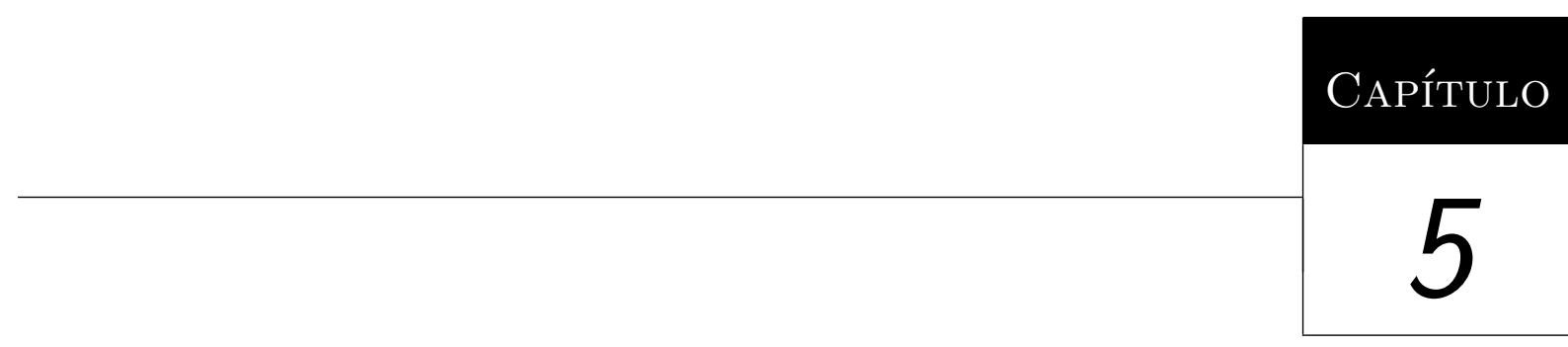

\section{Neighborhood map (NMap)}

s técnicas de preenchimento do espaço visual compõem uma família de algoritmos
que tem por objetivo maximizar a utilização do espaço visual para representar os
dados em estudo. Exemplos incluem as técnicas Sunburst (Stasko e Zhang, 2000), Quantum Treemaps (Bederson et al., 2002), Voronoi Treemap (Balzer et al., 2005; Nocaj e Brandes, 2012), e a Treemap Retangular (Johnson e Shneiderman, 1991; Shneiderman, 1992) com suas variações (Bruls et al., 1999; Wattenberg, 1999; Bederson et al., 2002; Wood e Dykes, 2008; Tu e Shen, 2007; Tak e Cockburn, 2013). Em comum, todas as técnicas dividem o espaço visual em regiões com áreas proporcionais a algum atributo ou peso.

Dentre elas, a Treemap Retangular, ou simplesmente Treemap, se destaca e recebe grande atenção devido à sua simplicidade, baixa complexidade gráfica e total uso do espaço visual disponível (Wood e Dykes, 2008). As técnicas Squarified Treemap (Bruls et al., 1999) e Cluster Treemap (Wattenberg, 1999) procuram manter o máximo possível a razão de aspecto das regiões próximos de um e, de maneira similar, a Quantum Treemap (Bederson et al., 2002) cria retângulos com tamanhos fixos. Se comparada com a técnica original Treemap, ambos os critérios podem gerar com sucesso layouts mais agradáveis, porém eles não foram projetados para levar em conta as relações que possam existir entre os diferentes elementos. Isso viola a metáfora distância-similaridade que é um aspecto importante reconhecido por trabalhos anteriores (Buchin et al., 2011; Mansmann et al., 2007; Wood e Dykes, 2008). 
Algumas tentativas foram realizadas com o objetivo de incorporar a relação de similaridade na visualização final. A maioria delas impõe uma ordenação unidimensional sobre os dados e utiliza esta informação para organizar os retângulos no layout de visualização. Apesar de uma melhora na preservação da relação de similaridade, mapear informações de um espaço unidimensional para um bidimensional ainda viola a metáfora distância-similaridade na maioria dos casos. Atualmente, algumas técnicas são capazes de fazer esse mapeamento preservando a relação bidimensional dos dados, como por exemplo a Spatially Ordered Treemap (Wood e Dykes, 2008). No entanto, até mesmo estas técnicas violam a metáfora dependendo da distribuição dos pesos associados a cada elemento dos dados.

Neste cenário, este trabalho de mestrado propôs e desenvolveu uma nova técnica de preenchimento do espaço visual chamada Neighborhood Treemap (NMap). A NMap baseia-se na estratégia de corte e escala em que o espaço visual é sucessivamente seccionado em cortes horizontais e verticais e as novas regiões são escaladas. Todo este processo é repetido até que cada retângulo represente apenas uma unidade dos dados analisados.

Este capítulo apresenta uma descrição detalhada do funcionamento do algoritmo NMap, a definição do recorte, o posicionamento inicial e a complexidade computacional. Ao fim é feito um resumo do funcionamento do algoritmo e suas principais características.

\subsection{Algoritmo de Recorte e Escala}

A técnica Neighborhood Map (NMap) aborda o problema da preservação da metáfora de distância-similaridade enquanto constrói a visualização. Para isto utiliza uma abordagem que secciona a área disponível e escala as novas duas sub-áreas. Assim, seja $\mathcal{D}=\left\{d_{1}, \ldots, d_{n}\right\}$ o conjunto dos elementos da base de dados com $P: \mathcal{D} \rightarrow \mathcal{P}$ sendo uma função que atribui pesos $\mathcal{P} \subset \mathbb{R}$ (normalmente um atributo dos dados) a cada elemento. Seja $R$ o retângulo que determina a área disponível e $\mathcal{X}=\left\{\left(x_{1}, y_{1}\right), \ldots,\left(x_{n}, y_{n}\right)\right\} \subset \mathbb{R}^{2}$ as coordenadas cartesianas de cada ponto, dentro da região $R$, que representa um elemento pertencente a $\mathcal{D}$. A ideia por trás do algoritmo é aplicar o processo de recorte e escala até que cada retângulo represente um único elemento. Este retângulo terá então sua área proporcional ao peso, preservando a relação de similaridade estabelecida em $\mathcal{X}$, i.e., os pontos próximos em $\mathcal{X}$ devem definir retângulos próximos, e os pontos mais distantes retângulos distantes no layout final.

Durante o processo, os retângulos intermediários podem ser seccionados verticalmente ou horizontalmente. No corte horizontal, um segmento de reta $b_{v}$ é definido separando $R$ em dois novos retângulos $R_{A}$ e $R_{B}$ tal que $R_{A} \cup R_{B}=R$ e $R_{A} \cap R_{B}=\emptyset$. Pesos 
$p_{A}$ e $p_{B}$ são associados as áreas de $R_{A}$ e $R_{B}$ que são computados como a soma dos pesos dos elementos pertencentes a cada retângulo, ou seja, $p_{A}=\sum_{d_{i} \in R_{A}} P\left(d_{i}\right)$ e $p_{B}=$ $\sum_{d_{i} \in R_{B}} P\left(d_{i}\right)$. Baseado nestes pesos, $R_{A}$ e $R_{B}$ são escalados horizontalmente para que suas áreas sejam proporcionais a $p_{A}$ e $p_{B}$, respectivamente.

Sendo $w_{R_{A}}$ e $w_{R_{B}}$ a largura, respectivamente, de $R_{A}$ e $R_{B}$, a largura dos retângulos transformada $R_{A}^{\prime}$ e $R_{B}^{\prime}$ pode ser calculada em função dos pesos $p_{A}$ e $p_{B}$

$$
w_{R_{A}^{\prime}}=\frac{p_{A}}{p_{A}+p_{B}} \cdot w_{R} \quad \text { e } \quad w_{R_{B}^{\prime}}=\frac{p_{B}}{p_{A}+p_{B}} \cdot w_{R}
$$

em que $w_{R}$ é a largura da região total $R$. Deste modo, com as equações para cálculo da nova largura e considerando $\left(x_{R}, y_{R}\right)$ as coordenadas cartesianas do canto superior esquerdo do retângulo $R$, as matrizes de transformação em coordenadas homogêneas que transformam $R_{A}$ e $R_{B}$ em $R_{A}^{\prime}$ e $R_{B}^{\prime}$ horizontalmente escalando cada área de acordo com o seu respectivo peso estão expressas nas Equações (5.2) e (5.3).

$$
\begin{gathered}
\mathbf{H}_{R_{A}}=\left[\begin{array}{ccc}
\frac{w_{R_{A}^{\prime}}}{w_{R_{A}}} & 0 & x_{R}\left(1-\frac{w_{R_{A}^{\prime}}}{w_{R_{A}}}\right) \\
0 & 1 & 0 \\
0 & 0 & 1
\end{array}\right] \\
\mathbf{H}_{R_{B}}=\left[\begin{array}{ccc}
\frac{w_{R_{B}^{\prime}}}{w_{R_{B}}} & 0 & \left(x_{R}+w_{R}\right)\left(1-\frac{w_{R_{B}^{\prime}}}{w_{R_{B}}}\right) \\
0 & 1 & 0 \\
0 & 0 & 1
\end{array}\right]
\end{gathered}
$$

Estas matrizes são aplicadas sobre os pontos e retângulos alterando as coordenadas $x$ de cada um. Como são transformações lineares, a relação de similaridade entre os pontos dentro de cada região não é alterada. De maneira análoga, as matrizes $\mathbf{V}_{R_{A}}$ e $\mathbf{V}_{R_{B}}$ são utilizadas pra transformações verticais. Mudando apenas o segmento de reta $\left(b_{h}\right)$ para cortar horizontalmente os retângulos, estas são aplicadas também sobre os retângulos e pontos escalando-os e mudando as coordenadas $y$. Elas são definidas como

$$
\begin{gathered}
\mathbf{V}_{R_{A}}=\left[\begin{array}{ccc}
1 & 0 & 0 \\
0 & \frac{h_{R_{A}^{\prime}}}{h_{R_{A}}} & y_{R}\left(1-\frac{h_{R_{A}^{\prime}}}{h_{R_{A}}}\right) \\
0 & 0 & 1
\end{array}\right] \\
\mathbf{V}_{R_{B}}=\left[\begin{array}{ccc}
1 & 0 & 0 \\
0 & \frac{h_{R_{B}^{\prime}}}{h_{R_{B}}} & \left(y_{R}+h_{R}\right)\left(1-\frac{h_{R_{B}^{\prime}}}{h_{R_{B}}}\right) \\
0 & 0 & 1
\end{array}\right]
\end{gathered}
$$


em que $h_{R}, h_{R_{A}}, h_{R_{B}}, h_{R_{A}^{\prime}}$, e $h_{R_{B}^{\prime}}$ representam a altura de $R, R_{A}, R_{B}, R_{A}^{\prime}$, e $R_{B}^{\prime}$, respectivamente. Todo este processo está ilustrado na Figura 5.1.

Primeiro, determina-se o retângulo $R$ que irá delimitar o espaço disponível para visualização e para posicionamento dos pontos (Figura 5.1(a)). Em particular, neste exemplo, a base de dados é constituída de 5 elementos. Em seguida, $R$ é recortado em dois novos retângulos, $R_{A}$ e $R_{B}$, e os seus pesos, $p_{A}$ e $p_{B}$, são calculados como a soma dos pesos dos elementos pertencentes a cada região (Figura 5.1(b)). Nesta primeira etapa do exemplo foi aplicado um recorte horizontal na região $R$.

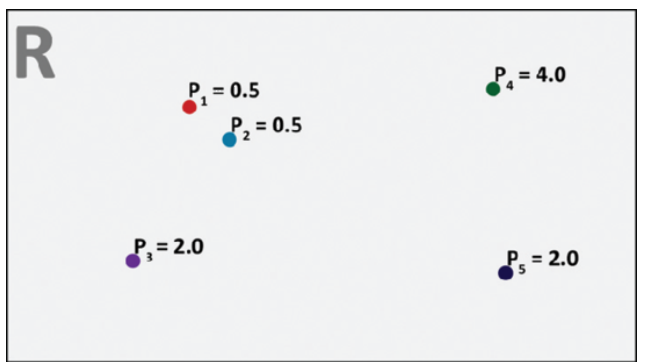

(a)

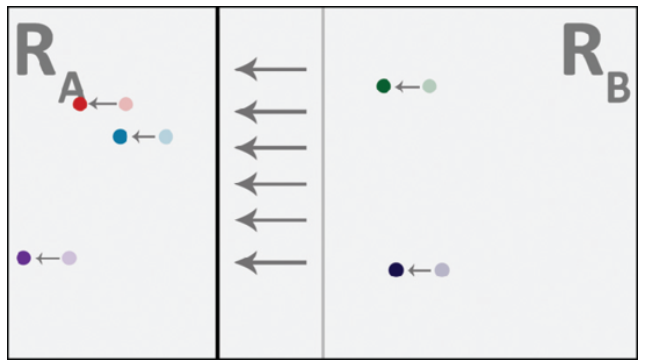

(c)

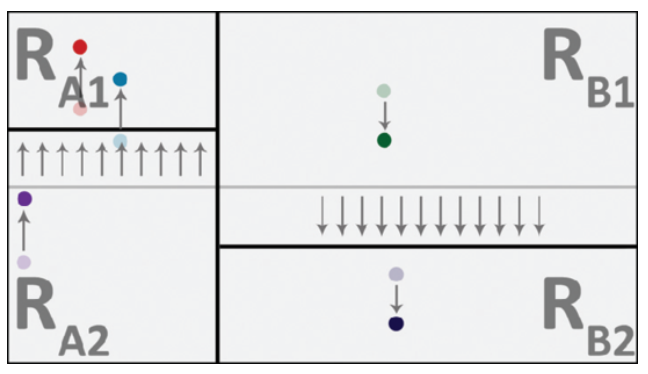

(e)

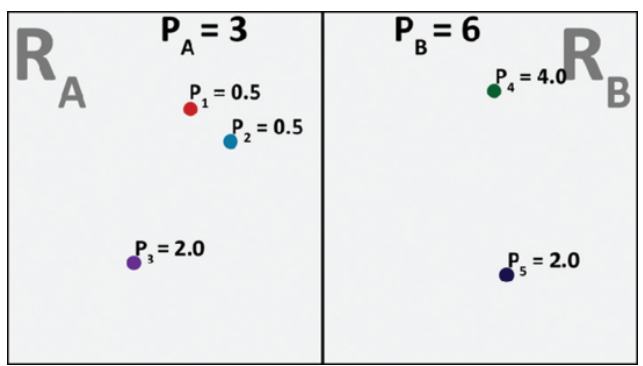

(b)

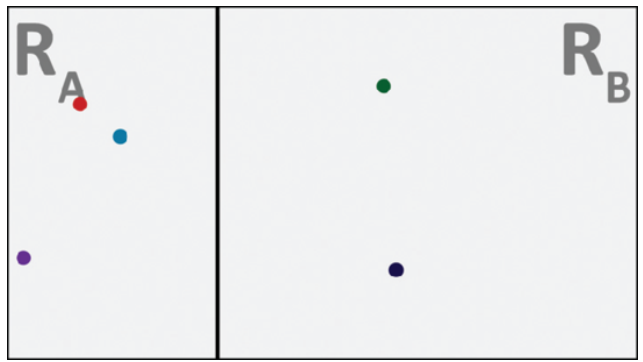

(d)

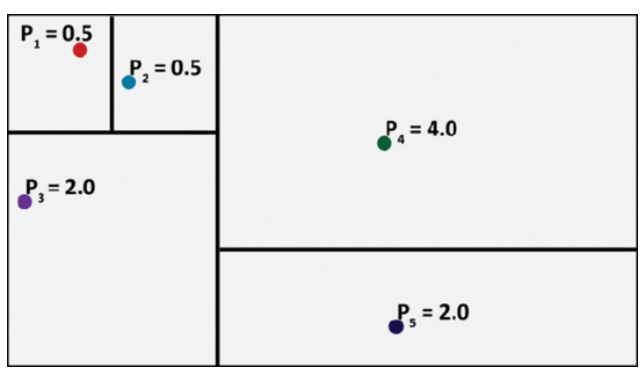

(f)

Figura 5.1: Processo de Recorte e Escala. Em (a) os pontos que representam os elementos dos dados são posicionados dentro do retângulo $R$. Em (b), o primeiro recorte é realizado no sentido horizontal. Em (c) e (d), baseado nos pesos dos elementos, aplica-se escala sobre os retângulos e pontos para que a área fique proporcional ao peso de cada região. Em (e) e (f) o processo de recorte e escala é feito alternando entre cortes verticais e horizontais até que cada retângulo represente apenas um único elemento e sua área seja proporcional ao peso. 
Por fim, os novos retângulos e os pontos pertencentes a cada região são escalados (Figura 5.1(c)) criando assim os retângulos finais $R_{A}^{\prime}$ e $R_{B}^{\prime}$ com áreas proporcionais aos pesos $p_{A}$ e $p_{B}$ (Figura 5.1(d)). Todo este processo é recursivamente aplicado aos retângulos $R_{A}^{\prime}$ e $R_{B}^{\prime}$ (Figura $5.1(\mathrm{e})$ ) e repetido até que cada retângulo contenha apenas um único elemento (Figura 5.1(f)). O Algoritmo 1 descreve o processo completo.

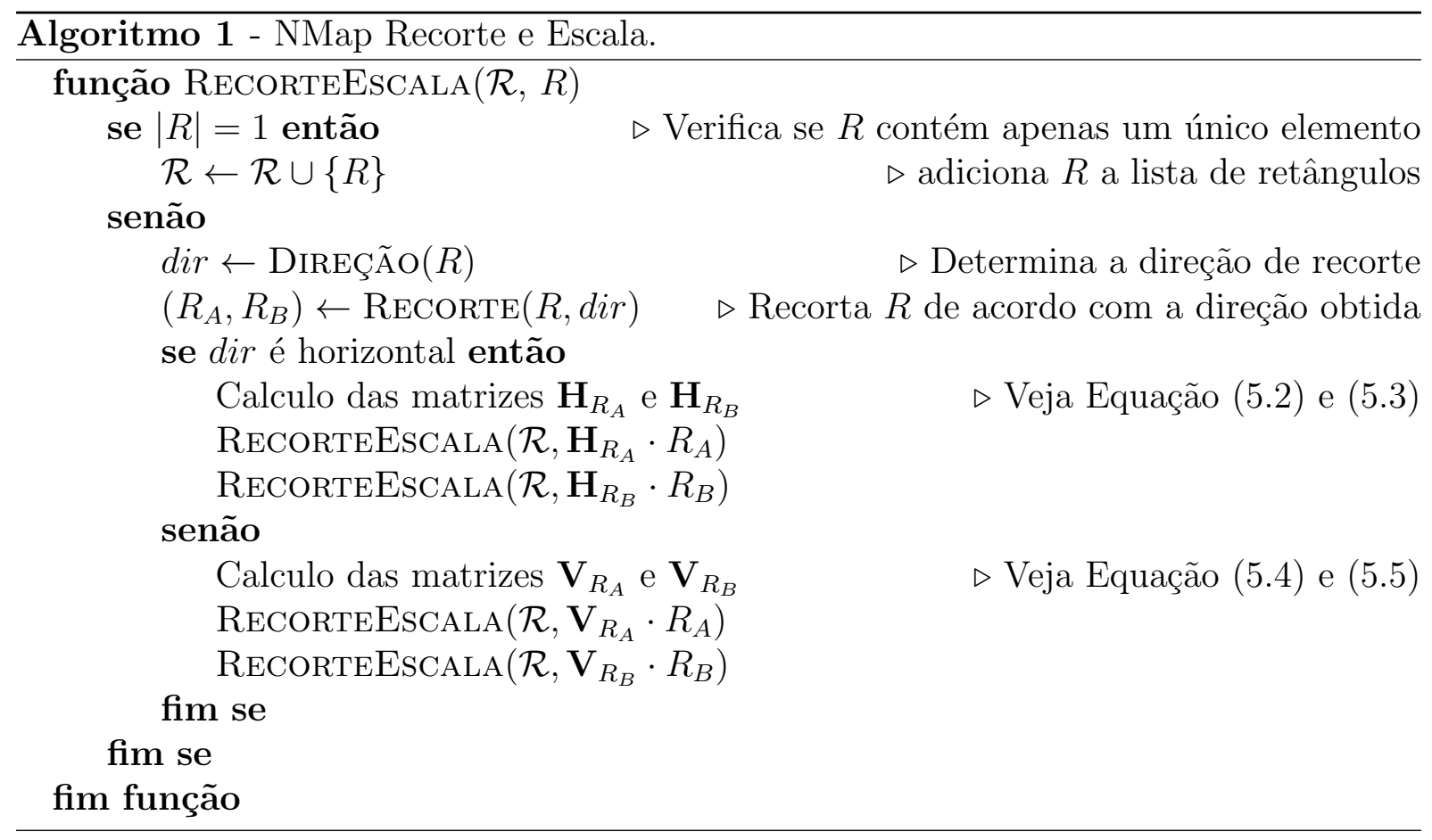

\subsection{Definição do Recorte}

Diferentes variações deste algoritmo podem ser obtidas mudando apenas a direção do recorte e a posição da reta horizontal $\left(b_{h}\right)$ e da vertical $\left(b_{v}\right)$. Neste trabalho de mestrado desenvolvemos e testamos varias abordagens e obtemos os melhores resultado com cortes alternados (do inglês Alternate Cut - AC) e pesos iguais (do inglês Equal-Weight - EW).

A NMap com cortes alternados $(N M a p-A C)$ é a abordagem mais simples. Nesta os recortes verticais e horizontais são alternados até que se atinja o critério de parada. Se $R$ for recortado horizontalmente, $R_{A}$ e $R_{B}$ serão recortados verticalmente, e assim sucessivamente. A direção do primeiro corte é determinada de acordo com a largura $R_{w} \mathrm{e}$ a altura $R_{h}$ do retângulo $R$. Se $R_{w}>R_{h}$ o recorte será feito verticalmente, caso contrário será horizontal.

As retas de recorte $b_{h}$ e $b_{v}$ são posicionadas de modo que $R_{A}$ e $R_{B}$ apresentem a mesma quantidade de elementos (caso o número seja ímpar, $R_{A}$ irá conter um elemento a mais que 
$\left.R_{B}\right)$. Para determinar este posicionamento, os elementos são ordenados de acordo com suas coordenadas $x$, para o corte vertical, e $y$ para o corte horizontal. Assim, a primeira metade dos elementos é atribuída a região $R_{A}$ e o restante a região $R_{B}$. O posicionamento da reta de recorte é calculado como a média do posicionamento do elemento de maior coordenada de $R_{A}$ e do elemento de menor coordenada de $R_{B}$ (Figura 5.2(a)).

A segunda estratégia, NMap com pesos iguais (NMap-EW), tem por objetivo melhorar a razão de aspecto dos retângulos formados. Diferente da $N M a p-A C, R$ é divido em $R_{A}$ e $R_{B}$ tal que $p_{A} \approx p_{B}$. A direção do recorte em cada etapa é calculada tal como o primeiro recorte da $N M a p-A C$, i.e., se $R_{w}>R_{h}$ o recorte será vertical e horizontal caso contrário. De acordo com a direção de corte, ordena-se os elementos pela coordenada $x$ ou $y$. Por fim, adiciona-se todos os elementos a região $R_{B}$ e um-a-um são transferidos para $R_{A}$ seguindo a ordenação estabelecida anteriormente. Este processo é feito até que $\left|2 \cdot p_{A}-p\right|$ seja minimizado em que $p$ é o peso total da região $R$, i.e., até que ambas regiões tenham aproximadamente o mesmo peso. Novamente, o posicionamento inicial da reta de recorte é calculado como a média do posicionamento do elemento de maior coordenada de $R_{A}$ e do elemento de menor coordenada de $R_{B}$ (Figura 5.2(b)).

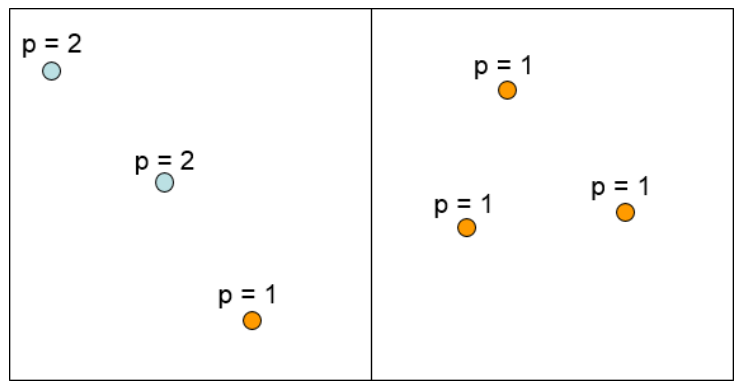

(a)

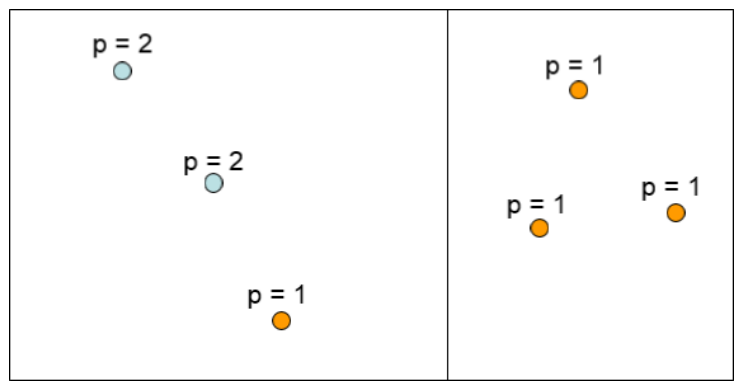

(c)

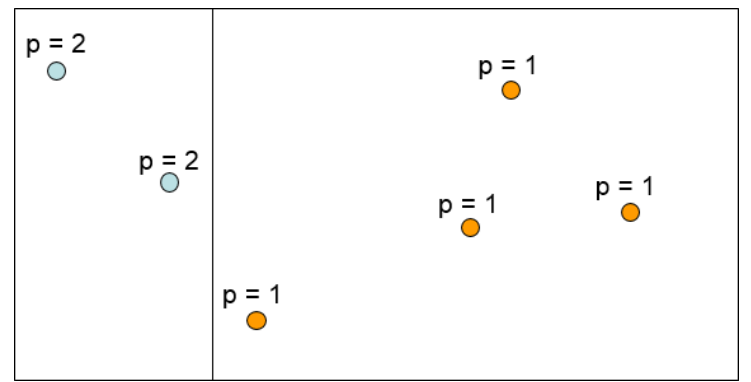

(b)

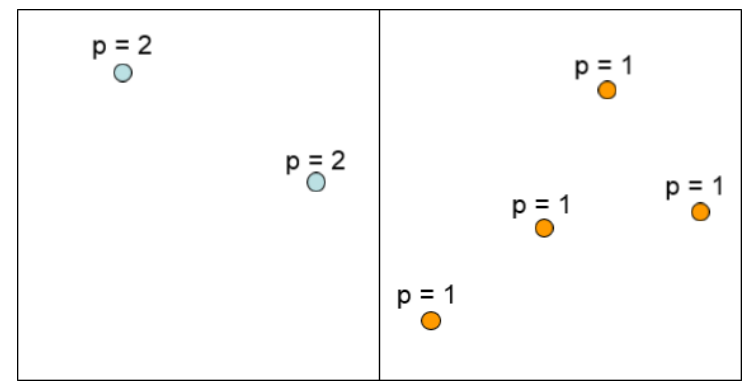

(d)

Figura 5.2: Diferença entre $N M a p-A C$ e $N M a p-E W$. Em (a) o posicionamento inicial de acordo com NMap-AC provocando o layout final (c). Em (b) o posicionamento inicial de acordo com NMap-EW, o que resultado no layout final (d). Este cenário evidencia a principal diferença entre as técnicas. 
A diferença entre as abordagens se dá pela atribuição dos elementos aos grupos e pelo posicionamento da reta de corte. Na NMap-AC o corte é recursivamente alternado sem que se tenha qualquer cálculo que determine a melhor direção. Esta característica influencia diretamente na razão de aspecto dos retângulos finais. Além disso, como o corte é posicionado dividindo os elementos ao meio, em muitos casos regiões desbalanceadas são formadas criando assim retângulos finos e com razão de aspecto ruim.

Estas diferenças podem ser notadas na Figura 5.2 em que a divisão por peso e por número de elementos fica evidenciada. A primeira coluna mostra o corte proposto pela abordagem NMap-AC em que o layout é divido igualmente pelo número de elementos. Na segunda coluna a abordagem $N M a p-E W$ está representada e exibe como o corte é feito levando em consideração o peso total das regiões formadas. Comparando ambas as abordagens, é possível notar que a $N M a p-E W$ produz visualizações com regiões mais balanceadas.

\subsection{Posicionamento Inicial}

O objetivo principal da NMap é preservar, na medida do possível, a relação de similaridade existente entre os pontos $\mathcal{X}=\left\{\left(x_{1}, y_{1}\right), \ldots,\left(x_{n}, y_{n}\right)\right\}$ posicionados dentro de uma região. Uma possível solução para o posicionamento inicial dos pontos é utilizando scatterplot bidimensionais. Este é usado para correlacionar atributos dos dados mapeando dois deles na abscissa e coordenada e assim verificar como os elementos da base se comportam com relação aos dois atributos. Este cenário pode ser ilustrado, por exemplo, para visualizar dados de uma loja virtual. Mapeando o preço em uma coordenada e avaliação do consumidor em outra, é possível visualizar o custo benefício das mercadorias exibidas. Utilizando a NMap, um terceiro atributo poderia ser mapeado no peso de cada produto construindo assim uma visualização mais completa e robusta dos produtos desta loja virtual.

No entanto, existem cenários em que os dados em estudo apresentam inúmeras dimensões e cada uma sozinha não traz significado suficiente, i.e., é necessário analisar os dados utilizando todas as dimensões. Uma possível solução é a utilização de técnicas de projeção multidimensional (Tejada et al., 2003). Estas conseguem fazer um mapeamento dos dados em alta dimensão para o plano de visão, preservando, na medida do possível, a relação de similaridade que existe entre eles. Se $\delta\left(e_{i}, e_{j}\right)$ representa uma distância euclidiana entre dois elementos no espaço $n$-dimensional, e $d\left(\left(x_{i}, y_{i}\right),\left(x_{j}, y_{j}\right)\right)$ a distância de dois pontos que os representam, as técnicas de projeções multidimensionais objetivam minimizar $\left|\delta\left(e_{i}, e_{j}\right)-d\left(\left(x_{i}, y_{i}\right),\left(x_{j}, y_{j}\right)\right)\right| \forall d_{i}, d_{j} \in \mathcal{D}$, assim como a técnica classical 
scaling (Torgeson, 1965). Existem diversas técnicas de redução de dimensionalidade e a escolha depende do domínio dos dados em estudo. Um exemplo ilustrativo é o processamento de coleção de documentos. Ao utilizar técnicas convencionais de processamento de texto, um descritor é gerado para cada documento podendo este chegar a milhares de dimensões não relacionadas.

Por fim, os dados em estudo podem não apresentar relação entre eles e, portanto, não existir uma relação de similaridade a ser preservada. Este cenário pode ser ilustrado com o estudo número de funcionários de um grupo de empresas. Não existe uma relação de similaridade entre as empresas no entanto existe um peso (número de funcionários) atrelado a cada dado que se deseja visualizar. Para cenários como este, a utilização de posicionamento aleatório pode ser uma solução, porém não resulta em um layout determinístico.

\subsection{Complexidade Computacional}

A complexidade computacional de ambas as estratégias da NMap é ditada pela fase de corte. A técnica $N M a p-A C$ ordena os elementos através de suas coordenadas $x$ ou $y$ e divide o retângulo de modo que cada nova região tenha aproximadamente a mesma quantidade de elementos. Por tanto, a complexidade envolvida neste processo é $\mathrm{O}(n \log n)$ em que $n$ é o número de elementos da base de dados. Esta é a complexidade para ordenar os pontos iniciais se as coordenadas dos mesmos estarem representadas em pontos flutuantes. Caso estejam representadas como inteiros, pode-se utilizar o algoritmo de ordenação radix sort diminuindo a complexidade para $\mathrm{O}(n)$.

Para a abordagem NMap-EW, a complexidade computacional é $\mathrm{O}\left(n^{2}\right)$. Isto se deve à necessidade de iterar sobre todos os elementos da região para encontrar a melhor posição para particionar o retângulo. Este processo é necessário para garantir que as somas dos pesos das duas novas regiões serão aproximadamente iguais.

No entanto, o pior cenário pode ocorrer quando os elementos estão ordenados por peso de forma crescente sobre a coordenada x e sobre a coordenada y. Além disto, em todas as etapas de corte, o peso do último elemento da lista ordenada deve ser maior que o somatório dos elementos restantes. Na prática, este cenário é muito improvável e, na média, a NMap-EW tem um excelente desempenho computacional que pode ser visto na Seção 6.4 . 


\subsection{Considerações Finais}

Ambas as abordagens desenvolvidas, $N M a p-A C$ e $N M a p-E W$, apresentam baixa complexidade computacional o que motiva a sua utilização para visualização de grandes quantidades de dados. Além disso, devido a utilização total do espaço visual disponível, está técnica pode ser amplamente utilizada em dispositivos móveis que possuem telas com tamanhos reduzidos.

Diferente das técnicas tradicionais de Treemap que utilizam uma abordagem top-down, a NMap utiliza uma abordagem bottom-up em que a construção do mapa parte de todos os elementos refinando até a criação da visualização de um único elemento. Por este motivo, o resultado final é sensível ao posicionamento inicial e ao posicionamento da reta de recorte em que pequenas modificações podem gerar visualizações distintas. Além disso, esta abordagem dificulta a visualização de dados que não possuem posicionamento inicial ou relação de similaridade entre si, sendo necessário aleatoriamente criar o posicionamento. 


\section{Resultados e avaliações}

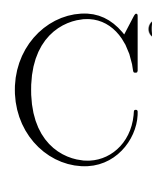

om o objetivo de validar a técnica NMap, comparamos as duas abordagens desenvolvidas neste trabalho, NMap-AC e NMap-EW, contra as principais técnicas do estado da arte, Ordered Squarified Treemap (OOT) (Bederson et al., 2002) e Spatially-Ordered Treemap (SOT) (Wood e Dykes, 2008). Em comum, todas têm por objetivo preservar a relação de similaridade dada por um posicionamento no plano bidimensional.

As análises e comparações foram realizadas levando em consideração quatro diferentes métricas: razão de aspecto, deslocamento, preservação de vizinhança e tempo de processamento. Importante ressaltar que todos os algoritmos estão implementados na linguagem Java e o código da $O O T$ e da $S O T$ foi gentilmente cedido pelos autores dos trabalhos.

Neste capítulo estão descritas todas as métricas utilizadas para avaliação, os resultados visuais obtidos por meio da visualização final gerada por cada técnica e uma avaliação quantitativa para mensurar a eficácia e diferença entre as técncias. Ao fim, é feito um apanhado dos resultados obtidos.

\subsection{Métricas de Avaliação}

Quatro diferentes métricas foram utilizadas para avaliar as técnicas NMap-AC e NMap-EW com as do estado da arte, OOT e SOT; são elas: razão de aspecto, deslocamento, preservação de vizinhança e tempo de processamento. Estas medidas foram 
escolhidas por avaliarem diferentes características importantes das técnicas de preenchimento do espaço visual.

\subsubsection{Razão de Aspecto}

A razão de aspecto é uma proporção matemática entre as duas dimensões de um retângulo e tem a capacidade de mensurar a proximidade deste elemento a um quadrado. Esta medida é importante pois retângulos estreitos e longos dificultam o posicionamento de elementos gráficos dentro deles, comparação de sua área com a dos retângulos que compõe a visualização e sua seleção em telas sensíveis ao toque.

Diferente da maioria dos trabalhos da literatura, que utilizam a razão de aspecto convencional expressa por $\max \left(w_{R_{i}} / h_{R_{i}}, h_{R_{i}} / w_{R_{i}}\right)$, neste trabalho foi utilizado a razão de aspecto normalizada expressa por $\min \left(w_{R_{i}} / h_{R_{i}}, h_{R_{i}} / w_{R_{i}}\right)$. Essa nova formulação apresenta resultados contidos no intervalo ]0..1], o que facilita a análise e comparação dos resultados obtidos. Ao contrário do método tradicional, quanto maior o valor obtido para a razão de aspecto normalizada mais próximo de um quadrado o retângulo está (1 representa um quadrado perfeito). Assim, é necessário que os algoritmos em estudo produzam layouts que maximizem a razão de aspecto normalizada.

Em nosso cenário, a razão de aspecto de toda a visualização foi calculada como a média aritmética da razão de aspecto normalizada de todos os retângulos que compõem a visualização final. Esta equação pode ser expressa por:

$$
\sum_{i=1}^{n} \frac{\min \left(w_{R_{i}} / h_{R_{i}}, h_{R_{i}} / w_{R_{i}}\right)}{n}
$$

em que $n$ é o número total de elementos da base de dados em estudo e, para cada retângulo $i$, a razão de aspecto normalizada é calculada como o menor quociente entre sua altura $h_{R_{i}}$ e largura $w_{R_{i}}$.

\subsubsection{Deslocamento}

Outra medida utilizada foi o deslocamento total. Este é calculado como a média aritmética da distância entre a posição inicial de cada elemento até a posição final do retângulo correspondente levando em consideração o centro dele. Assim, esta métrica é modelada pela equação

$$
\sum_{i=1}^{n} \frac{\sqrt{\left(x_{i}-R c_{i}^{x}\right)^{2}+\left(y_{i}-R c_{i}^{y}\right)^{2}}}{n}
$$


em que $\left(x_{i}, y_{i}\right)$ são as coordenadas cartesianas da posição inicial do elemento $i$ e $R c_{i}^{x}$ e $R c_{i}^{y}$ são as coordenadas $x$ e $y$, respectivamente, do centro do retângulo $R c_{i}$. Esta medida consegue mensurar quanto do posicionamento inicial foi preservado na visualização final. Ela é importante para aplicações que utilizam informações geográficas para o posicionamento inicial dos pontos, como o caso de cartogramas.

\subsubsection{Preservação de Vizinhança}

Com importância reconhecida em diversos trabalhos anteriores (Mansmann et al., 2007; Wood e Dykes, 2008; Buchin et al., 2011), a metáfora distância-similaridade diz que elementos similares devem ser posicionados próximos e elementos diferentes distantes. Assim, a métrica de preservação de vizinhança consegue determinar a porcentagem de vizinhos do posicionamento inicial que foi preservado ao fim. A preservação total da visualização é calculada como a média da porcentagem de vizinhos preservados dos $n$ elementos da base. Seja $k \in[l, m]$ em que $1 \leq l \leq m \leq n-1, N_{k_{i}}^{P}$ o conjunto que contém os índices dos $k$ pontos vizinhos mais próximos do ponto projetado $p_{i}$ e $N_{k_{i}}^{R}$ o conjunto que contém os índices dos $k$ centros dos retângulos vizinhos mais próximos do centro do retângulo que representa o ponto $p_{i}$. A preservação de vizinhança final pode ser expressa através da equação

$$
N P=\frac{1}{n m} \sum_{k=l}^{m} \sum_{i=1}^{n} \frac{N_{k_{i}}^{P} \cap N_{k_{i}}^{R}}{k}
$$

que varia no intervalo $[0,1]$ com valores maiores indicando melhores preservações de vizinhança.

\subsubsection{Tempo de processamento}

Por fim, o tempo total de processamento é calculado como a diferença entre o fim da execução do algoritmo e o momento que a função é executada, i.e., não são levados em consideração o tempo necessário para renderizar a visualização ou ler e pré processar os dados. Como esta medida é influenciada diretamente pelas características do equipamento, todos os testes descritos neste capítulo foram feitos em um computador com processador Intel ${ }^{\circledR}$ Xeon CPU E7-2870 2.40GHz, com 32GB de RAM. 


\subsection{Base de Dados}

Para os testes, foram criadas 9 configurações iniciais, com 600 pontos cada, divididas em três grupos (Figura 6.1). O primeiro (primeira linha da Figura 6.1) é formado por configurações usadas para medir a capacidade dos algoritmos em preservar o formato inicial considerando relações lineares e não-lineares. O segundo grupo (segunda linha da Figura 6.1) é formado por bases capazes de medir a capacidade dos algoritmos em preservar a separação entre dois grupos de elementos variando a densidade dos pontos e a orientação dos grupos. Por fim, o terceiro e último grupo (terceira linha da Figura 6.1) é formado por configurações com mais de dois grupos com diferentes densidades e orientações.

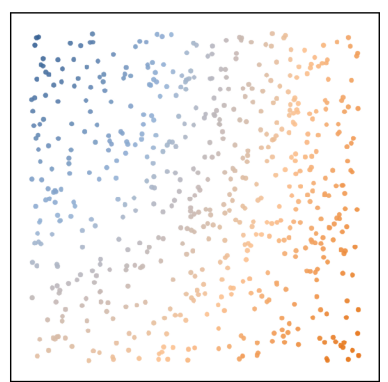

(a) Configuração 1

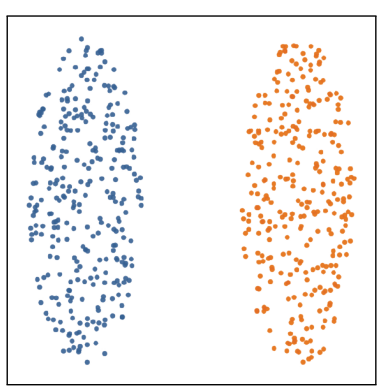

(d) Configuração 4

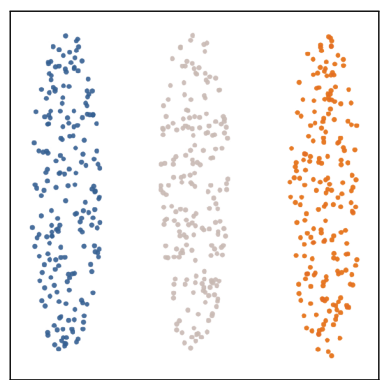

(g) Configuração 7

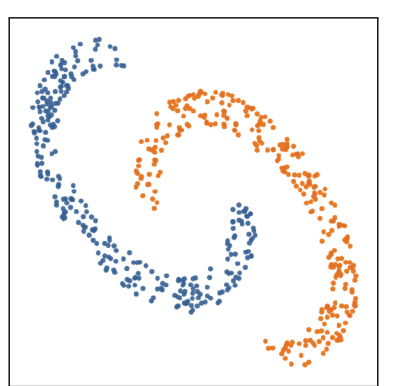

(b) Configuração 2

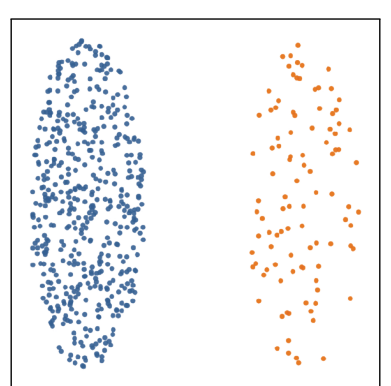

(e) Configuração 5

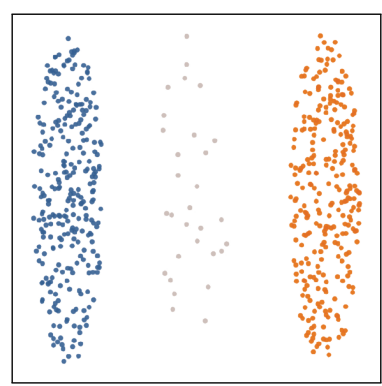

(h) Configuração 8

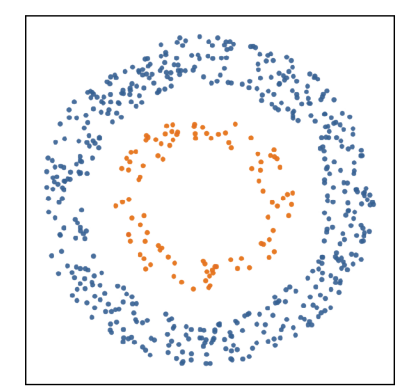

(c) Configuração 3

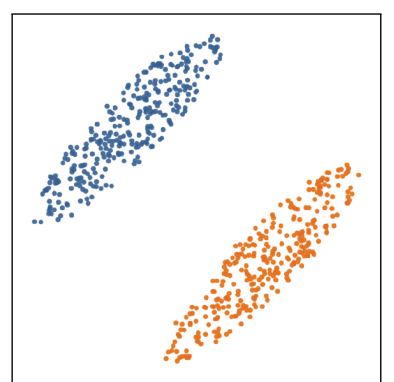

(f) Configuração 6

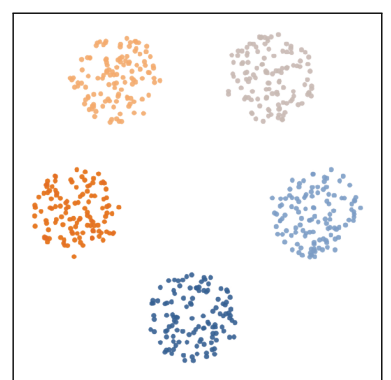

(i) Configuração 9

Figura 6.1: Configuração inicial das bases dados utilizadas para testes comparativos. 
Os pesos de cada elemento foram aleatoriamente calculados seguindo uma distribuição Gaussiana com a razão entre o menor e o maior peso de 1/1 (pesos constantes), 1/10, $1 / 50,1 / 100,1 / 150,1 / 200$, e 1/250. Estas bases de dados tentam representar, na medida do possível, os mais diversos cenários reais. Assim, estas foram aplicadas a cada algoritmo e os resultados estão sumarizados nas seções seguintes.

\subsection{Avaliação Visual}

Uma avaliação visual foi realizada para compreender o comportamento das diversas técnicas em preservar a configuração inicial dos pontos. Para isto, as 9 configurações iniciais foram submetidas aos algoritmos e a visualização final de cada um está reunida na Figura 6.2. Cada quadrado do layout final é pintado de acordo com a cor da classe do ponto correspondente no posicionamento inicial.

Para o primeiro grupo de configurações, a técnica OOT apresentou bons resultados para a configuração 1 porém resultados ruins para as configurações 2 e 3 . Este problema é causado pela ordenação unidimensional imposta pela técnica que considera a distância do ponto à origem (canto superior esquerdo). Por este motivo, como o gradiente de cores no caso 1 varia do canto superior esquerdo até o inferior direito, favoreceu a ordenação unidimensional da OOT.

De modo similar, a técnica $S O T$ apresentou bons resultados para a configuração 1 , mas, para as configurações 2 e 3 , posicionou os retângulos diferente do formato inicial dos pontos. As técnicas $N M a p-A C$ e $N M a p-E W$ apresentaram os melhores resultados neste primeiro grupo de casos de teste. Nestas, o gradiente de cores dos retângulos representou fielmente o gradiente dos pontos originais, e as configurações não lineares foram coerentemente preservadas no layout final.

Para o grupo 2, formado por dados com diferentes densidades e direções, as técnicas SOT, NMap-AC e NMap-EW apresentaram bons resultados para as configurações 4 e 5 . Ao contrário, a técnica OOT apresentou os piores resultados novamente. De fato, a OOT sempre irá apresentar resultados ruins quando a direção de maior variação dos dados está aproximadamente paralela aos eixos dos retângulos delimitadores. Quando a direção desta variação se alinha com a diagonal do retângulo, a $O O T$ consegue preservar a forma inicial (configuração 6). As técnicas $N M a p-A C$ e $N M a p-E W$ também demonstraram bons resultados em preservar o formato diagonal dos dados e, ao contrário, a técnica SOT apresentou o pior resultado perdendo por completo a informação da diagonal dos pontos iniciais, violando assim a metáfora distância-similaridade. 


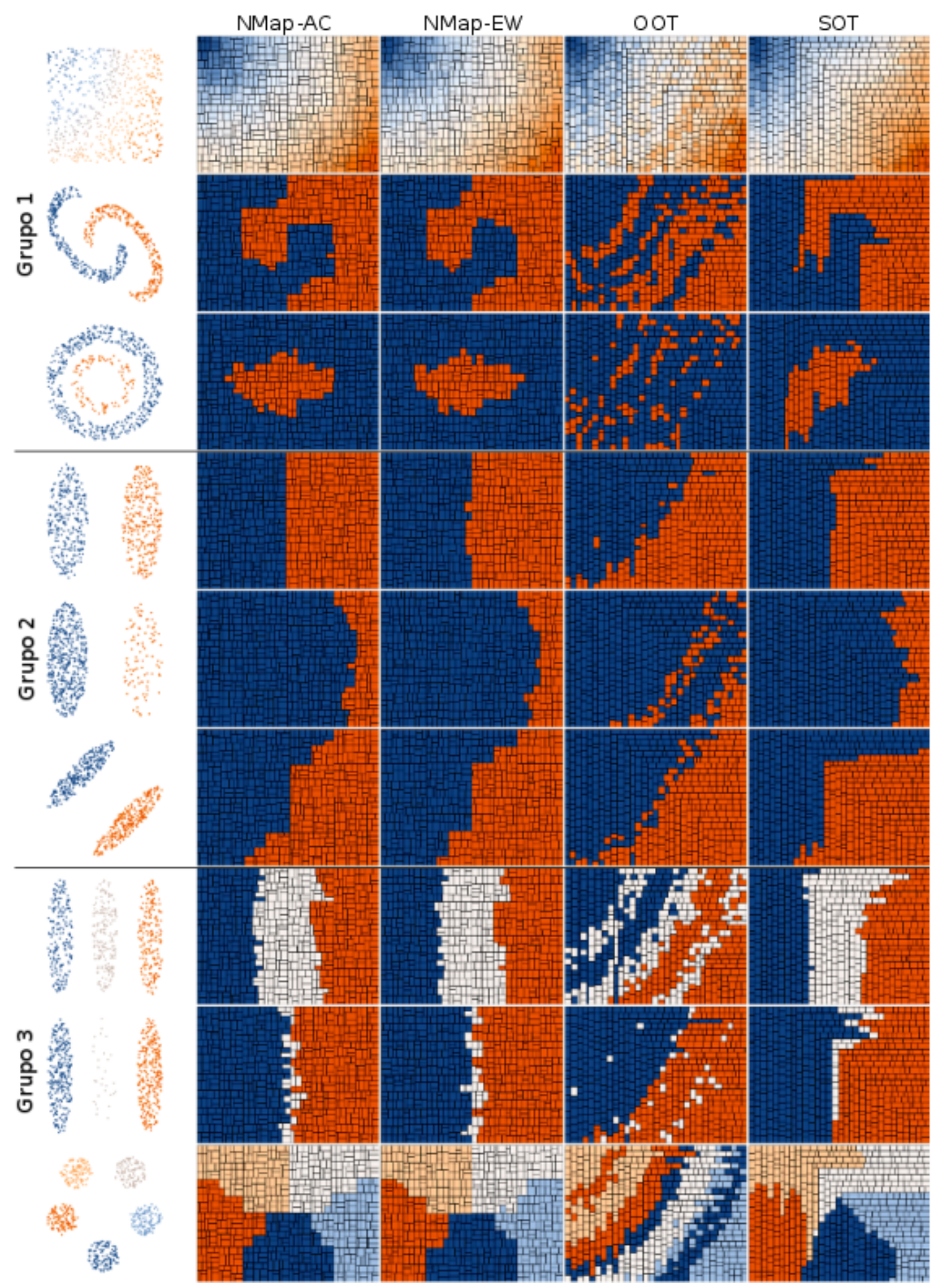

Figura 6.2: Resultado final ao aplicar as técnicas NMap-AC, NMap-EW, OOT e SOT com as 9 diferentes configurações iniciais apresentadas na Seção 6.2. As cores dos pontos são usadas para pintar o retângulo correspondente no layout final. De modo geral a NMap apresentou os melhores resultados produzindo layouts que melhor preservam o formato inicial dos dados. 
Os testes realizados com o último grupo, que tem por objetivo avaliar as técnicas quando existem mais de dois agrupamentos nos dados, confirmaram a qualidade dos algoritmos NMap-AC e NMap-EW. Estes, em todos os cenários, apresentaram os melhores resultados visuais. A técnica $O O T$ apresentou os piores resultados por não preservar o formato inicial dos pontos em nenhuma das três configurações deste grupo. A SOT teve problemas em apresentar a configuração composta de um grupo pouco denso cercado por dois muito densos (configuração 8). As configurações 7 e 9 foram representadas por layouts que lembram a disposição inicial dos pontos.

Por fim, o layout produzido pelas técnicas, utilizando como entrada a configuração 4, foi colorido de acordo com o deslocamento, razão de aspecto e preservação de vizinhança (Figura 6.3). A primeira linha da Figura mostra o resultado visual para o deslocamento. É notório que a NMap não só produz o melhor resultado na média mas também o desvio padrão é pequeno, o que indica, de modo geral, pouco deslocamento dos pontos iniciais até o ponto final.

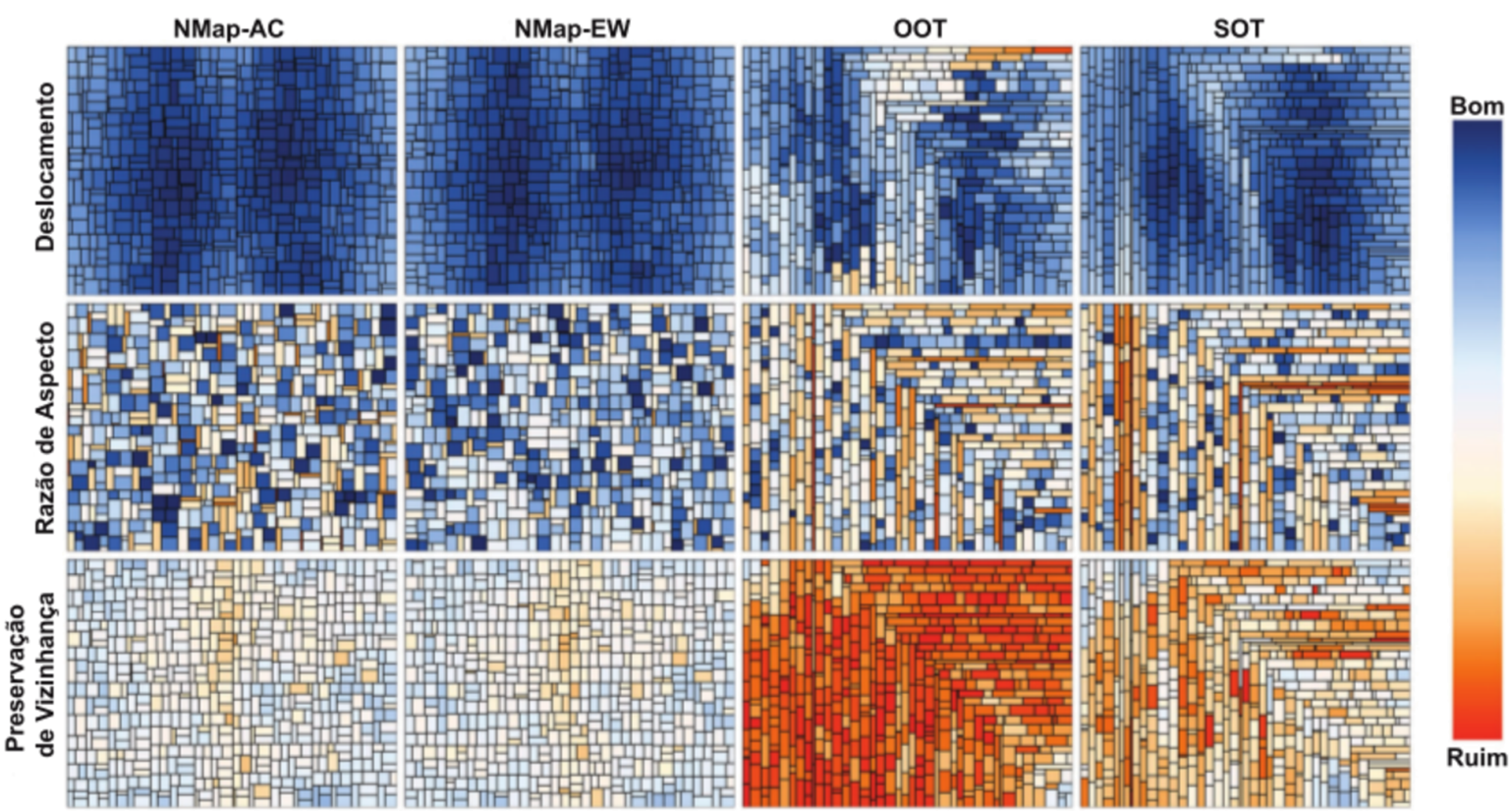

Figura 6.3: Comparação entre as técnicas NMap-AC, NMap-EW, SOT e OOT utilizando a configuração 4. Os retângulos estão coloridos de acordo com deslocamento, razão de aspecto e preservação de vizinhança. Em todas estas medidas, visualmente, a técnica NMap apresentou melhores resultados, não só produzindo retângulos menos alongados, mas também preservando melhor a vizinhança demonstrando assim o compromisso com a metáfora distância-similaridade.

Alem disso, é possível observar, na segunda linha, que as técnicas $N M a p-E W$ e NMap-AC apresentam melhores resultados levando em consideração a razão de aspecto dos retângulos. Importante destacar que a proporção de pesos dos dados é 1/50 e, quando 
essa proporção diminui, a vantagem é ainda maior sobre as técnicas OOT e SOT. A última linha da Figura 6.3 exibe a preservação de vizinhança. Mais uma vez a técnica NMap apresenta os melhores resultados, o que é importante para preservação da metáfora distância-similaridade.

\subsection{Avaliação Quantitativa}

De modo geral, visualmente as técnicas $N M a p-A C$ e $N M a p-E W$ apresentaram os melhores resultados. Assim, para validar estes resultados, cada técnica foi executada 30 vezes para as 9 configurações iniciais e 7 distribuições de pesos distintas (vide Seção 6.2). O número de execuções e a diversidade das bases fornecem um embasamento estatístico significativo para afirmar qual a melhor abordagem. Os resultados estão sumarizados nos boxplots da Figura 6.4, que apresentam os resultados com relação às métricas razão de aspecto, preservação de vizinhança e deslocamento.

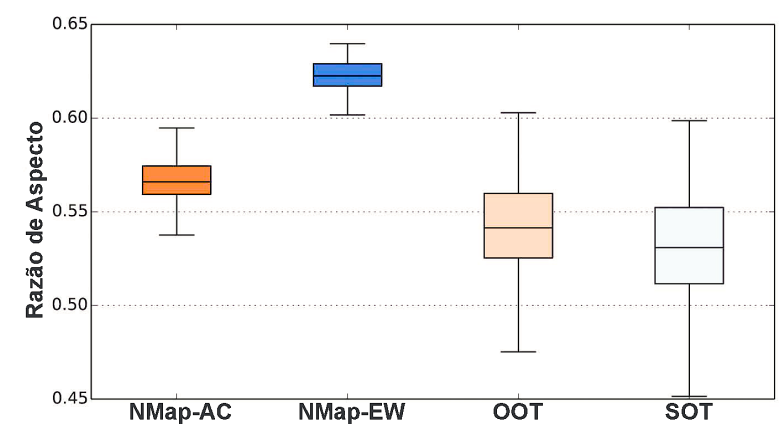

(a) Razão de Aspecto

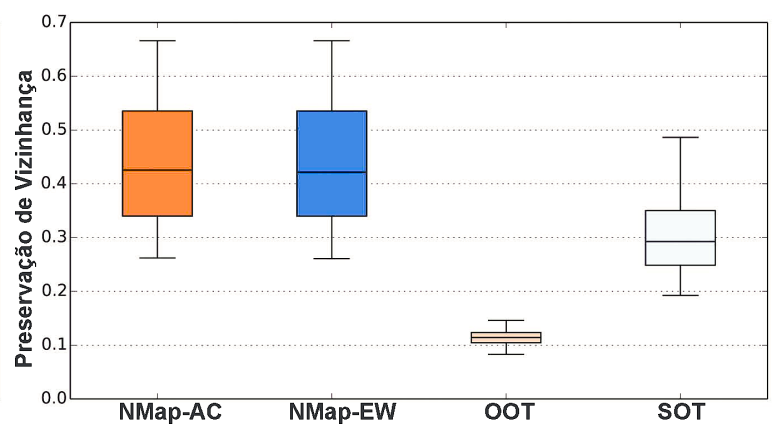

(b) Preservação de vizinhança

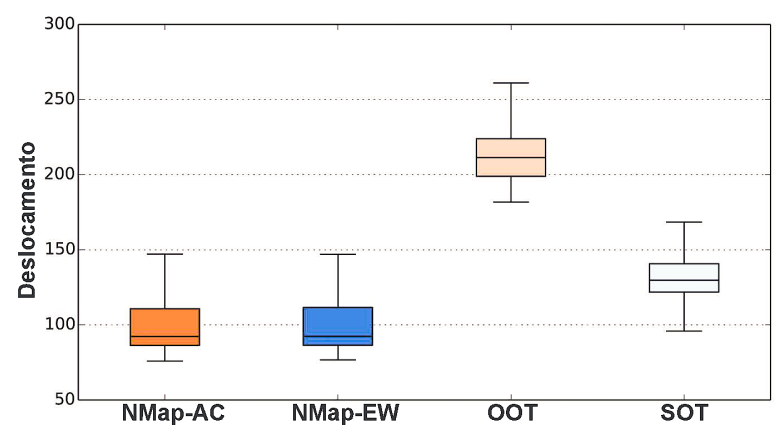

(c) Deslocamento

Figura 6.4: Boxplots das medidas razão de aspecto (a), preservação de vizinhança (b) e deslocamento (c): em todos os casos a técnica NMap superou as técnicas atuais do estado da arte comprovando assim sua qualidade.

Em termos de razão de aspecto (Figura 6.4(a)), a técnica NMap apresentou os melhores resultados por obter valores mais próximos de 1 . Apesar de sua abordagem simples, ela 
superou as técnicas $O O T$ e SOT, que adaptam o algoritmo Squarified Treemap e tem por objetivo maximizar a razão de aspecto, i.e., formar regiões mais próximas possível do quadrado. Entre as técnicas $N M a p-E W$ e $N M a p-A C$, como esperado, a primeira apresenta melhores resultados. A média e o pequeno desvio padrão da $N M a p-E W$ indicam que os retângulos produzidos possuem razão de aspecto bem próximos e o número de retângulos alongados e estreitos é minimizado no processo. Ainda assim, a NMap-AC apresenta bons resultados.

Com relação à preservação de vizinhança (Figura 6.4(b)), NMap-AC e NMap-EW apresentam os melhores resultados, enquanto a OOT, devido a sua natureza unidimensional, apresenta o pior. Em particular, neste teste, executamos o algoritmo para detecção dos $k$ vizinhos mais próximos com $k \in[5,20]$, i.e., $l=5$ e $m=20$ (vide Seção 6.1.3). O mesmo resultado é encontrado na medida de deslocamento (Figura 6.4(c)), indicando que a técnica NMap preserva melhor o posicionamento inicial dos pontos enquanto constrói o layout final. Estes resultados claramente mostram a superioridade da técnica NMap em preservar a metáfora distância-similaridade na visualização final.

Diferente das outras métricas que utilizaram as 9 configurações durante os testes, para avaliar o tempo de processamento, foram geradas bases de dados com posicionamento aleatórios variando o número de elementos em 5, 10, 50, 100, 500, 1000, 5 mil, 100 mil, 500 mil e 1 milhão. Cada técnica foi executada 200 vezes para cada base de dados. Os tempos de processamento estão representados no gráfico de tempo por tamanho da base de dados na Figura 6.5.

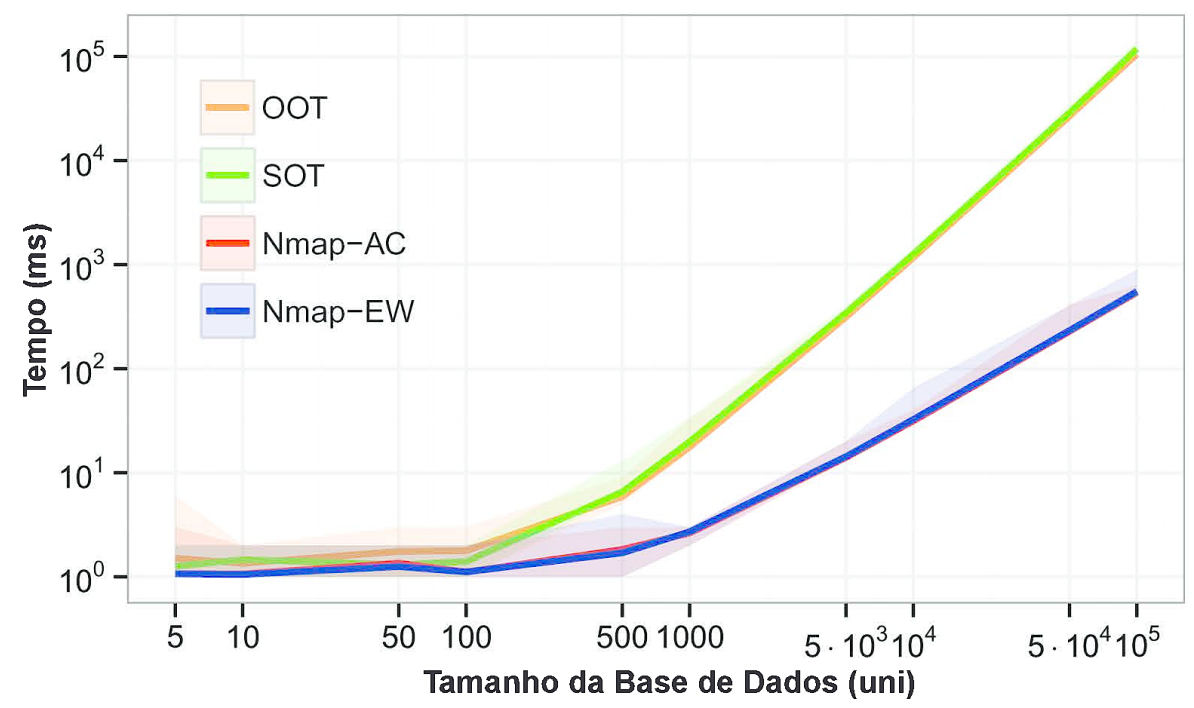

Figura 6.5: Gráfico tamanho da base de dados versus tempo de processamento: na média, As abordagens da NMap apresentaram desempenhos similares estando até 3 ordens de magnitude mais rápidas que a SOT e OOT. 
No gráfico, as linhas centrais representam a média do tempo de cada técnica, e o sombreamento de mesma cor a região que contempla o máximo e mínimo. Importante notar que, na média, o tempo de processamento da $N M a p-E W$ é similar ao tempo apresentado pela NMap-AC devido a raridade do pior cenário (vide Seção 5.4). No entanto, apesar da $N M a p-E W$ ser mais lenta que a NMap-AC em alguns cenários, ambas se destacam pelo tempo de processamento quando comparadas as técnicas OOT e SOT. Em cenários com grandes quantidades de dados, esta diferença pode chegar a ordem de 3 casas de magnitude.

\subsection{Considerações Finais}

Quando os pesos dos elementos são iguais, as técnicas OOT e SOT apresentam os melhores resultados com relação a razão de aspecto por serem baseadas na técnica Squarified Treemap. No entanto, a maioria dos dados em estudo possuem diferentes pesos para os elementos. Neste contexto, as técnicas NMap-AC e NMap-EW demonstraram obter os melhores resultados, produzindo visualizações com razões de aspecto melhores que as técnicas do estado da arte. De fato, quanto maior a discrepância entre os pesos da base de dados, melhores os resultados obtidos pela NMap sobre a OOT e SOT.

Independente dos pesos dos elementos, a NMap apresentou os melhores resultados com relação a preservação de vizinhança e deslocamento. Estas duas medidas, de certo modo, estão correlacionadas, pois layouts que apresentam baixo deslocamento consequentemente apresentam alta preservação de vizinhança. Estes resultados demonstraram a capacidade da técnica NMap em preservar a metáfora distância-similaridade.

Por fim, o tempo de processamento apresentado pela NMap foi até 3 ordens de magnitude menor que o das técnicas SOT e OOT. Isto demonstra a facilidade da técnica em trabalhar com grandes bases de dados com milhões de elementos. Este resultado pode ser melhorado em uma implementação paralela do algoritmo. Uma vez que os pontos são separados em duas novas regiões, cada uma pode continuar o processamento paralelamente sem dependência entre os processos. 


7

\section{Squarified ProjCloud (SPCloud)}

$\mathrm{O}$ considerável aumento no número de usuários de dispositivos móveis provocou uma mudança nos hábitos da população. A cultura de ler o jornal de papel todas as manhãs está dando lugar a aplicativos e equipamentos que exibem notícias durante todo o dia das mais diversas fontes da imprensa. Um fato que corrobora com esta mudança comportamental pode ser encontrado nas loja de aplicativos Play Store ${ }^{1}$. Esta possui uma categoria exclusiva para leitores de notícias e livros, o que demonstra o grande interesse de seus usuários por este tipo de aplicação.

Estes aplicativos, em sua maioria, utilizam o paradigma de lista unidimensional para exibir as notícias. Devido ao grande volume de informação produzida diariamente, explorar todas estas notícias para manter-se informado pode se tornar uma tarefa árdua e pouco eficiente. Assim, o desenvolvimento de uma ferramenta capaz de sumarizar todo o conteúdo de uma coleção de documentos se mostra algo relevante e necessário. Além disto, este deve levar em consideração o tamanho limitado do espaço visual, utilizando-o por completo para exibir a maior quantidade de informação possível. Neste contexto surgiu a ferramenta Squarified ProjCloud (SPCloud).

\footnotetext{
${ }^{1}$ Play Store: loja de aplicativos, livros e filmes para dispositivos móveis com o sistema operacional Android. Disponível em http://play.google.com/.
} 


\subsection{Squarified ProjCloud}

Levando em consideração as características inerentes aos dispositivos móveis, a ferramenta SPCloud (Figura 7.1) faz uso de todo o espaço visual para exibir coleções com centenas ou até milhares de documentos texto. Para isso, ela utiliza a técnica NMap (Capítulo 5) para separar o layout de visualização preservando, na medida do possível, a similaridade entre os documentos. Além disso, o paradigma de nuvens de palavras é empregado para exibir a sumarização do conteúdo de coleções de documentos evidenciando as palavras mais significativas. Com uma arquitetura cliente-servidor, a ferramenta SPCloud processa no servidor toda a coleção de documentos, separa-os em grupos e encontrar as palavras mais importantes. No dispositivo móvel somente a visualização final e interação com usuário é realizada.

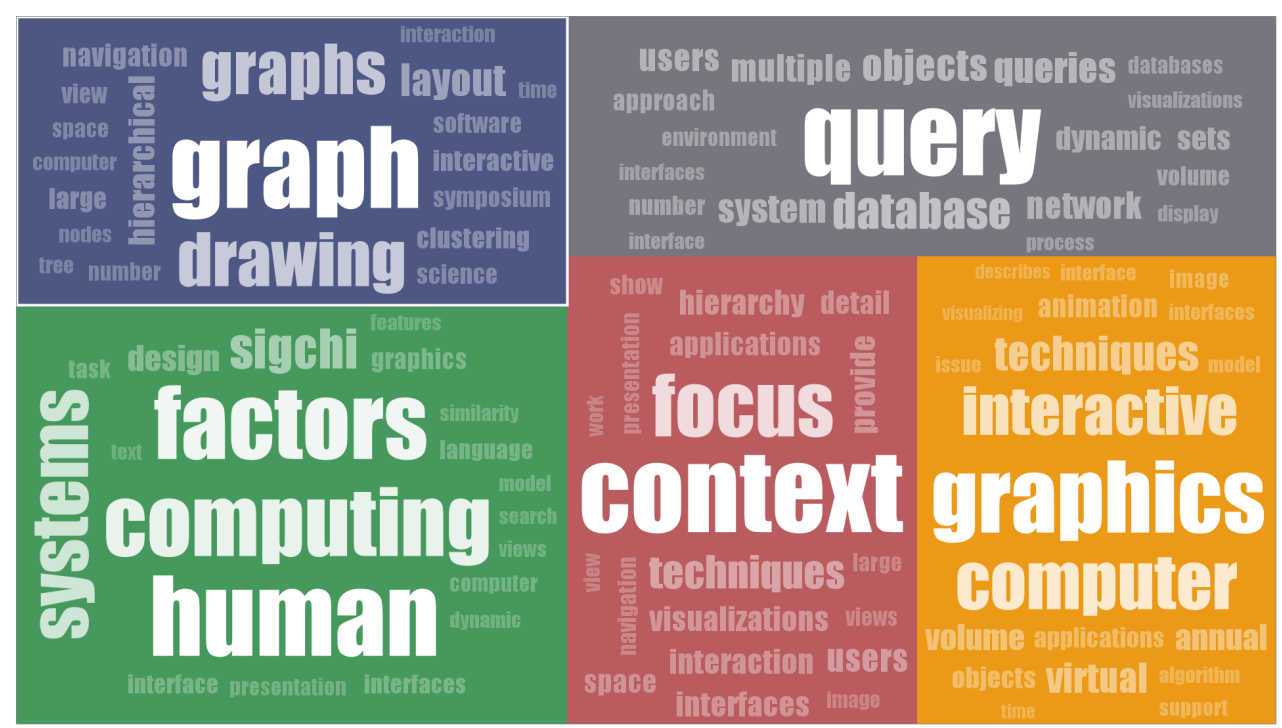

Figura 7.1: Ferramenta Squarified ProjCloud: Visualização da base de dados "Inforvis2004" formada por 613 artigos aceitos e publicados na Infovis de 1995 à 2002.

Todo o processo utilizado na ferramenta está resumido no fluxograma da Figura 7.2. Dado uma coleção de documentos ou notícias, a ferramenta processa-os e constrói o descritor de cada documento ${ }^{2}$ em um espaço $\mathbb{R}^{n}$. A união desses descritores forma a matriz de frequência dos termos (do inglês Term Frequency - TF) e a matriz de frequência dos termos pela frequência nos documentos da coleção (do inglês Term Frequency Inverse Document Frequency - TFIDF) (Salton e McGill, 1986). Estas matrizes, comumente utilizadas em técnicas de mineração de dados, têm como função abstrair as informações

\footnotetext{
${ }^{2}$ Descritores são representações numéricas que tentam armazenar as características do documento que eles representam.
} 
dos textos para o processamento da coleção. De modo geral, essas matrizes dizem a frequência de cada palavra dentro de cada texto da coleção (Subseção 7.2).

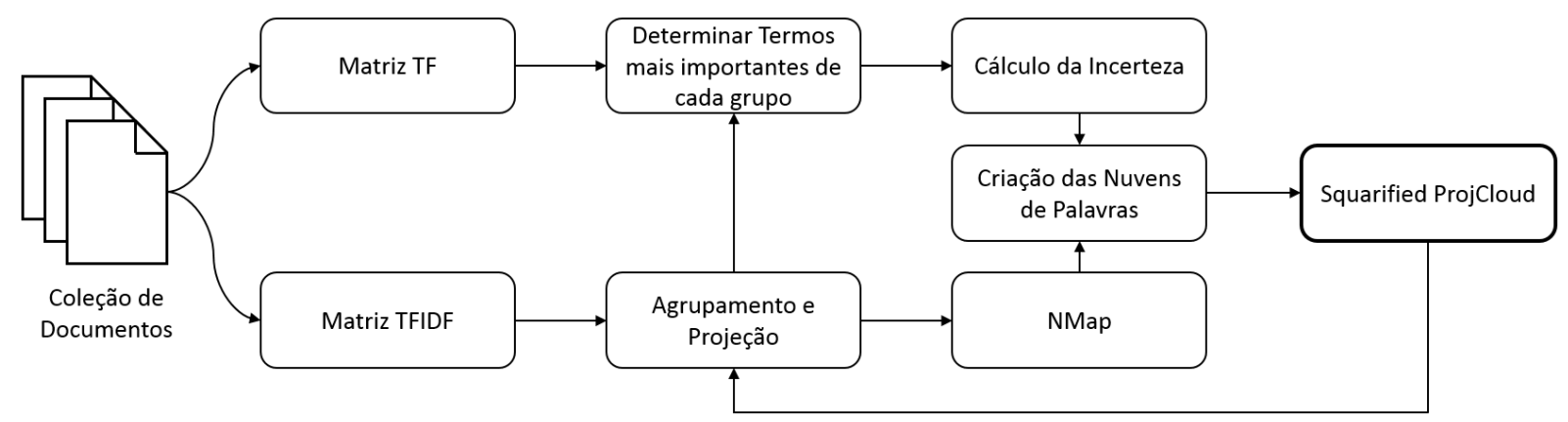

Figura 7.2: Fluxograma do processo de criação da visualização da ferramenta SPCloud. Iniciando com a coleção de documentos em seguida processamento dos mesmos, projeção, algoritmo de recorte do layout e por fim a visualização finalizada.

Devido a característica esparsa destes descritores, é utilizado a dissimilaridade cosseno para o calculo da diferença entre cada par de documentos. Está diferença permite separar os documentos em grupos de documentos similares calculado através do algoritmo de agrupamento K-means (MacQueen, 1967). Para o funcionamento do algoritmo de agrupamento e necessário informar o número de grupos presente nos dados. Impiricamente foi utilizado cinco como o número de grupos presentes por ter demonstrado melhores resultados visuais, no entanto este número pode ser alterado pelo usuário para melhor se adaptar a base em estudo.

Como o espaço visual é bidimensional, é necessário que exista um mapeamento dos documentos em $\mathbb{R}^{n}$ para $\mathbb{R}^{2}$. Para isto, utiliza-se um algoritmo de redução de dimensionalidade que tem por objetivo fazer este mapeamento mantendo a relação de similaridade do espaço original. Em particular, na ferramenta SPCloud, foi utilizado a técnica Loch (Fadel et al., 2014) por trabalhar melhor com dados esparsos e de muitas dimensões (como no caso de coleções de documentos). Esta técnica pode ser substituída por qualquer outra técnica de redução de dimensionalidade, que melhor represente e reduza os dados, sem que exista perda de qualidade na visualização final.

Com os dados já agrupados e utilizando o algoritmo de projeção multidimensional, projeta-se o medoide de cada grupo. Sobre esta projeção aplica-se o algoritmo NMap (Capítulo 5) para corte e montagem do layout final da visualização. Para cada medoide posicionado no plano a NMap gerará uma região no espaço visual com área proporcional a quantidade de documentos ali representada.

Para sumarizar o conteúdo de cada agrupamento, utiliza-se uma nuvem de palavras. Para isso é necessário determinar quais são as palavras mais relevantes. Para isso 
constrói-se um grafo das palavras com os documentos e calcula-se o Fiedler Vector (Fiedler, 1954). Esta abordagem gerá um vetor com as palavras mais importantes ordenadas de mandeira decrescente (Para mais informação leia (Paulovich et al., 2008a)). Estas palavras sumarizam todo o conteúdo da coleção de documentos. Porém, apesar destas palavras serem as melhores para representar o conjunto de documentos, elas podem não sumarizar o conteúdo de todos os documentos da coleção. Este cenário é comum em grupos heterogeneos que podem ser ocasionados pela escolha errada do número de grupos na etapa de agrupamento. Com o objetivo de contornar este problema, e deixa-lo vísivel ao usuário, é calculado a confiabilidade dos termos da nuvem de palavras em sumarizar aquela coleção (Seção 7.3).

Com as regiões estabelecidas pela NMap e com os termos mais importantes e suas respectivas confiabilidades calculadas, constroí-se a visualização final da ferramento $S P$ Cloud. As nuvens de palavras são calculadas utilizando o mesmo algoritmo implementado na técnica ProjCloud (Paulovich et al., 2012). Interativamente, o usuário pode selecionar uma área na visualização fazendo com que esta seja subdividida, refinando assim a representação dos dados. Deste modo, o usuário realimenta todo o processo de agrupamento em $\mathbb{R}^{n}$, projeção dos medoides, determinação dos termos mais importantes, divisão do espaço visual e criação de novas nuvens de palavras.

À medida que o usuário desce na hierarquia dos dados, dependendo da quantidade de documentos sumarizados na área, é possível que o mesmo seja representado por uma área muito pequena, e consequentemente, por uma nuvem de palavras ilegíveis. Para solucionar este problema, a ferramenta possibilita ao usuário ampliar a área e a nuvem de palavras através do zoom. Ao fazer tal ação, todo o layout se readapta ao novo tamanho do grupo em análise.

\subsection{Matrizes de Frequência dos Termos}

Para comparação de documentos é necessário criar uma forma de abstraí-los dentro do sistema e para isso é comum a criação de descritores. Para cria-los, na SPCloud, utiliza-se a técnica "Bag of Words" (Harris, 1973). Esta cria um vetor para cada documento em que cada índice do vetor representa uma palavra e o seu valor a quantidade de vezes que o termo aparece no texto, descrevendo deste modo a frequência dos termos dentro de cada documento.

Importante ressaltar que antes da criação dos descritores, é feito um pré-processamento de todos os documentos da coleção. Primeiro, eliminam-se todos os artigos, preposições e palavras pouco representativas para o domínio do texto, conhecidas como stopwords. 
Esta remoção acontece pois estas palavras aparecem com maior frequência nos textos e, por este motivo, são pouco uteis para diferenciar os documentos dentro de uma coleção.

Por fim, após a criação do descritor, removem-se dele os termos mais frequentes e os mais raros. Estes cortes, conhecidos como cortes de Luhn, acontecem pois palavras que aparecem com frequência em muitos textos não tem utilidade para diferenciar os documentos. O corte dos termos mais raros, além de diminuir o vocabulário, favorece a obtenção de melhores resultados na análise. É importante observar que a quantidade de termos que serão cortados deve ser determinada empiricamente, pois ainda não existem estudos que forneçam uma forma de calcular estes valores.

A união de todos os descritores calculados para cada documento forma a matriz de frequência dos termos (do inglês Term Frequency - TF)(Equação (7.1)). Denotemos $j$ como sendo o j-ésimo documento da coleção com tamanho $M ; i$ é o i-ésimo termo dentro desta coleção em um total de $N$ termos. Assim, $t f_{j i}$ é a frequência do termo $i$ dentro do documento $j$, i.e., o número de vezes que o termo $i$ aparece dentro do documento $j$.

$$
T F=\left[\begin{array}{cccc}
t f_{11} & t f_{12} & \cdots & t f_{1 N} \\
\vdots & \vdots & \ddots & \vdots \\
t f_{M 1} & t f_{M 2} & \cdots & t f_{M N}
\end{array}\right]
$$

De modo complementar, outra matriz que descreve a coleção de documentos é a matriz de frequência dos termos pela frequência nos documentos (do inglês term-frequency inverse document-frequency - TFIDF). Para a sua formação, cada termo é reduzido a seu radical, técnica essa conhecida como Lematização. A redução deve acontecer para que conjugações verbais não resultem em termos distintos, i.e., os verbos "comprei" e "comprando", por exemplo, devem representar o mesmo verbo "comprar". Ao fim, os termos reduzidos são contados gerando o vetor de frequência que descreve aquele texto. A união destes vetores forma uma matriz intermediaria de frequência (TFIDF) em que os termos estão reduzidos. Sobre esta matriz, pondera-se a frequência dos termos pela frequência do mesmo nos diversos documentos daquela coleção. Essa ponderação é dada pela Equação $(7.2)$.

$$
t f i d f_{j i}=t f_{j i} \times \log \left(\frac{M}{d f_{j}}\right)
$$

em que $t f_{j i}$ é frequência do termo $i$ no documento $j$, isto é, quantas vezes o termo $i$ apareceu no documento $j ; M$ é a quantidade de documentos na coleção; $d f_{i}$ é a quantidade de documentos em que o termo $i$ aparece pelo menos uma vez. 
Esta ponderação se faz necessária, pois um termo muito frequente pode aparecer em muitos documentos, oferecendo baixo poder de distinção entre os documentos. Ao fim, a matriz TFIDF é definida como:

$$
T F I D F=\left[\begin{array}{cccc}
t f i d f_{11} & t f i d f_{12} & \cdots & t f i d f_{1 N} \\
\vdots & \vdots & \ddots & \vdots \\
t f i d f_{M 1} & t f i d f_{M 2} & \cdots & t f i d f_{M N}
\end{array}\right]
$$

\subsection{Confiabilidade}

Em um cenário em que a nuvem de palavras sumariza um agrupamento heterogeneo, é possível que os termos encontrados não sejam suficientes para sumarizar todos os assuntos abordados nos documentos. Outro possível cenário possível é quando uma única palavra ou pequeno conjunto aparece muitas vezes em uma pequena parcela dos documentos da coleção. Estes serão tidos como os mais importantes porém, assim como no agrupamento heterogeneo, representam apenas uma pequena parcela de documentos.

Desta maneira, é importante mapear para o usuário a confiança que uma dada palavra tem em representar o grupo de documentos para que ele não tire conclusões erradas. Para isso, a ferramenta SPCloud mapeia esta confiabilidade na transparência das palavras da nuvem. Quanto mais transparente uma palavra, mais incerta ela é em representar aquele grupo. Para o cálculo da confiabilidade propõe-se duas abordagens, a primeira baseia-se em uma matriz binária dos termos e a segunda nos termos mais importantes de um grupo. O usuário tem a opção de selecionar aquela que julgar mais conveniente para sua análise.

\subsubsection{Matriz Binária dos Termos}

A primeira abordagem consiste em construir uma matriz binária que determina a presença ou não dos termos em cada arquivo de um grupo. Esta abordagem é particularmente interessante em um cenário em que um dado termo aparece diversas vezes em um pequeno conjunto de documentos e, portanto, ele acaba tendo um grande tamanho no layout final.

Baseado nesta matriz binária, mapeia-se a confiabilidade dos termos na transparência com que ele é desenhado na tela. Assim, um termo que aparece em bastantes documentos irá ter uma cor mais intensa e, caso ele não seja confiável para representar o grupo, este será desenhado com alta transparência.

Seja uma matriz binária $M B_{G}$, com $N$ colunas e $M$ linhas, que representa um grupo $G$ qualquer. Esta matriz informa se um dado termo $i$ está ou não presente em um documento 
$j$ do grupo $G$. Assumamos que o valor de $a_{j i}$ da matriz $M B_{G}$ é igual a 1 , caso o i-ésimo termo esteja presente no j-ésimo documento, ou zero caso contrário. Podemos então determinar a matriz binária como:

$$
M B_{G}=\left[\begin{array}{cccc}
a_{11} & a_{12} & \cdots & a_{1 N} \\
a_{21} & a_{22} & \cdots & a_{2 N} \\
\vdots & \vdots & \ddots & \vdots \\
a_{M 1} & a_{M 2} & \cdots & a_{M N}
\end{array}\right]
$$

em que,

$$
a_{j i}= \begin{cases}1 & \text { Caso o termo } i \text { esteja presente no documento } j, \\ 0 & \text { Caso contrário }\end{cases}
$$

Somando-se todos os elementos de uma mesma coluna, é possível determinar a incerteza $I$ do um termo $i$. Assim, o cálculo da incerteza de cada termo $I_{i}$ pode ser dado por:

$$
I_{i}=\sum_{j=1}^{M} \frac{a_{j i}}{M}
$$

Por fim, para mapear os valores da confiabilidade na transparência do termo $i$, o valor obtido é normalizado no intervalo $[0.2,1]$ (Equação (7.7)), em que 1 significa totalmente opaco e 0.2 o mais transparente possível. O valor mínimo do intervalo foi determinado empiricamente para que o termo menos confiável ainda fique visível.

$$
T_{t}=\frac{I_{t} * 0.8}{\max \left(I_{t}\right)}+0.2
$$

É importante notar que esta confiabilidade é um valor local e não global, ou seja, não existe relação intergrupos para as confiabilidades calculadas.

\subsubsection{Termos mais importantes}

Esta segunda abordagem utiliza o valor dado aos termos mais importantes e mapeia a confiabilidade também na transparência com que o termo é desenhado no layout final. No entanto, ela não é calculada para cada termo, mas sim para o conjunto deles. Ou seja, tenta-se visualizar a confiabilidade que o conjunto de palavras têm em sumarizar todos os documentos do grupo. 
Para isso, o algoritmo utiliza a matriz de covariância dos termos para calcular a importância através do Fiedler Vector que retorna a lista de termos ordenados pela sua importância. Ao plotarmos um gráfico deste retorno (Figura 7.3) é possível observar uma função $f$ com decaimento exponencial.

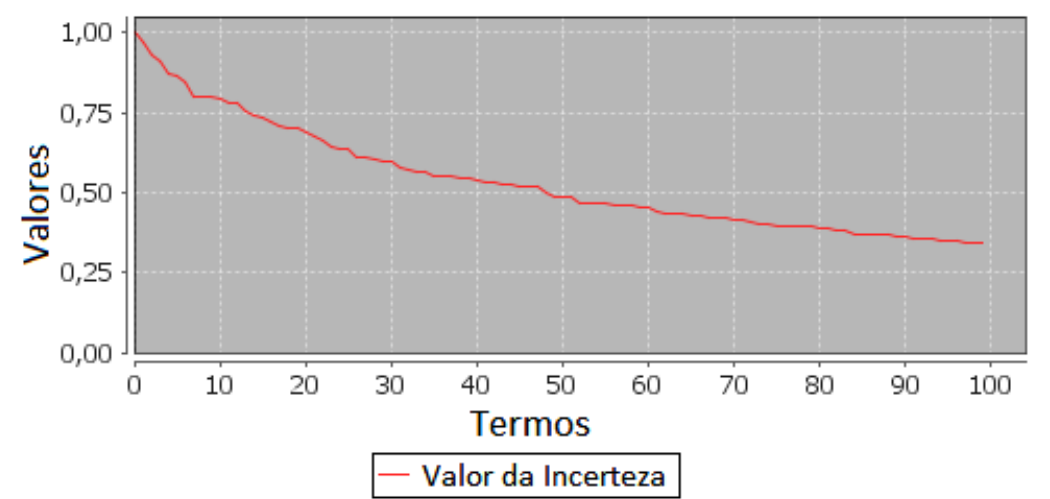

Figura 7.3: Gráfico de termos por importância calculado pelo Fiedler Vector. A relação destes atributos gera uma função $f$ com decaimento exponencial.

Em analogia a abordagem utilizada para determinar o número de grupos de acordo coma silhueta (Rousseeuw, 1987), para calcularmos a confiabilidade $C$ utilizamos as $a_{i}$ palavras mais importantes retornado pelo algoritmo Fiedler Vector, em que max $(x)$ é o indice do maior valor assumido pela derivada da função $f$ com relação as palavras (Equação (7.8)).

$$
x_{i}=a b s\left(\frac{a_{i-1}-a_{i}}{a_{i}-a_{i+1}}\right)
$$

O gráfico da derivada da função $f$ pode ser visto na Figura 7.4. Nele é possível observar que a função $f^{\prime}(x)$ tem seu maior valor em $x=8$, ou seja, as 8 primeiras palavras são as mais importantes para sumarizar aquela coleção de documentos.

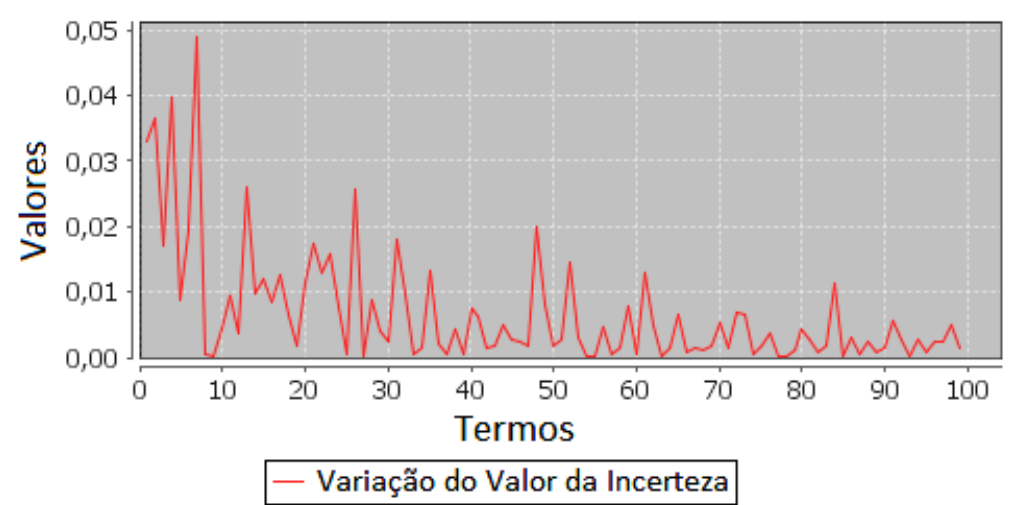

Figura 7.4: Gráfico de termos pela derivada da função $f$. O maior valor assumido representa o número de termos importantes para sumarizar a coleção de documentos. 
A confiabilidade é dada pela média da importância dos elementos de cada grupo no intervalo $[1, \max (x)]$. Esta confiança é mapeada em todos os termos da nuvem

de palavras, ficando eles com a mesma transparência. Assim, é possível verificar a confiabilidade da nuvem de palavras em mapear os documentos presentes naquele grupo. É importante ressaltar que como não há uma normalização local, esta abordagem permite uma comparação global das confiabilidades, ou seja, é possível fazer uma análise da confiança intergrupos.

\subsection{Interação com Usuário}

A interação do usuário é fundamental para exploração de coleções de doumentos na ferramenta SPCloud. Como layout inicial da visualização é dividido em no máximo 10 grupos, cada região pode representar centenas ou até milhares de documentos. Assim, é necessária uma forma de refinar a busca no grupo de interesse do usuário. Para isso, selecionando uma região que representa o grupo de interesse, esse se subdivide em cinco outros grupos (Figura 7.5). Este número foi determinado empiricamente para que forme subgrupos suficientes para refinar o layout mas que não sejam pequenos demais para a visualização. Portanto, o número de subgrupos está atrelado ao tamanho do visor do dispositivo do usuário, ou seja, quanto menor for o tamanho disponível para a visualização, aconselha-se que subdivida o grupo em quantidades menores. De qualquer modo, este número pode ser controlado pelo usuário.

Apesar de todos os esforços, ainda é possível que a área que representa um grupo fique muito pequena e, consequentemente, a nuvem de palavras fique ilegível. Na tentativa de contornar tal problema, o usuário pode ampliar um grupo (Figura 7.6). Esta ação soma valores ao peso total daquela região e faz com que esta seja redesenhada maior pela ténica NMap. Todos os outro grupos se adaptam ao novo tamanho do grupo ampliado.

A qualquer momento e em qualquer nível da hierarquia que esteja sendo exibido, o usuário pode querer ver os documentos ali representados. Para isso, uma barra lateral com todos os documentos presentes na região de interesse é exibida no canto direito da visualização, escalando horizontalmente todo o layout de visualização (Figura 7.7). Esta mesma barra é exibida quando o usuário atinge o fim da hierarquia e não mais é possível subdividir a região. Por fim, caso o usuário deseje ler o conteúdo de qualquer um dos documentos, ao seleciona-lo na lista, uma janela com o texto irá aparecer sobre a visualização (Figura 7.7). 


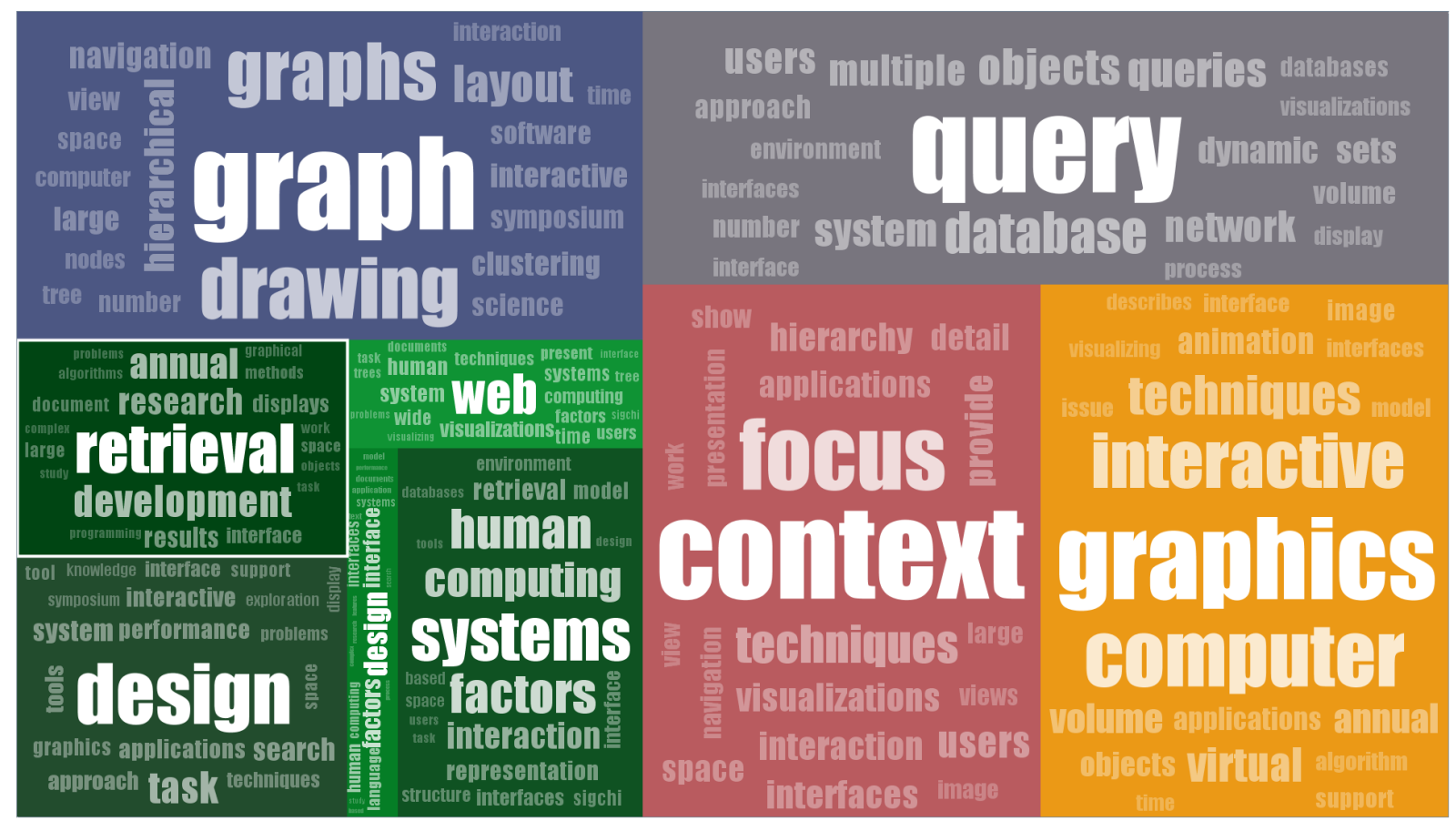

Figura 7.5: Subdivisão do grupo inferior esquerdo da Figura 7.1 em 5 subgrupos.

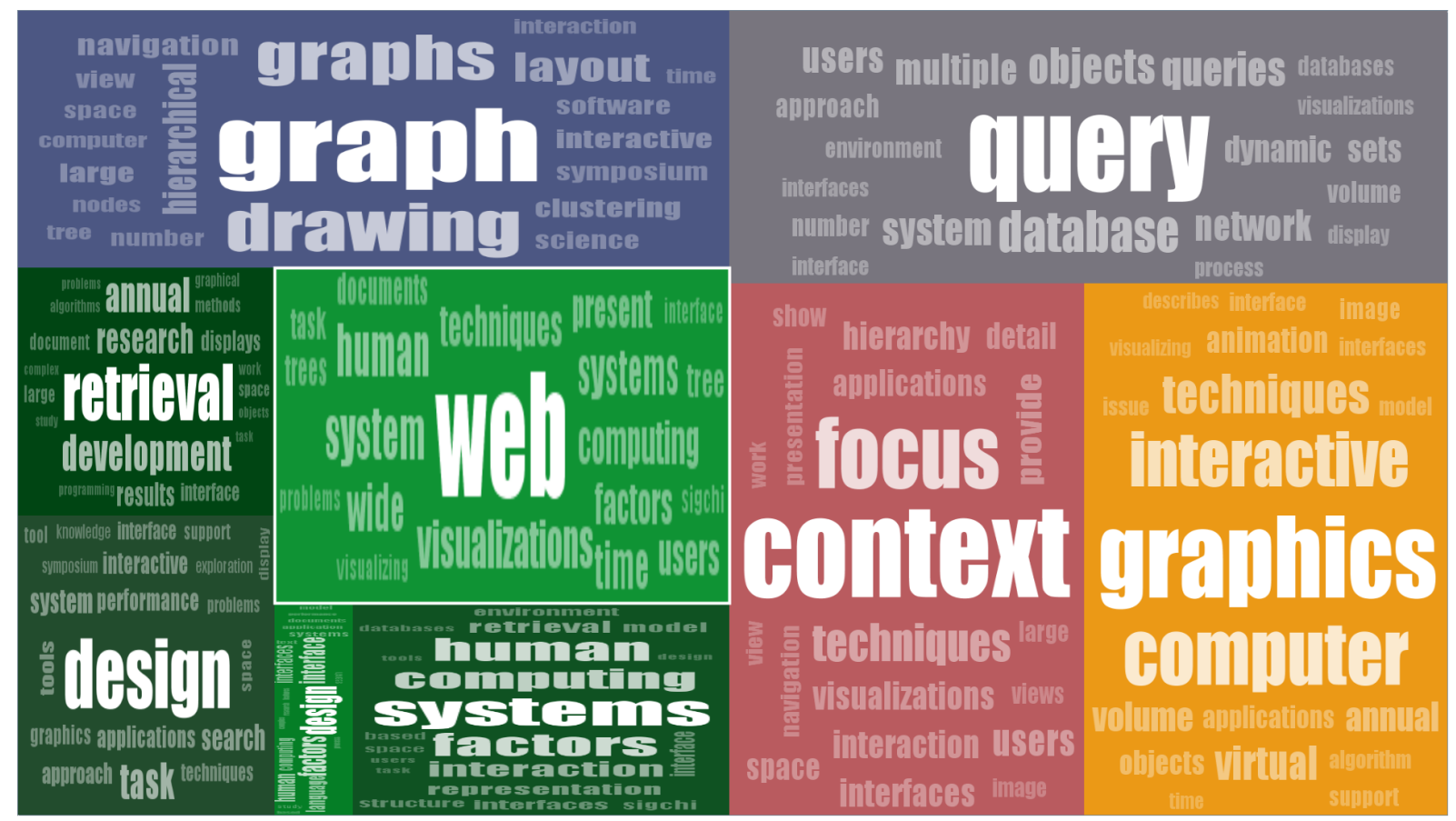

Figura 7.6: Interação com o usuário garante o zoom no grupo de interesse. 


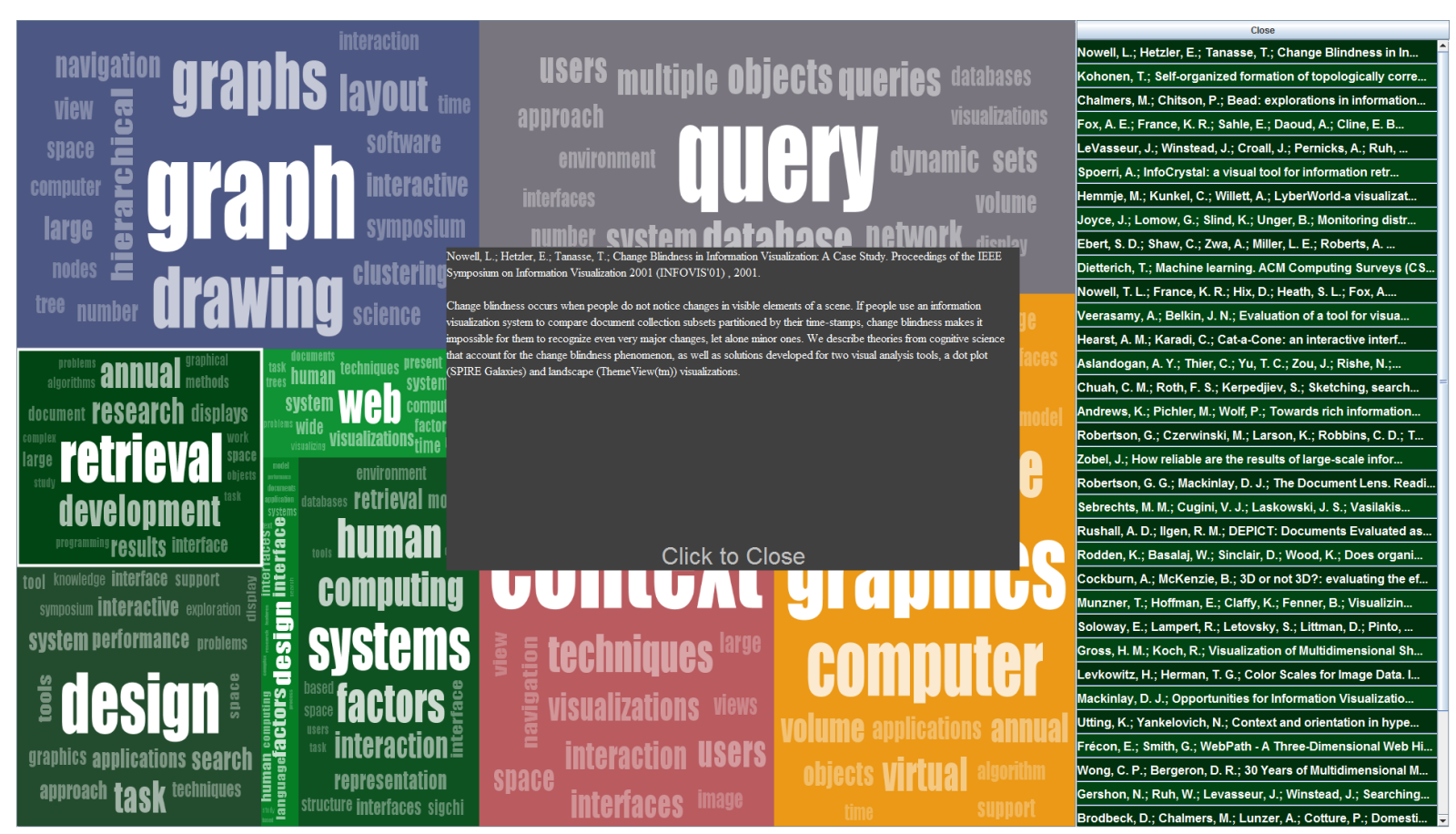

Figura 7.7: Interação com o usuário garante o zoom no grupo de interesse.

\subsection{Estudo de Caso}

Para validação da ferramenta SPCloud, testou-se a ferramenta com duas bases textuais distintas e in loco por proporcionar um cenário mais controlado. A primeira base é formada por 2625 notícias web, mais precisamente $R S S$ News Feed, de quatro fontes distintas da impressa internacional (Associated Press (APP), BBC, CNN e Reuters). As notícias foram coletadas entre os dias 6 e 7 de Abril de 2006 e contem, cada uma, o título e uma breve introdução ou resumo da mesma (Paulovich et al., 2008b).

Estas notícias foram coletadas no contexto global em que a gripe aviária havia sido detectada em países como Alemanha e Canadá. Concomitantemente, o governo dos Estados Unidos, chefiado pelo então presidente George W. Bush, estava devolvendo Iraque para o primeiro governo eleito após a "segunda guerra do Iraque", que começou em março de 2003

De fato, utilizando a SPCloud (Figura 7.8), é possível identificar estes principais assuntos, os quais foram organizados em grupos distintos e sumarizados por nuvens de palavras que contêm termos que representam o assunto ali abordado. Palavras como Flu, bird, dead, found (que em português significa gripe, ave, morte, encontrado) dão forte indícios de que as notícias presentes naquele grupo tratam do assunto "gripe aviária".

Analisando os outros grupos, é possível identificar que algo está ocorrendo no Iraque e que envolve os Estados Unidos e o presidente George W. Bush. No entanto, somente a 


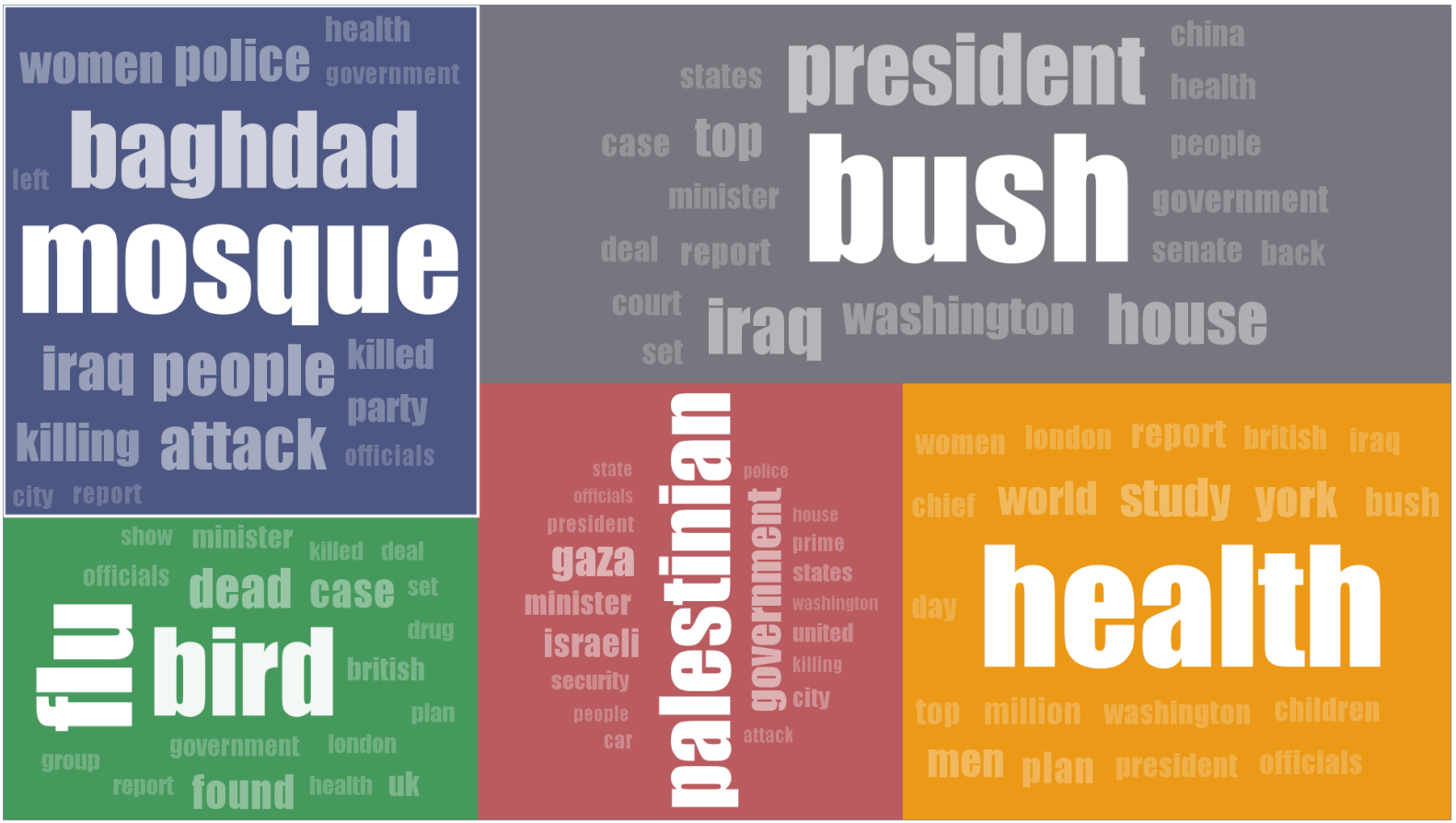

Figura 7.8: Visualização da base de dados de notícias formada por 2625 notícias de quatro fontes distintas da impressa internacional (Associated Press (APP), BBC, CNN e Reuters). As notícias foram coletas entre os dias 6 e 7 de Abril de 2006.

nuvem de palavras não consegue sumarizar o complexo assunto que envolve a guerra e as eleições diretas no Iraque. Assim, caso seja vontade do usuário, o mesmo pode interagir com a visualização e refinar o grupo de interesse com o intuito de visualizar mais palavras, e consequentemente mais detalhes, sobre o tema escolhido (Figura 7.9).

O número de novos grupos é uma variável configurada pelo usuário e, neste exemplo, o pai é dividido em cinco outros grupos. Este estão diretamente ligados ao assunto exibido pela nuvem de termos do pai. Caso alguns destes tenha poucos elementos e o usuário tente refinar ainda mais a visualização, descendo na hierarquia, uma lista com os documentos abrirá exibindo para ele todos os documentos contidos no grupo em estudo. Neste exemplo, é possível verificar a lista de documentos sumarizados pelo grupo azul circundado em branco com as os principais termos "States" e "United". Com base nos títulos das reportagens é possível inferir o contexto em que os estão inseridos.

A segunda base de dados utilizada é a "Infovis2004". Esta é formada por 613 artigos aceitos e publicados na Infovis nos anos de 1995 à 2002 e cada arquivo contém o título e o resumo dos trabalhos. O Infovis é o principal congresso para visualização de dados e, por estar inserido no ramo da computação, os artigos apresentam termos e palavras inseridos neste contexto. Independente disto, é notório a existência de grupos distintos que é possível observar através da visualização gerada pela SPCloud (Figura 7.1). De maneira 


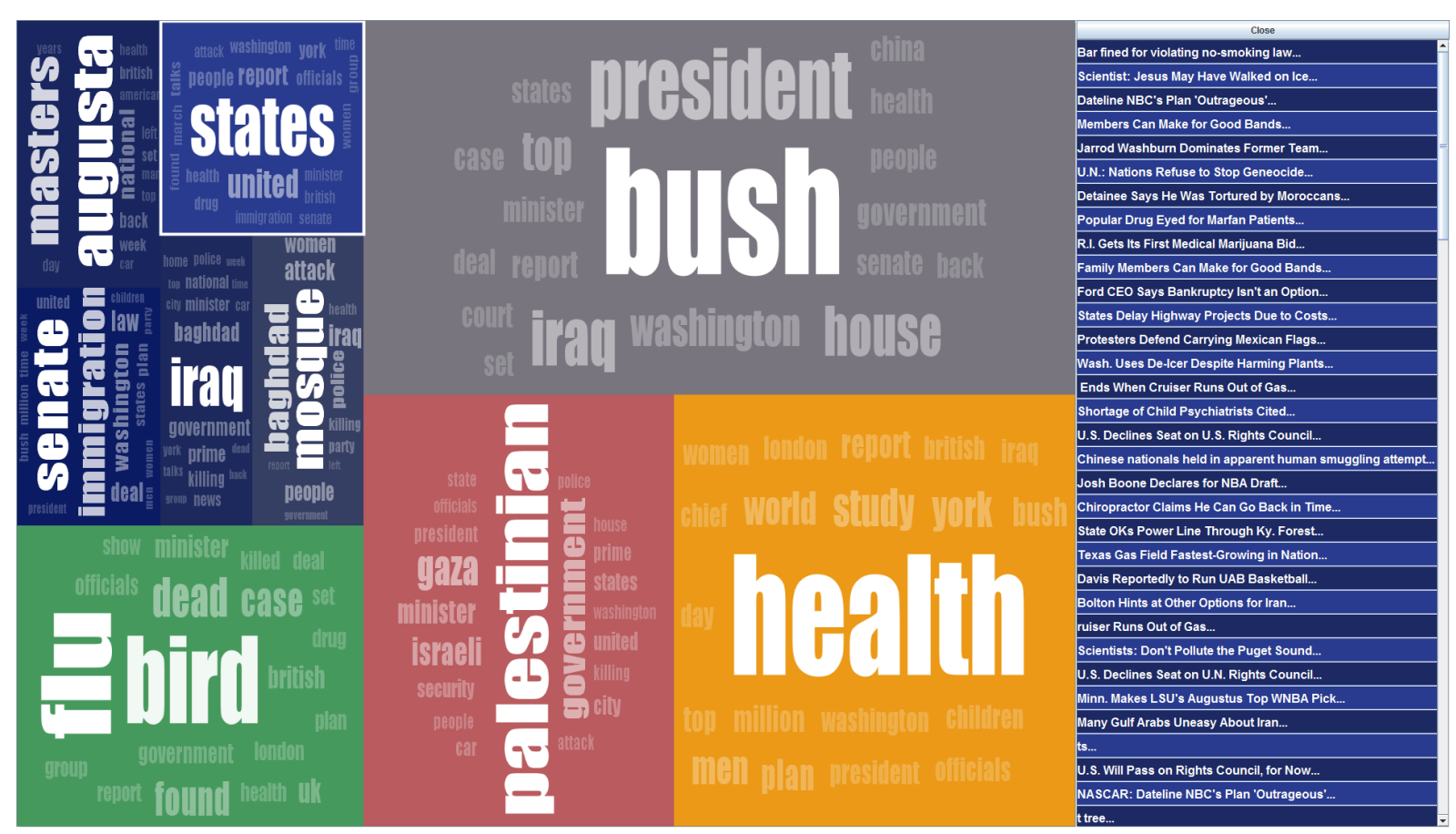

Figura 7.9: Interação do usuário com a ferramenta garante refinar o grupo de interesse e ler as notícias ali contidas. Deste modo, é possível entender a semântica que os termos da nuvem estão inseridos e assim apenas se inteirar das notícias de interesse.

exploratória, o usuário consegue dividir as regiões filtrando assim a base e facilitando acompanhar os artigos da sua área (Figura 7.5).

\subsection{Considerações Finais}

Com a grande quantidade de informações produzidas diariamente na web, a necessidade de uma ferramenta que sintetize todo este conteúdo torna-se extremamente necessária. Neste contexto, a SPCloud tem como objetivo proporcionar uma visualização capaz de sumarizar coleções de documentos web do tipo texto. Mais ainda, com foco em dispositivos móveis, utiliza todo espaço visual disponível tentando adaptar-se a equipamentos com pequenas telas.

Durante todas as fases de desenvolvimento, para validação e verificação da ferramenta, testes informais com usuários foram realizados no laboratório. Estes apontaram um excelente desempenho da ferramenta para filtrar e localizar informações em coleções de documentos. Além disso, testes também foram realizados para avaliar a interação do usuário com a ferramenta através de telas sensíveis ao toque. Todos os resultados e observações foram incorporados à ferramenta apresentada neste capítulo. 
O algoritmo utilizado para particionamento do layout de visualização foi o NMap-EW. Para cada grupo que era aberto, descendo assim o nível da hierarquia, o algoritmo era executando gerando assim a visualização do novo nível. Como a divisão de um grupo não tem relação com a divisão do seu vizinho, é possível que em um nível muito baixo da hierarquia a metáfora distância-similaridade seja violada e que grupos de ramos distintos da hierarquia sejam posicionados próximos mesmo não representando assuntos similares.

Outro problema está relacionado à necessidade do usuário de determinar o número de grupos que deseja separar e visualizar a coleção de documentos. Na maior parte dos cenários os usuários não têm conhecimento sobre este número. Este ainda é um problema em aberto na literatura e diversos trabalhos foram realizadas com o objetivo de prever a quantidade de grupos nos dados. Por decisão de projeto, optou-se por deixar o número de grupos como parâmetro para o usuário e, para tentar amenizar este problema, a confiabilidade dos termos em sumarizar o conteúdo foi mapeada na transparência das palavras. Ela exibe para o usuário a qualidade da nuvem de palavras em sumarizar o conteúdo do grupo de documentos.

Por fim, toda a ferramenta foi desenvolvida levando em consideração sua aplicação em dispositivos móveis. Para isso, toda a interação com o usuário foi testada em um monitor sensível ao toque por ter um padrão de interação semelhante ao dos dispositivos móveis. Além disto, a ferramenta foi implementada em Java e testada nos dispositivos móveis com a ajuda de um sistema que utiliza estes como uma segunda tela do computador, i.e., o tablet era ligado no computador e a aplicação era renderizada nele. Deste modo, todo o processamento era realizado no computador e somente a renderização e interação era realizada no tablet emulando assim uma arquitetura cliente-servidor. Desta maneira, não houve a necessidade da transcrição do código para a plataforma Android. Caso exista este interesse no futuro, adaptações mínimas são necessárias. 


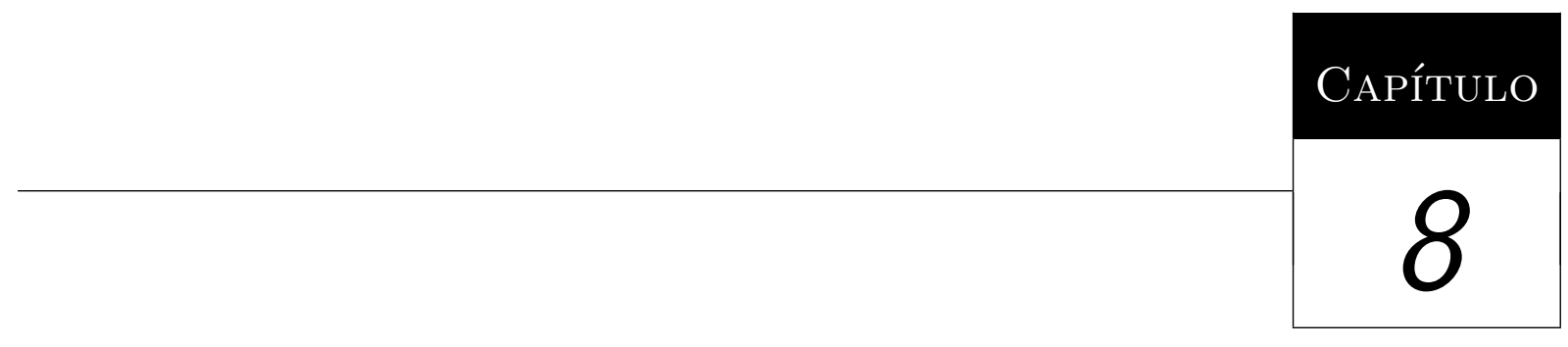

\section{Conclusões}

$\mathrm{N}$

este trabalho foram desenvolvidas a técnica NMap e a ferramenta para visualização de dados textuais SPCloud. Com o propósito de dar apoio ao processo de mineração visual de dados, elas foram desenvolvidas levando em consideração as particularidades dos dispositivos móveis. A técnica NMap segue o paradigma de preenchimento do espaço visual particionando o layout em regiões proporcionais a algum atributo dos dados. A ferramenta SPCloud utiliza a técnica NMap para produzir uma visualização de dados textuais. Esta processa o grupo de documentos gerando uma nuvem de palavras para cada região que é então posicionada dentro do retângulo produzido pela NMap.

Para a definição de um arcabouço teórico, foram feitos estudos nas três principais áreas que este trabalho se inclui: visualização de dados web, visualização de dados textuais e algoritmos de preenchimento do espaço visual e dispositivos móveis. As técnicas de visualização de dados web tentam acelerar o poder analítico do usuário para dados provindos da Internet, como resultados de pesquisa, notícias ou produtos de uma loja virtual. Para isto, a utilização da bidimensionalidade como forma de exibir e relacionar uma maior quantidade de informação demonstrou ser uma abordagem adequada a este contexto. As técnicas de visualização de dados textuais, de modo geral, utilizam nuvens de palavras para exibir somente os termos mais relevantes ao conjunto de dados que elas representam. Por fim, as técnicas de preenchimento do espaço visual demonstraram 
ser adaptáveis aos dispositivos móveis por utilizarem todo o espaço disponível, o que é importante para dispositivos com tamanhos limitado de telas.

Estes estudos levaram ao desenvolvimento da técnica NMap. Esta segue o paradigma de preenchimento do espaço visual preservando, na medida do possível, a vizinhança estabelecida no posicionamento inicial dos dados no plano. Foram desenvolvidas duas abordagens distintas: NMap-AC e NMap-EW. A primeira divide os dados em dois grupos de mesmo tamanho e particiona o espaço alternando entre cortes verticais e horizontais. A segunda abordagem, a NMap-EW, divide os elementos em dois grupos com aproximadamente o mesmo peso e corta o layout perpendicular ao maior lado. Estudos comparativos demonstraram que a técnica NMap tem melhores resultados quando comparada com as atuais técnicas do estado da arte. Para a avaliação foram considerados as métricas de preservação de vizinhança, deslocamento, razão de aspecto e tempo de processamento. Estes resultados fazem com que a NMap se estabeleça como uma das melhores e mais rápidas técnicas de preenchimento do espaço visual.

A ferramenta SPCloud funciona em uma arquitetura cliente-servidor, i.e., efetua todo o processamento dos textos e calculo dos termos mais importantes em um servidor, ficando os dispositivos móveis responsáveis apenas pela visualização e interação com o usuário. Devido os excelentes resultados da técnica NMap, esta foi utilizada como metáfora visual para visualização de coleção de documentos. Para isto, utiliza-se a representação vetorial dos documentos e através de algoritmos de agrupamento de dados e projeção, posicionam-se os centroides de cada grupo no espaço visual. Sobre esta projeção, aplica-se a NMap com o peso proporcional à quantidade de documentos que cada grupo representa. A nuvem de palavras é calculada utilizando os termos mais importantes do grupo de acordo com a abordagem proposta na técnica ProjCloud. Testes informais com usuários demonstraram a eficiência da ferramenta SPCloud em exibir e sumarizar centenas de notícias das mais diversas categorias.

Assim, a ferramenta SPCloud demonstrou ser uma abordagem adequada para visualizar dados web, em especial notícias textuais, em dispositivos móveis. Por utilizar a NMap, a ferramenta SPCloud utiliza todo o espaço visual disponível no aparelho para exibir as informações, o que é importante em dispositivos com telas pequenas. Alem disto, como a razão de aspecto das regiões formadas se aproximam de 1, facilita a seleção destas através de telas sensíveis ao toque. Por fim, as funcionalidades implementadas na ferramenta, como o zoom e a filtragem dos dados através da subdivisão do grupo de interesse, são características importantes para aplicações voltadas a dispositivos móveis como elencados por Chittaro (2006). 


\subsection{Limitações}

Embora os resultados apresentados pela NMap superaram os do estado da arte, algumas limitações devem ser observadas. Para o correto funcionamento da técnica NMap é necessário que os pontos já estejam posicionados no plano e que estes estejam dispostos preservando a metáfora distância-similaridade. Caso isto não esteja acontecendo, a NMap não tem a capacidade de concertar possíveis violações da metáfora, sendo ainda possível o acréscimo de mais erros ao layout produzido. Ainda, caso os elementos já não estejam posicionados no espaço visual disponível ou não possuam uma ordenação bidimensional ou ainda uma característica que possibilite o cálculo da similaridade entre eles, a técnica NMap não consegue gerar o layout de visualização final.

Além disto, caso um dos elementos possua um peso muito maior que os demais, é possível que o layout final produzido tenha um único grande retângulo e as outras regiões tenham pouca ou nenhuma representatividade na visualização final. Esta limitação, no entanto, permeia todas as técnicas que fazem alguma característica dos dados proporcionais a área dos elementos gráficos que os representa.

Com relação à ferramenta SPCloud, devido ao uso de um algoritmo de agrupamento de dados, que precisa do número de grupos que devem ser encontrados, o usuário precisa informar o número de categorias presentes dentro do conjunto de documentos em estudos. Esta limitação pode ser contornada com a substituição do algoritmo por um que consiga prever o número de grupos. Além disto, devido à alta dimensionalidade encontrada na representação vetorial dos textos, estes estão sujeitos a "maldição da dimensionalidade" em que todos os elementos são similares uns aos outros, o que dificulta o posicionamento no plano obedecendo a metáfora distância-similaridade. Estes problemas podem ser atenuados utilizando-se metadados para facilitar o agrupamento e classificação dos dados.

\subsection{Trabalhos Futuros}

Uma condição de funcionamento da NMap é que os dados a serem visualizados já estejam posicionados no plano. No entanto, muitos deles não possuem uma ordenação bidimensional ou atributos que possibilitem o cálculo da similaridade. Assim, como trabalho futuro, é necessário criar uma estratégia que produza visualizações para dados que não estejam posicionados no plano. Independente destes não possuírem uma metáfora distância-similaridade que deva ser preservada, espera-se que esta nova abordagem gere visualizações com o mesmo apelo visual que a técnica original NMap. 
Além disto, acredita-se que a remoção e adição de novos elementos à visualização da NMap deva causar uma modificação significativa localmente, mas imperceptível no contexto global. Assim, um estudo mais aprofundado sobre a estabilidade da visualização final produzida pela NMap deve ser feita tomando como comparação as principais técnicas existentes no estado da arte. Esta característica é importante, principalmente, para visualização de fluxo de dados em que os elementos são amostrados ao longo do tempo e não estão todos disponíveis no começo da visualização.

Duas características principais precisam ser consideradas durante a construção das abordagens da NMap: o ponto de corte e a direção deste. A mudança na forma como estes são feitos produz layouts finais diferentes. Assim, é possível que exista uma estratégia que gere melhores resultados com relação à preservação de vizinhança, deslocamento ou uma outra métrica de interesse. Desta maneira, é necessário um estudo mais aprofundado sobre os efeitos da mudança destes parâmetros na visualização final para que seja possível desenvolver abordagens que maximizem as métricas de interesse. 


\section{Referências Bibliográficas}

Andrews, K.; Kienreich, W.; Sabol, V.; Becker, J.; Droschl, G.; Kappe, F.; Granitzer, M.; Auer, P.; Tochtermann, K. The infosky visual explorer: exploiting hierarchical structure and document similarities. Information Visualization, v. 1, n. 3/4, p. 166-181, 2002.

Disponível em http://dx.doi.org/10.1057/palgrave.ivs.9500023

BAE, B. P. Big data, for better or worse: $90 \%$ of world's data generated over last two years. Artigo Web, acessado em 03/11/2014, 2013.

Disponível em http://www.sciencedaily.com/releases/2013/05/130522085217. $\mathrm{htm}$

Balzer, M.; Deussen, O.; Lewerentz, C. Voronoi treemaps for the visualization of software metrics. In: Proceedings of the 2005 ACM Symposium on Software Visualization, New York, NY, USA: ACM, 2005, p. 165-172 (SoftVis '05, v.1).

Disponível em http://doi.acm.org/10.1145/1056018.1056041

Becker, R. A.; Cleveland, W. S. Brushing scatterplots. Technometrics, v. 29, n. 2, p. 127-142, 1987.

Disponível em http://dx.doi.org/10.2307/1269768

Bederson, B. B.; Shneiderman, B.; Wattenberg, M. Ordered and quantum treemaps: Making effective use of 2d space to display hierarchies. ACM Trans. Graph., v. 21, n. 4, p. 833-854, 2002.

Disponível em http://doi.acm.org/10.1145/571647.571649

Berners-Lee, T.; Fischetti, M. Weaving the web. HarperBusiness; 1 edition (November 7, 2000), 2000. 
Bruls, M.; Huizing, K.; Wijk, J. J. Squarified treemaps. In: In Proceedings of the Joint Eurographics and IEEE TCVG Symposium on Visualization, Press, 1999, p. $33-42$.

Disponível em http://citeseerx.ist.psu.edu/viewdoc/download?doi=10.1.1. 36.6685\&rep $=$ rep $1 \&$ type $=$ pdf

Buchin, K.; Eppstein, D.; Löffler, M.; Nöllenburg, M.; Silveira, R. I. Adjacency-preserving spatial treemaps. In: Proceedings of the 12th International Conference on Algorithms and Data Structures, Berlin, Heidelberg: Springer-Verlag, 2011, p. 159-170 (WADS'11, v.1).

Disponível em http://dl . acm.org/citation. cfm?id=2033190.2033204

Chittaro, L. Visualizing information on mobile devices. IEEE Computer Society Press, v. 39, n. 3, p. 40-45, 2006.

Disponível em http://dx.doi.org/10.1109/MC.2006.109

da Silva Junior, J. D. J. N.; Meiguins, B. S.; Carneiro, N. S.; Meiguins, A. S. G.; Da Silva Franco, R. Y.; Soares, A. G. M. Prisma mobile: An information visualization tool for tablets. In: 2012 16th International Conference on Information Visualisation, IEEE, 2012, p. 182-187.

Disponível em http://ieeexplore.ieee.org/lpdocs/epic03/wrapper.htm? arnumber $=6295812$

Dork, M.; Carpendale, S.; Collins, C.; Williamson, C. Visgets: coordinated visualizations for web-based information exploration and discovery. IEEE Transactions on visualization and computer graphics, v. 14, n. 6, p. 1205-12, 2008.

Disponível em http://www.ncbi.nlm.nih.gov/pubmed/18988965

Drucker, P. Landmarks of tomorrow: A report on the new. Transaction Publishers, 1996.

Duarte, F.; Sikansi, F.; Fatore, F.; Fadel, S.; Paulovich, F. Nmap: A novel neighborhood preservation space-filling algorithm. Visualization and Computer Graphics, IEEE Transactions on, v. 20, n. 12, p. 2063-2071, 2014.

Engdahl, B.; Koksal, M.; Marsden, G. Using treemaps to visualize threaded discussion forums on pdas. In: CHI '05 extended abstracts on Human factors in computing systems - CHI '05, New York, New York, USA: ACM Press, 2005, p. 1 - 4. Disponível em http://portal . acm.org/citation. cfm?doid=1056808.1056915 
Fadel, S. G.; Fatore, F. M.; Duarte, F. S.; Paulovich, F. V. Loch: A neighborhood-based multidimensional projection technique for high-dimensional sparse spaces. Neurocomputing, , n. 0, p. -, 2014.

Disponível em http://www.sciencedirect.com/science/article/pii/ S0925231214012867

FEEDLY Feedly. http://www.feedly.com/, acessado em: 25/11/2012, 2012.

FeinBerG, J. Wordle. http://www.wordle.net/, acessado em: 04/07/2013, 2013.

Fiedler, M. Algebraic connectivity of graphs. Czechoslovak Mathematical Journal, v. $23,1954$.

Gomez-Nieto, E.; San Roman, F.; Pagliosa, P.; Casaca, W.; Helou, E.; Oliveira, M.; NonAto, L. Similarity preserving snippet-based visualization of web search results. IEEE Transactions on Visualization and Computer Graphics, v. 20, n. 3, p. 457-470, 2014.

Google Google reader. http://www.google.com/reader, acessado em: 25/11/2012, 2012.

Group, M. M. Internet world stats. http://www.internetworldstats.com/stats . htm, acessado em: 25/11/2012, 2012.

Ham, F. V.; Wattenberg, M.; Viegas, F. B. Mapping text with phrase nets. IEEE Transactions on Visualization and Computer Graphics, v. 15, n. 6, p. 1169-1176, 2009.

Disponível em http://dx.doi.org/10.1109/TVCG. 2009.165

HaO, J.; Gabrysch, C.; ZhaO, C.; Zhu, Q.; Zhang, K. Visualizing and navigating hierarchical information on mobile user interfaces. International Journal of Advanced Intelligence, v. 2, n. 1, p. 81-103, 2010.

Disponível em http://aia-i.com/ijai/sample/vol2/no1/81-103.pdf

HARRIS, Z. Distributional structure. Word, v. 10, p. 146-162, 1973.

Hearst, M. A. Multi-paragraph segmentation of expository text. In: Proceedings of the 32nd annual meeting on Association for Computational Linguistics, Stroudsburg, PA, USA: Association for Computational Linguistics, 1994, p. 9-16 (ACL '94, v.1). Disponível em http://dx.doi.org/10.3115/981732.981734 
HeARst, M. A. Tilebars: visualization of term distribution information in full text information access. In: Proceedings of the SIGCHI Conference on Human Factors in Computing Systems, New York, NY, USA: ACM Press/Addison-Wesley Publishing Co., 1995, p. 59-66 (CHI'95, v.1).

Disponível em http://dx.doi.org/10.1145/223904.223912

Hoeber, O.; YAng, X. A comparative user study of web search interfaces: Hotmap, concept highlighter, and google. In: IEEE/WIC/ACM International Conference on Web Intelligence, 2006. WI 2006., IEEE, 2006a, p. 866-874.

Disponível em http://ieeexplore.ieee.org/lpdocs/epic03/wrapper.htm? arnumber $=4061487$

Hoeber, O.; YAng, X. D. The visual exploration of web search results using hotmap. In: Proceedings of the conference on Information Visualization, Washington, DC, USA: IEEE Computer Society, 2006b, p. 157-165 (IV '06, v.1).

Disponível em http://dx.doi.org/10.1109/IV.2006.108

Hoeber, O.; YAnG, X.-D. Visually exploring concept-based fuzzy clusters in web search results. In: LAST, M.; SzczePaniak, P. S.; Volkovich, Z.; Kandel, A., eds. Advances in Web Intelligence and Data Mining, Berlin/Heidelberg: Springer-Verlag, 2006c, p. 81-90 (Studies in Computational Intelligence, v.23). Disponível em http://www.springerlink.com/index/10.1007/3-540-33880-2

Hoeber, O.; YAng, X.-D. Visually exploring concept-based fuzzy clusters in web search results. In: Advances in Web Intelligence and Data Mining, Springer Berlin Heidelberg, 2006d, p. 81-90.

Disponível em http://link.springer.com/chapter/10.1007\%2F3-540-33880-2_9

Inselberg, A. The plane with parallel coordinates. The Visual Computer, v. 1, n. 2, p. 69-91, 1985.

Disponível em http://dx.doi.org/10.1007/BF01898350

IProspect Search engine user behavior study. v. 1, n. April, p. 0-16, 2006.

Johnson, B.; Shneiderman, B. Tree-maps: a space-filling approach to the visualization of hierarchical information structures. In: Proceedings of the 2nd conference on Visualization '91, Los Alamitos, CA, USA: IEEE Computer Society Press, 1991, p. 284-291 (VIS '91, v.1).

Disponível em http://dl . acm.org/citation. cfm?id=949607.949654 
KAKU, M. Physics of the future: How science will shape human destiny and our daily lives by the year 2100. Anchor; Reprint edition, 2012.

KoH, K.; LeE, B.; KIM, B.; SEO, J. Maniwordle: providing flexible control over wordle. IEEE Transactions on Visualization and Computer Graphics, v. 16, n. 6, p. $1190-7,2010$.

Disponível em http://www.ncbi.nlm.nih.gov/pubmed/20975158

Levkowitz, H.; Kelleher, C. Cloud and mobile web-based graphics and visualization. In: 25th SIBGRAPI Conference on Graphics, Patterns and Images Tutorials, IEEE, 2012, p. 21-35.

Disponível em http://ieeexplore.ieee.org/lpdocs/epic03/wrapper.htm? arnumber $=6382716$

MacQueEn, J. B. Some methods for classification and analysis of multivariate observations. In: CAm, L. M. L.; Neyman, J., eds. Proc. of the fifth Berkeley Symposium on Mathematical Statistics and Probability, University of California Press, 1967, p. 281-297.

Mansmann, F.; Keim, D.; North, S.; Rexroad, B.; Sheleheda, D. Visual analysis of network traffic for resource planning, interactive monitoring, and interpretation of security threats. IEEE Transactions on Visualization and Computer Graphics, v. 13, n. 6, p. 1105-1112, 2007.

Mosmondor, M.; Komericki, H.; PAndzic, I. S. 3d visualization on mobile devices. Telecommunication Systems, v. 32, n. 2-3, p. 181-191, 2006.

Disponível em http://www.springerlink.com/index/10.1007/s11235-006-9137-3

NocAJ, A.; Brandes, U. Computing Voronoi treemaps: Faster, simpler, and resolution-independent. Computer Graphics Forum, v. 31, n. 3pt1, p. 855-864, 2012. Disponível em http://dx.doi.org/10.1111/j.1467-8659.2012.03078.x

Paley, W. B. Textarc: Showing word frequency and distribution in text. IEEE Symposium on Information Visualization, 2002.

Disponível em http://www.textarc.org/appearances/InfoVis02/InfoVis02_ TextArc.pdf

Paulovich, F. V.; Minghim, R. Hipp: A novel hierarchical point placement strategy and its application to the exploration of document collections. IEEE Transactions on Visualization and Computer Graphics, v. 14, n. 6, p. 1229-1236, 2008.

Disponível em http://dx.doi.org/10.1109/TVCG.2008.138 
Paulovich, F. V.; Nonato, L. G.; Minghim, R.; Levkowitz, H. Least square projection: A fast high-precision multidimensional projection technique and its application to document mapping. IEEE Transactions on Visualization and Computer Graphics, v. 14, n. 3, p. 564-575, 2008a.

Paulovich, F. V.; Pinho, R.; Botha, C. P.; Heiss, A.; Minghim, R. Pex-web: Content-based visualization of web search results. In: 12th International Conference Information Visualisation, IEEE, 2008b, p. 208-214.

Disponível em http://ieeexplore.ieee.org/lpdocs/epic03/wrapper.htm? arnumber $=4577949$

Paulovich, F. V.; Toledo, F. M. B.; Telles, G. P.; Minghim, R.; Nonato, L. G. Semantic wordification of document collections. Computer Graphics Forum, v. 31, n. 3, Part 3, p. 1145-1153, 2012.

Reiterer, H.; Tullius, G.; MAnN, T. M. Insyder: a content-based visual-information-seeking system for the web. International Journal on Digital Libraries, v. 5, n. 1, p. 25-41, 2005.

Disponível em http://www.springerlink.com/index/10.1007/s00799-004-0111-y

Robbins, D. C.; Cutrell, E.; Sarin, R.; Horvitz, E. Zonezoom: map navigation for smartphones with recursive view segmentation. In: Proceedings of the working conference on Advanced visual interfaces - AVI '04, New York, New York, USA: ACM Press, 2004, p. 231-234.

Disponível em http://portal . acm.org/citation . cfm?doid=989863.989901

Roto, V.; Popescu, A.; Koivisto, A.; Vartiainen, E. Minimap - a web page visualization method for mobile phones. In: Proceedings of the SIGCHI conference on Human Factors in computing systems - CHI '06, New York, New York, USA: ACM Press, 2006, p. 35.

Disponível em http://dl.acm.org/citation.cfm?id=1124779http://portal .acm. org/citation. cfm?doid=1124772.1124779

Rousseeuw, P. J. Silhouettes: A graphical aid to the interpretation and validation of cluster analysis. Journal of Computational and Applied Mathematics, v. 20, n. 0, p. $53-65,1987$.

Disponível em http://www.sciencedirect.com/science/article/pii/ 0377042787901257 
Salton, G.; McGill, M. J. Introduction to modern information retrieval. New York, NY, USA: McGraw-Hill, Inc., 1986.

Shin, H.; PARK, G.; HAN, J. Tablorer - an interactive tree visualization system for tablet pcs. In: Proceedings of the 13th Eurographics / IEEE - VGTC conference on Visualization, Aire-la-Ville, Switzerland, Switzerland: Eurographics Association, 2011, p. 1131-1140 (EuroVis'11, v.1).

Disponível em http://dx.doi.org/10.1111/j.1467-8659.2011.01962.x

Shneiderman, B. Tree visualization with tree-maps: 2-d space-filling approach. $A C M$ Transactions on Graphics, v. 11, n. 1, p. 92-99, 1992.

Disponível em http://doi.acm.org/10.1145/102377.115768

Stasko, J.; Zhang, E. Focus+context display and navigation techniques for enhancing radial, space-filling hierarchy visualizations. In: Information Visualization, 2000. Info Vis 2000. IEEE Symposium on, 2000, p. 57-65.

Steinbock, D. Tagcrowd: make your own tag cloud from any text. http://tagcrowd. com/, acessado em: 07/01/2013, 2006.

TAK, S.; CockBurn, A. Enhanced spatial stability with Hilbert and Moore treemaps. IEEE Transactions on Visualization and Computer Graphics, v. 19, n. 1, p. 141-148, 2013.

Tejada, E.; Minghim, R.; Nonato, L. G. On improved projection techniques to support visual exploration of multidimensional data sets. Information Visualization, v. 2, n. 4, p. 218-231, 2003.

Todorovic, D. Gestalt principles. Scholarpedia, v. 3, n. 12, p. 5345, revision 91314, 2008.

Torgeson, W. S. Multidimensional scaling of similarity. Psychometrika, v. 30, p. 379-393, 1965.

Tu, Y.; Shen, H.-W. Visualizing changes of hierarchical data using treemaps. IEEE Transactions on Visualization and Computer Graphics, v. 13, n. 6, p. 1286-1293, 2007.

Viegas, F. B.; Wattenberg, M.; Feinberg, J. Participatory visualization with wordle. IEEE Transactions on Visualization and Computer Graphics, v. 15, n. 6, p. $1137-44,2009$.

Disponível em http://www.ncbi.nlm.nih.gov/pubmed/19834182 
WAtt, R. J. C. Concordance: Software for text analysis gives you better insight into electronic texts. http://www.concordancesoftware.co.uk/, acessado em: 11/12/2012, 2012.

Wattenberg, M. Visualizing the stock market. In: CHI '99 Extended Abstracts on Human Factors in Computing Systems, New York, NY, USA: ACM, 1999, p. 188-189 (CHI EA '99, v.1).

Disponível em http://doi.acm.org/10.1145/632716.632834

Wattenberg, M.; Viegas, F. B. The word tree, an interactive visual concordance. IEEE Transactions on Visualization and Computer Graphics, v. 14, n. 6, p. 1221-1228, 2008.

Disponível em http://dx.doi.org/10.1109/TVCG. 2008.172

Weskamp, M. Newsmap. http://newsmap.jp/, acessado em: 07/01/2013, 2004.

WiJk, J.; Wetering, H. Cushion treemaps: visualization of hierarchical information. In: Information Visualization, 1999. (Info Vis '99) Proceedings. 1999 IEEE Symposium on, 1999, p. 73-78, 147.

Wong, P. C. Visual data mining. IEEE Computer Graphics and Applications, v. 19, n. 5, p. 20-21, 1999.

Wood, J.; Dykes, J. Spatially ordered treemaps. IEEE Transactions on Visualization and Computer Graphics, v. 14, n. 6, p. 1348-1355, 2008.

Disponível em http://dx.doi.org/10.1109/TVCG.2008.165 